\title{
PREPARAÇÃO, CARACTERIZAÇÃO E PROPRIEDADES CATALÍTICAS DE FILMES DE POLITIOFENO CONTENDO ELETROCATALISADORES DISPERSOS
}

Márcia Toline Giacomini

Tese apresentada ao Instituto de Química de São Carlos, da Universidade de São Paulo para obtenção do título de Doutor em Ciências Físico-Química.

Orientador: Prof. Dr. Edson Antonio Ticianelli

\section{São Carlos}



À todos aqueles que persistem e lutam pelos seus sonhos mesmo encontrando descaso, solidão e incompreensão ao longo do caminho. Aos meus pais e irmãos que sempre estiverem ao meu lado regando minha vida com muito amor. To Dieter, the person that supports me and gives me strength with his love to run after my dreams. 


\section{AGRADECIMENTOS}

- Ao Instituto de Química de São Carlos/USP, pela formação e informação.

- Aos professores e funcionários do IQSC/USP, pela atenção e prontidão dispensadas.

- Ao professor Dr.Edson Ticianelli por estar sempre pronto a ensinar, pelo carinho e atenção de amigo, e pelas oportunidades de crescimento profissional que me ofereceu.

- Ao Grupo de Eletroquímica pela convivência e facilidades.

- Aos técnicos do Grupo de Eletroquímica Janete, Valdecir, Paulinho e Jonas por terem sido sempre tão atenciosos e me auxiliado sempre que necessário.

- To Dr. James McBreen, Helen Sun, Mali Balasubramanian, MaryAnn Larese, Ken Sutter, Dr. Otto Haas and all the people from Brookhaven National Laboratory that helped so much during my time there.

- To my friends Alistair, Carole, Mike, Maria, Nuria, John, Dennis, Vivek, Jun, Nadine and Susan for making my life much nicer and for giving me motivation to work.

- Às amizades aqui plantadas e regadas ao longo de tantos anos de convivência, sem as quais, talvez este e muitos outros trabalhos não tivessem chegado ao final. Muito obrigada.

- Aos meus grandes amigos de todas as horas Luiz Henrique, Paulinha e Maria Helena por estarem presentes mesmo na distância.

- A FAPESP e CAPES pelo apoio financeiro. 
SUMÁRIO

LISTA DE FIGURAS i

LISTA DE TABELAS vii

LISTA DE ABREVIATURAS viii

RESUMO ix

ABSTRACT

I. INTRODUÇÃO 1

1. 1. Sintese do politiofeno 2

1. 2. Mecanismos de condução

1. 3. Aplicações como suporte para eletrocatalisadores

1. 4. Mecanismo da cinética da ROH e RRO 11

1. 5. Objetivos e metodologia empregada 16

II. PARTE EXPERIMENTAL 19

2. 1. Reagentes, soluções, eletrodos e células 19

2. 1. 1. Reagentes e soluções 19

2. 1. 2. Eletrodos 20

2. 1.3. Células 22

2. 2. Aquisição dos Dados Experimentais

2. 2. 1. Preparação dos filmes de PT 25

2. 2. 2. Espectroscopia de Reflectância na Região do
Infravermelho

2. 2. 3. Espectroscopia de UV-visivel 28

2. 2. 4. Microscopia Eletrônica de varredura (MEV) 30

2. 2. 5. Espectroscopia de Absorção de Raio $X$

III. RESULTADOS E DISCUSSÃO 39

3. 1. Síntese e propriedades morfológicas dos filmes de politiofeno 39

3. 1. 1. Efeito da natureza do eletrólito 39

3. 1. 2. Efeito da concentração e temperatura de $\mathrm{H}_{2} \mathrm{SO}_{4}$

3. 1. 3. Efeito da rotação do eletrodo 49

3. 1. 4. Síntese em diferentes materiais eletródicos 50 
3. 1. 5. Propriedades morfológicas dos filmes formados

3. 1. 6. Espectro de FTIR 56

3. 1. 7. Mecanismo de síntese $\quad 57$

3. 2. Propriedades REDOX dos filmes de PT 58

3. 2. 1. Estudo do Comportamento Voltamétrico do PT em várias concentrações de $\mathrm{H}_{2} \mathrm{SO}_{4}$

3. 2. 2. Estudos espectroscópicos de UV-visível

3. 3. Propriedades catalíticas dos filmes contendo catalisadores dispersos

3. 3. 1. Caracterização dos catalisadores

3. 3. 2. Reação de oxidação de hidrogênio $(R O H)$

3. 3. 3. Reação de redução de oxigênio (RRO)

80

3. 3. 4. Sumário dos Resultados 


\section{LISTA DE FIGURAS}

FIGURA 1 -

FIGURA 2 -

FIGURA 3 -

FIGURA 4 -

FIGURA 5 -

FIGURA 6 -

FIGURA 7 -

FIGURA 8 -

FIGURA 9 -
Oxidação eletroquímica do politiofeno. a) a cadeia polimérica neutra é oxidada pela remoção de um elétron; b) o íon radical formado na etapa (a) cria um defeito estrutural e c) ocorre uma segunda oxidação formando um bipolaron dicatiônico...

Suporte de Teflon $^{\circledR}$ e fio de platina utilizados para colocar o tecido de carbono em solução e fazer o contato elétrico do mesmo

Eletrodo de referência reversível de hidrogênio

Vista lateral da célula utilizada para medidas de espectroscopia de UV-Visível in situ.....................

Célula de Plexiglas utilizada para as medidas de raio X...

(A) O retorno de um elétron da Banda de Condução para a Banda de Valência pode liberar um fóton com energia igual a energia de "gap" da banda. O elétron pode também retornar sem liberar a luz por vibrações atômicas no material. (B) Um espectro de emissão típico correspondendo à transição eletrônica mostrada em (A)...

Arranjo experimental para medidas de absorção de raios $\mathrm{X}$ (esquema da célula mostrado na Figura 5).

Espectro bruto de politiofeno em $\mathrm{H}_{2} \mathrm{SO}_{4}$ 2,0 M contendo platina obtido na borda $\mathrm{L}_{\text {III }}$ da $\mathrm{Pt}$, polarizado em $0,0 \mathrm{~V}$ ( $v s . \mathrm{ERH})$. Modo de fluorescência........................

Voltamogramas de crescimento de politiofeno em acetonitrila $+\mathrm{TBAClO}_{4} \quad 0,1 \mathrm{M}$ e tiofeno $3,0 \mathrm{M}$ a temperatura ambiente, em eletrodo de carbono vítreo. Velocidade de varredura: $75 \mathrm{mV} \mathrm{s}^{-1}$. 
FIGURA 10 -

FIGURA 11 -

FIGURA 12 -

FIGURA 13 -

FIGURA 14 -

FIGURA 15 -

FIGURA 16 -

FIGURA 17 -

FIGURA 18 -

FIGURA 19 -

FIGURA 20 -

FIGURA 21 -
Voltamograma cíclico de politiofeno crescido por 25 ciclos em acetonitrila $+\mathrm{TBAClO}_{4}$ 0,1 M e tiofeno 3,0 M e ciclado na mesma solução na ausência de monômero. $\mathrm{v}$ $=100 \mathrm{mV} \mathrm{s}^{-1}$

Voltamogramas de crescimento de politiofeno em solução de $\mathrm{H}_{2} \mathrm{SO}_{4} 12,5 \mathrm{M}$ e tiofeno $0,05 \mathrm{M}, 3{ }^{\circ} \mathrm{C}$, velocidade de varredura de $75 \mathrm{mV} \mathrm{s}^{-1}$ e rotação de 1000 rpm....

Voltamograma cíclico de politiofeno sintetizado em $\mathrm{H}_{2} \mathrm{SO}_{4} 12,5 \mathrm{M}$, tiofeno $0,05 \mathrm{M}$ e ciclado na mesma solução na ausência do monômero. Velocidade de varredura: $75 \mathrm{mV} \mathrm{s}^{-1}$....

Gráfico da densidade de corrente em potencial igual a 0,5 $\mathrm{V}$ (vs. ERH) para o $5^{\circ}$ e o $25^{\circ}$ ciclos de crescimento do politiofeno em função da concentração de ácido sulfúrico

Espectro de UV-visível de acetonitrila e acetonitrila + tiofeno em diferentes tempos a $23{ }^{\circ} \mathrm{C}$

Espectros de UV-visível de ácido sulfúrico 12,5 M e ácido sulfúrico $12,5 \mathrm{M}+$ tiofeno em diferentes tempos a $23{ }^{\circ} \mathrm{C}$

Espectros de UV-visível de ácido sulfúrico $12,5 \mathrm{M}$ e ácido sulfúrico $12,5 \mathrm{M}+$ tiofeno em diferentes tempos a $3{ }^{\circ} \mathrm{C}$.

Espectros de UV-Visível de ácido perclórico 8,0 M e ácido perclórico 8,0 M + tiofeno em diferentes tempos a $23{ }^{\circ} \mathrm{C}$

Espectros de UV-Visível de ácido perclórico 8,0 M e ácido perclórico 8,0 M + tiofeno em diferentes tempos a $3{ }^{\circ} \mathrm{C}$

Voltametria cíclica de crescimento de politiofeno em eletrodo de $\mathrm{Pt}$ em ácido sulfúrico $12,5 \mathrm{M}$ a $3{ }^{\circ} \mathrm{C}$ com rotação do eletrodo $(1000 \mathrm{rpm}) . \mathrm{v}=100 \mathrm{mV} \mathrm{s}^{-1}$.....

Voltametria cíclica de crescimento de politiofeno em eletrodo de $\mathrm{Pt}$ em ácido sulfúrico $12,5 \mathrm{M}$ a $3{ }^{\circ} \mathrm{C}$ sem rotação do eletrodo. $\mathrm{v}=100 \mathrm{mV} \mathrm{s}^{-1}$

Comparação entre a síntese de politiofeno em $\mathrm{H}_{2} \mathrm{SO}_{4}$ $12,5 \mathrm{M}, 1000 \mathrm{rpm}, 3{ }^{\circ} \mathrm{C}, \mathrm{v}=75 \mathrm{mV} \mathrm{s}^{-1}$, com 35 ciclos de 
crescimento sobre os três eletrodos estudados: platina, carbono vítreo e ouro. Voltametrias realizadas em $\mathrm{H}_{2} \mathrm{SO}_{4}$

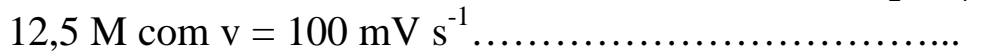

FIGURA 22 -

FIGURA 23 -

FIGURA 24 -

FIGURA 25 -

FIGURA 26 -

FIGURA 27 -

FIGURA 28 -

FIGURA 29 -

FIGURA 30 -

FIGURA 31 -

FIGURA 32a e b -

FIGURA 33 -
Voltamogramas cíclicos de crescimento de politiofeno em eletrodo de tecido de carbono em $\mathrm{H}_{2} \mathrm{SO}_{4} 12,5 \mathrm{M}$ e tiofeno $0,05 \mathrm{M}$. Temperatura de $3^{\circ} \mathrm{C}$, velocidade de 75

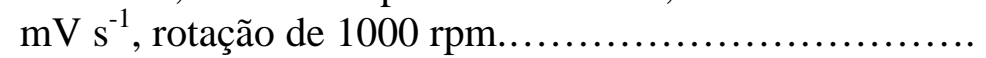

MEV de eletrodo de platina sem presença de PT. Aumento de 20000 vezes................................

MEV de filme de PT sintetizado em $\mathrm{H}_{2} \mathrm{SO}_{4} 12,5 \mathrm{M}, 3{ }^{\circ} \mathrm{C}$, $1000 \mathrm{rpm}, \mathrm{v}=75 \mathrm{mV} \mathrm{s}^{-1}$ por 15 ciclos sobre eletrodo de platina. Aumento de 25000 vezes

MEV de eletrodo de ouro sem presença de PT. Aumento de 20000 vezes..........................................

MEV de filme de PT sintetizado em $\mathrm{H}_{2} \mathrm{SO}_{4} 12,5 \mathrm{M}, 3{ }^{\circ} \mathrm{C}$, $1000 \mathrm{rpm}, \mathrm{v}=75 \mathrm{mV} \mathrm{s}^{-1}$ por 35 ciclos sobre eletrodo de ouro. Aumento de 20000 vezes.

MEV de eletrodo de carbono vítreo sem presença de PT. Aumento de 20000 vezes

MEVde filme de PT sintetizado em $\mathrm{H}_{2} \mathrm{SO}_{4} 12,5 \mathrm{M}, 3{ }^{\circ} \mathrm{C}$, $1000 \mathrm{rpm}, \mathrm{v}=100 \mathrm{mV} \mathrm{s}^{-1}$ por 15 ciclos sobre eletrodo de carbono vítreo. Aumento de 20000 vezes. ...

EDX de filme de PT sintetizado em $\mathrm{H}_{2} \mathrm{SO}_{4} 12,5 \mathrm{M}, 3{ }^{\circ} \mathrm{C}$, $1000 \mathrm{rpm}, \mathrm{v}=75 \mathrm{mV} \mathrm{s}^{-1}$ por 65 ciclos sobre eletrodo de $\mathrm{Au}$.

MEV de filme de politiofeno sintetizado em $\mathrm{H}_{2} \mathrm{SO}_{4}$ 12,5 $\mathrm{M}, 3{ }^{\circ} \mathrm{C}, 1000 \mathrm{rpm}, \mathrm{v}=100 \mathrm{mV} \mathrm{s}^{-1}$ por 15 ciclos sobre eletrodo de platina. Aumento de 26710 vezes...............

Espectro de FTIR de politiofeno crescido em ácido sulfúrico $12,5 \mathrm{M} \mathrm{a} 3{ }^{\circ} \mathrm{C} \mathrm{e} \mathrm{v}=100 \mathrm{mV} \mathrm{s}^{-1}$

FIGURAS 32a e 32b - Curvas voltamétricas de PT sintetizado em $\mathrm{H}_{2} \mathrm{SO}_{4} 12,5 \mathrm{M}, 1000 \mathrm{rpm}, 3{ }^{\circ} \mathrm{C}, \mathrm{v}=75$ $\mathrm{mV} \mathrm{s}^{-1}$, com 65 ciclos de crescimento sobre eletrodo de $\mathrm{Pt}$ em diversas concentrações de $\mathrm{H}_{2} \mathrm{SO}_{4}$ (concentrações apresentadas nas próprias figuras). $\mathrm{v}=100 \mathrm{mV} \mathrm{s}^{-1}$

Espectros de UV-Visível de politiofeno sintetizado sobre platina em $\mathrm{H}_{2} \mathrm{SO}_{4} 12,5 \mathrm{M}$ por 35 ciclos, com $1000 \mathrm{rpm}, 3$ 
${ }^{\circ} \mathrm{C} \mathrm{e} \mathrm{v}=75 \mathrm{mV} \mathrm{s}^{-1}$. Solução utilizada: $\mathrm{H}_{2} \mathrm{SO}_{4} 12,5 \mathrm{M}$ Potenciais aplicados mostrados na própria figura ( $v s$. ERH)

FIGURA 34 -

FIGURA 35 -

FIGURA 36 -

FIGURA 37 -

FIGURA 38 -

FIGURA 39 -

FIGURA 40 -

FIGURA 41 -
Espectros de UV-Visível do politiofeno apresentado na figura anterior em comprimentos de onda fixos de 530 e $670 \mathrm{~nm}$ durante voltametria cíclica a $50 \mathrm{mV} \mathrm{s}^{-1}$

Voltamogramas cíclicos de politiofeno crescido sobre eletrodo de $\mathrm{C}$ vítreo por 35 ciclos contendo platina e não contendo platina em solução de $\mathrm{H}_{2} \mathrm{SO}_{4} \quad 12,5 \mathrm{M}$. Velocidade de varredura: $75 \mathrm{mV} \mathrm{s}^{-1}, 40$ ciclos de incorporação de platina

Voltamogramas cíclicos de PT contendo prata em solução de $\mathrm{H}_{2} \mathrm{SO}_{4} 0,05 \mathrm{M}$. Velocidade de varredura: 20 $\mathrm{mV} \mathrm{s}^{-1}, 60 \mathrm{~s}$ de polarização do eletrodo em potencial de 0,54 V para incorporação de prata. Eletrodo utilizado: C vítreo.

Voltamogramas cíclicos de PT contendo paládio em solução de $\mathrm{H}_{2} \mathrm{SO}_{4}$ 0,05 M. Velocidade de varredura: 75 $\mathrm{mV} \mathrm{s}^{-1}, 120 \mathrm{~s}$ de polarização do eletrodo em potencial de $0,43 \mathrm{~V}$ para incorporação de paládio. Eletrodo utilizado: $\mathrm{C}$ vítreo.

Voltamograma cíclico de politiofeno contendo platina em solução de $\mathrm{H}_{2} \mathrm{SO}_{4} 12,5 \mathrm{M}, 65$ ciclos de crescimento de politiofeno sobre eletrodo de $\mathrm{C}$ vítreo. Velocidade de varredura: $75 \mathrm{mV} \mathrm{s}^{-1}, 40$ ciclos de incorporação de platina.

Filme de PT sintetizado em $\mathrm{H}_{2} \mathrm{SO}_{4} 12,5 \mathrm{M}, 3{ }^{\circ} \mathrm{C}, 1000$ $\mathrm{rpm}, \mathrm{v}=75 \mathrm{mV} \mathrm{s}^{-1}$ por 65 ciclos sobre eletrodo de carbono vítreo, com posterior incorporação de partículas de Pt através de ciclização do eletrodo em $\mathrm{H}_{2} \mathrm{PtCl}_{6}$ por 20 ciclos: a) MEV.Aumento de 10000 vezes; b) EDX.........

Espectros de XANES do Pd incorporado no politiofeno sintetizado em $\mathrm{H}_{2} \mathrm{SO}_{4} \quad 12,5 \mathrm{M}$ e com $60 \mathrm{~s}$ de eletrorredução, em solução de ácido sulfúrico 2,0 M à temperatura ambiente e polarizado em 0,$05 ; 0,5$ e $0,84 \mathrm{~V}$ (vs. ERH) sobre eletrodo de tecido de carbono. E do paládio metálico utilizado como referência em condições ex situ.

Espectros de XANES da Pt incorporada no politiofeno sintetizado em $\mathrm{H}_{2} \mathrm{SO}_{4} 12,5 \mathrm{M}$ e com 40 ciclos de eletrorredução, em solução de ácido sulfúrico $2,0 \mathrm{M}$ à 
temperatura ambiente e quatro potenciais de polarização $(0,05 ; 0,2 ; 0,5$ e $0,84 \mathrm{~V}$ vs. ERH) sobre eletrodo de tecido de carbono. E da platina metálica utilizada como referência em condições ex situ.........................

FIGURA 42 -

FIGURA 43 -

FIGURA 44 -

FIGURA 45 -

FIGURA 46 -

FIGURA 47 -

FIGURA 48 -

FIGURA 49 -

FIGURA 50 -
Gráficos de sinais de EXAFS do Pd incorporado no PT sintetizado em $\mathrm{H}_{2} \mathrm{SO}_{4} \quad 12,5 \quad \mathrm{M}$ e com $60 \mathrm{~s}$ de eletrodeposição e do $\mathrm{Pd}$ metálico utilizado como referência em condições ex situ..........................

Gráficos de Transformada de Fourier do Pd incorporado no PT sintetizado em $\mathrm{H}_{2} \mathrm{SO}_{4} 12,5 \mathrm{M}$ e com $60 \mathrm{~s}$ de eletrodeposição, em $\mathrm{H}_{2} \mathrm{SO}_{4} \quad 2,0 \quad \mathrm{M}$ à temperatura ambiente e 3 potenciais de polarização $(0,05 ; 0,5$ e 0,84 $\mathrm{V}$ vs. ERH) e do Pd metálico utilizado como referência em condições ex situ

Gráficos de Transformada de Fourier da Pt incorporada no PT sintetizado em $\mathrm{H}_{2} \mathrm{SO}_{4} 12,5 \mathrm{M}$ e com 40 ciclos de eletrorredução, em $\mathrm{H}_{2} \mathrm{SO}_{4} 2,0 \mathrm{M}$ à temperatura ambiente e 4 potenciais de polarização $(0,05 ; 0,2 ; 0,5$ e $0,84 \mathrm{~V} v s$. ERH) e da Pt metálica utilizada como referência em condições ex situ......................................

Números de coordenação Pt-Pt médios como um função do tamanho das partículas para estruturas icosahédricas

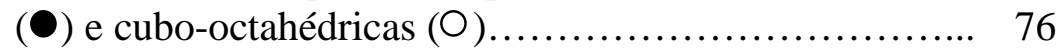

Curvas potenciodinâmicas da $\mathrm{ROH}$ em politiofeno crescido por 35 ciclos, sem presença de catalisadores e com 80 ciclos de incorporação de $\mathrm{Pt}$, em solução de $\mathrm{H}_{2} \mathrm{SO}_{4} 2,0 \mathrm{M}$ e velocidade de varredura de $5 \mathrm{mV} \mathrm{s}^{-1} \ldots \ldots$.

Curvas potenciodinâmicas da ROH em PT crescido por 35 ciclos, com $60 \mathrm{~s}$ de incorporação de $\mathrm{Pd}$, em solução de $\mathrm{H}_{2} \mathrm{SO}_{4} 2,0 \mathrm{M}$ e velocidade de varredura de $5 \mathrm{mV} \mathrm{s}^{-1} \ldots \ldots$.

Curvas potenciodinâmicas da RRO em politiofeno crescido por 35 ciclos em $\mathrm{H}_{2} \mathrm{SO}_{4} 12,5 \mathrm{M}$ em eletrodo de $\mathrm{C}$ vítreo, sem a presença de catalisador em solução de $\mathrm{H}_{2} \mathrm{SO}_{4} 2,0 \mathrm{M}$ e velocidade de varredura de $5 \mathrm{mV} \mathrm{s}^{-1} \ldots \ldots$.

Curvas potenciodinâmicas da RRO em PT crescido por 35 ciclos em $\mathrm{H}_{2} \mathrm{SO}_{4} 12,5 \mathrm{M}$ em eletrodo de $\mathrm{C}$ vítreo, com 60 s de incorporação de $\mathrm{Pd}$, em solução de $\mathrm{H}_{2} \mathrm{SO}_{4} 2,0 \mathrm{M}$ e velocidade de varredura de $5 \mathrm{mV} \mathrm{s}^{-1}$.

Curvas potenciodinâmicas da RRO em PT crescido por 35 ciclos em $\mathrm{H}_{2} \mathrm{SO}_{4}$ 12,5 em eletrodo de $\mathrm{C}$ vítreo $\mathrm{M}$, com 
80 ciclos de incorporação de $\mathrm{Pt}$, em solução de $\mathrm{H}_{2} \mathrm{SO}_{4}$ $2,0 \mathrm{M} \mathrm{e} \mathrm{v}=5 \mathrm{mV} \mathrm{s}^{-1}$

FIGURA 51 -

FIGURA 52 -

FIGURA 53 -

FIGURA 54 -

FIGURA 55 -

FIGURA 56 -

FIGURA 57 -

FIGURA 58 -
Curvas potenciodinâmicas da RRO em PT crescido por 35 ciclos em $\mathrm{H}_{2} \mathrm{SO}_{4} 12,5 \mathrm{M}$ em eletrodo de $\mathrm{C}$ vítreo, com 60, 120 e $180 \mathrm{~s}$ de incorporação de Pd e de PT na ausência do catalisador, em $\mathrm{H}_{2} \mathrm{SO}_{4} 2,0 \mathrm{M} \mathrm{e} \mathrm{v}=5 \mathrm{mV} \mathrm{s}^{-1}$. $\mathrm{w}=2500 \mathrm{rpm}$

Curvas potenciodinâmicas da RRO em politiofeno crescido por 15,35 e 95 ciclos em $\mathrm{H}_{2} \mathrm{SO}_{4} 12,5 \mathrm{M}$ em eletrodo de $\mathrm{C}$ vítreo, com 40 ciclos de incorporação de $\mathrm{Pt}$, em solução de $\mathrm{H}_{2} \mathrm{SO}_{4} 2,0 \mathrm{M} \mathrm{e} \mathrm{v}=5 \mathrm{mV} \mathrm{s}^{-1}$....

Curvas potenciodinâmicas da RRO de vários materiais em solução de $\mathrm{H}_{2} \mathrm{SO}_{4} 2,0 \mathrm{M}$ e velocidade de varredura de $5 \mathrm{mV} \mathrm{s}^{-1} . \mathrm{W}=2500 \mathrm{rpm}$.

Gráficos de Levich correspondendo ao politiofeno sintetizado por 35 ciclos em $\mathrm{H}_{2} \mathrm{SO}_{4} 12,5 \mathrm{M}$ em eletrodo de $\mathrm{C}$ vítreo, com $60 \mathrm{~s}$ de incorporação de $\mathrm{Pd}$, em solução de $\mathrm{H}_{2} \mathrm{SO}_{4}$ 2,0 $\mathrm{M}$ e velocidade de varredura de $5 \mathrm{mV} \mathrm{s}^{-1}$.

$(\square) \mathrm{E}=0,2 \mathrm{~V}$ e $(\nabla) \mathrm{E}=0,4 \mathrm{~V}(v s . \mathrm{ERH}) . \mathrm{w}=2500 \mathrm{rpm} .$.

Gráficos de Levich correspondendo ao politiofeno sintetizado por 35 ciclos em eletrodo de carbono vítreo correspondendo aos resultados da Figura 53: ( $\square$ ) 40 ciclos; (+) 80 ciclos de eletrorredução de Pt; ( $\mathbf{\square}$ ) 80 ciclos de eletrorredução de Pt recoberto por PT e $(\bullet) \mathrm{Pt}$ pura. Solução utilizada: $\mathrm{H}_{2} \mathrm{SO}_{4} 2,0 \mathrm{M}$ e velocidade de varredura de $5 \mathrm{mV} \mathrm{s}^{-1}$

Curvas de Tafel para politiofeno crescido por 35 ciclos em $\mathrm{H}_{2} \mathrm{SO}_{4} 12,5 \mathrm{M}$ em eletrodo de $\mathrm{C}$ vítreo, com $60 \mathrm{~s}$ de incorporação de $\mathrm{Pd}$, em solução de $\mathrm{H}_{2} \mathrm{SO}_{4} 2,0 \mathrm{M}$ e velocidade de varredura de $5 \mathrm{mV} \mathrm{s}^{-1}$

Gráficos de Tafel para RRO em eletrodo de politiofeno contendo partículas de $\mathrm{Pt}$ ( 35 ciclos de crescimento a 75 $\mathrm{mV} \mathrm{s}^{-1}$ ) em eletrodo de carbono vítreo e $\mathrm{H}_{2} \mathrm{SO}_{4} 2,0 \mathrm{M}$ para o polímero contendo diferentes quantidades de partículas de Pt: $(\square) 80$ ciclos; $(\triangle) 40$ ciclos de eletrorredução de Pt; $(\mathrm{O}) \mathrm{Pt}$ pura e $(+) \mathrm{PT} / \mathrm{Pt}$ t80/PT. w = $2500 \mathrm{rpm}$....

Esquema mostrando eletrodos poliméricos contendo partículas de Pt recobertas ou não por camada adicional de polímero 
LISTA DE TABELAS

TABELA 1 - Mecanismos mais prováveis para a $\mathrm{ROH}$ com os respectivos coeficientes de Tafel (b) ....................................

TABELA 2 - Parâmetros obtidos através da geração do sinal EXAFS. $\Delta \mathrm{r}=$ 1,40-3,20 A e 1,85-3,10 A para Pd e Pt, respectivamente.........

TABELA 3 - Parâmetros cinéticos obtidos dos ajustes da equação (1) para a polarização dos dados experimentais em altas correntes de densidade. 


\section{LISTA DE ABREVIAÇÕES}

$\begin{array}{ll}\text { EDX } & \text { Espectroscopia de Dispersão de Energia de Raios X } \\ \text { ERH } & \text { Eletrodo Reversível de Hidrogênio } \\ \text { EXAFS } & \text { Extended X-Ray Absorption Fine Structure } \\ \text { FTIR } & \text { Espectroscopia de Infravermelho por Transformada de Fourier } \\ \text { ITO } & \text { Indium Tin Oxide } \\ \text { MEV } & \text { Microscopia Eletrônica de Varredura } \\ \text { PANI } & \text { Polianilina } \\ \text { PPP } & \text { Poli-para-fenileno } \\ \text { PPy } & \text { Polipirrol } \\ \text { PT } & \text { Politiofeno } \\ \text { ROH } & \text { Reação de Oxidação de Hidrogênio } \\ \text { RRO } & \text { Reação de Redução de Oxigênio } \\ \text { UV-Vis } & \text { Espectroscopia de Ultra-Violeta Visível } \\ \text { XANES } & \text { X-Ray Absorption Near Edge Structure } \\ \text { XAS } & \text { Espectroscopia de Absorção de Raios X } \\ \end{array}$




\section{RESUMO}

Filmes de politiofeno foram eletroquimicamente depositados em diversos substratos eletródicos em meio aquoso fortemente ácido e as características dos materiais formados foram estudadas através de técnicas voltamétricas, espectroscópicas (FTIR e UV-Vis. e raios X) e por microscopia eletrônica de varredura. As propriedades foram comparadas com as de filmes sintetizados em meio não-aquoso concluindo-se que o material produzido em meio aquoso mostra-se mais adequado para a aplicação como suporte de partículas eletrocatalisadoras, por sua maior atividade eletroquímica, homogeneidade e estabilidade. Foram então incorporadas partículas de $\mathrm{Pd}$ e Pt que foram investigadas quanto a ação catalítica frente as reações de oxidação de hidrogênio $(\mathrm{ROH})$ e redução de oxigênio (RRO) em ácido sulfúrico 2,0 M. Os materiais produzidos foram primeiramente caracterizados através de técnica de absorção de raios $\mathrm{X}$, tendo sido observada a formação de aglomerados de partículas bastante pequenas que não alteram seu estado de oxidação com a mudança do potencial eletródico. Verificou-se que ambos os catalisadores apresentam uma certa atividade inicial frente a $\mathrm{ROH}$, mas o desempenho não é estável devido à ocorrência de processos degradativos da cadeia polimérica. Por outro lado, observou-se que os filmes contendo Pt apresentam elevada atividade catalítica frente a RRO, substancialmente maior que a de filmes contendo Pd. O mecanismo da reação mostrou-se dependente da natureza do catalisador, sendo também influenciado pelo contato com o filme polimérico. Para a Pt em contato direto com o eletrólito, a reação ocorre com envolvimento de 4 elétrons e com formação de água como produto final. Para o caso em que as partículas de Pt são recobertas por politiofeno, verifica-se a participação do peróxido de hidrogênio como intermediário, sendo que somente uma certa fração do mesmo reduz-se para formar água. No caso do $\mathrm{Pd}$, o processo leva à formação de peróxido de hidrogênio em baixos sobrepotenciais, que depois é reduzido, com formação de água, em sobrepotenciais mais elevados. 


\begin{abstract}
Polythiophene films were electrochemically grown on several electrode substrates from strong acid aqueous solutions, and the characteristics of the materials investigated using cyclic voltammetry, FTIR and UV-Vis spectroscopies, and scanning electron microscopy. Compared to the materials prepared in non-aqueous media, the polymer synthesized in aqueous media shows more adequate characteristics for using as support for electrocatalytic particles, because of its higher electrochemical activity and stability, and bulk homogeneity. Particles of Pd and Pt were electrochemically incorporated on these polymer films, and the electrocatalytic properties of such composites investigated with respect to the hydrogen oxidation (HOR) and oxygen reduction (ORR) reactions in $2.0 \mathrm{M}$ sulfuric acid solutions. Previously to these kinetic studies, the composites were characterized using X-ray absorption spectroscopy from which it is seen that the catalysts are deposited as agglomerates composed of very small particles whose oxidation states are not changed by changing the electrode potential. Both catalysts present some initial activity for the HOR, but the performance is not stable due to the occurrence of a degradation process involving the polymer chain. On the other hand, it is observed that the films containing Pt show an enhanced catalytic activity for the ORR which is considerably higher than of that containing Pd. The reaction mechanism is dependent on the catalyst nature and also influenced by the contact with a polymer film coating. For Pt in direct contact with the supporting electrolyte, the reaction occurs involving 4 electrons leading to water as final product. For Pt particles covered with a polymer layer, participation of hydrogen peroxide seems to be important with only a fraction of this specie being reduced to water. In the case of $\mathrm{Pd}$, the process involves formation of hydrogen peroxide at low overpotentials, which is then reduced to water at higher overpotentials.
\end{abstract}




\section{CAPÍTULO I:}

\section{INTRODUÇÃO}

Até a década de 70, os polímeros orgânicos eram utilizados em diversas aplicações, entre elas como isolante elétrico em substituição aos isolantes fabricados à base de papel, por serem mais leves e mais baratos [1,2]. Em 1974, Shirakawa e Ikeda [3] demonstraram a possibilidade de sintetizar filmes de poliacetileno através da polimerização do acetileno na presença de um catalisador tipo Ziegler-Natta. O polímero produzido era fracamente semi-condutor $\left(10^{-8} \mathrm{~S} \mathrm{~cm}^{-1}\right)$ e atraiu pouca atenção até 1977, quando MacDiarmid e cols. [4] verificaram que o tratamento do poliacetileno com ácido ou base de Lewis aumentava sua condutividade em até 10 ordens de grandeza. A partir deste momento, a pesquisa nessa área teve um grande avanço e outros polímeros intrinsecamente condutores foram sintetizados.

Entre os polímeros condutores mais estudados estão o politiofeno (PT), o polipirrol (Ppy) e a polianilina (Pani), por causa de sua boa estabilidade química no estado oxidado [5]. A condutividade elétrica e as propriedades eletroquímicas e eletrocrômicas desses materiais devem-se às suas longas cadeias poliênicas conjugadas, ou seja, de unidades repetitivas que interagem via sistema de elétrons $\pi$. Os polímeros intrinsecamente condutores passam de isolantes a condutores através de processos reversíveis de oxidação e redução do sistema $\pi$ conjugado, 
diferenciando-se dos polímeros redox, os quais também contêm grupos eletroativos mas não possuem sistemas $\pi$ conjugados e não conduzem corrente eletrônica [6].

\section{1. Síntese do politiofeno}

O politiofeno e seus derivados são a primeira classe de polímeros os quais são química e eletroquimicamente estáveis no ar e na umidade tanto em seu estado dopado como não-dopado [7]. Em contraste com o polipirrol e a polianilina que podem ser obtidos em meio aquoso, o politiofeno é geralmente sintetizado por oxidação eletroquímica do monômero em um meio não-aquoso com carbonato de propileno ou acetonitrila [5]. A insolubilidade do monômero em meio aquoso convencional e o fato de seu potencial redox ser mais alto que o potencial para decomposição de água são as duas principais razões pelas quais o tiofeno não eletropolimeriza. A isto soma-se a alta reatividade do cátion radical do tiofeno com água, o que se antecipa à eletropolimerização catiônica [5]. Estas dificuldades encontradas na preparação do politiofeno em meio aquoso são um problema sério que podem ser impedimento para sua aplicação industrial, por exemplo, para servir de recobrimento para materiais contra corrosão [5].

Por este motivo, muitos estudos têm surgido sobre a eletropolimerização do

tiofeno em meio aquoso. Usando emulsão aquosa, Czerwinski et al. [8] realizaram a oxidação eletroquímica do tiofeno, e obtiveram filmes condutores deste polímero. Entretanto, as propriedades condutoras e morfológicas eram muito diferentes daquelas geralmente observadas para filmes de PT sintetizados em meio não-aquoso [5,8]. Dong e Zhang [9] eletrossintetizaram filmes de PT em eletrodos de Pt e ITO 
(Indium Tin Oxide) por oxidação de oligômeros formados in situ a partir da reação de tiofeno dissolvido em soluções de ácido concentrado. Estes oligômeros possuem potencial de oxidação muito menor que aquele do tiofeno em acetonitrila [10] e podem ser eletropolimerizados em baixos potenciais. Porém, o polímero formado difere daqueles obtidos em meio orgânico pois contém alguns grupos carbonila nos anéis de tiofeno [5,9]. Lacaze et al. [5] mostraram ser possível a obtenção de filmes homogêneos de politiofeno em eletrodos de $\mathrm{Pt}$ pela eletropolimerização do monômero em ácido perclórico aquoso 5,0 M. O uso deste meio aumenta a solubilidade de tiofeno em água e, segundo estes autores, abaixa o potencial de oxidação do mesmo, provavelmente pela formação de um complexo- $\pi$ entre o monômero e o ácido. Este valor de potencial explica porque o polímero obtido neste caso tem melhores propriedades estruturais que politiofeno sintetizado em $\mathrm{H}_{3} \mathrm{PO}_{4}$ altamente concentrado [5]. Mu e Park [11] obtiveram politiofeno a partir de soluções aquosas contendo monômero, álcool etílico e os ácidos $\mathrm{HClO}_{4}, \mathrm{H}_{2} \mathrm{SO}_{4}$ e $\mathrm{HBF}_{4}$, e concluíram que os filmes formados possuem propriedades eletroquímicas diferentes das dos polímeros formados em meio orgânico, possuindo alto potencial anódico de decomposição e os valores de impedância encontrados são muito sensíveis ao pH e potenciais aplicados.

Os monômeros de tiofeno são preferencialmente ligados pelos carbonos nas posições 2 e 5 (acoplamento $\alpha-\alpha$ ) preservando o núcleo aromático [7], possuindo mais alto comprimento de conjugação e apresentando menores problemas de impedimento estérico que nas posições 3, 4 (acoplamento $\alpha-\beta$ ) [12].

A reação de polimerização do tiofeno envolve a remoção de 2,25 a 2,50 elétrons por molécula do mesmo e o polímero resultante é produzido no estado oxidado com 0,25 - 0,50 centros de cátions por unidade de monômero, dependendo 
da reação eletroquímica. Em meio orgânico, o esquema geral para o processo eletroquímico é do tipo [7],

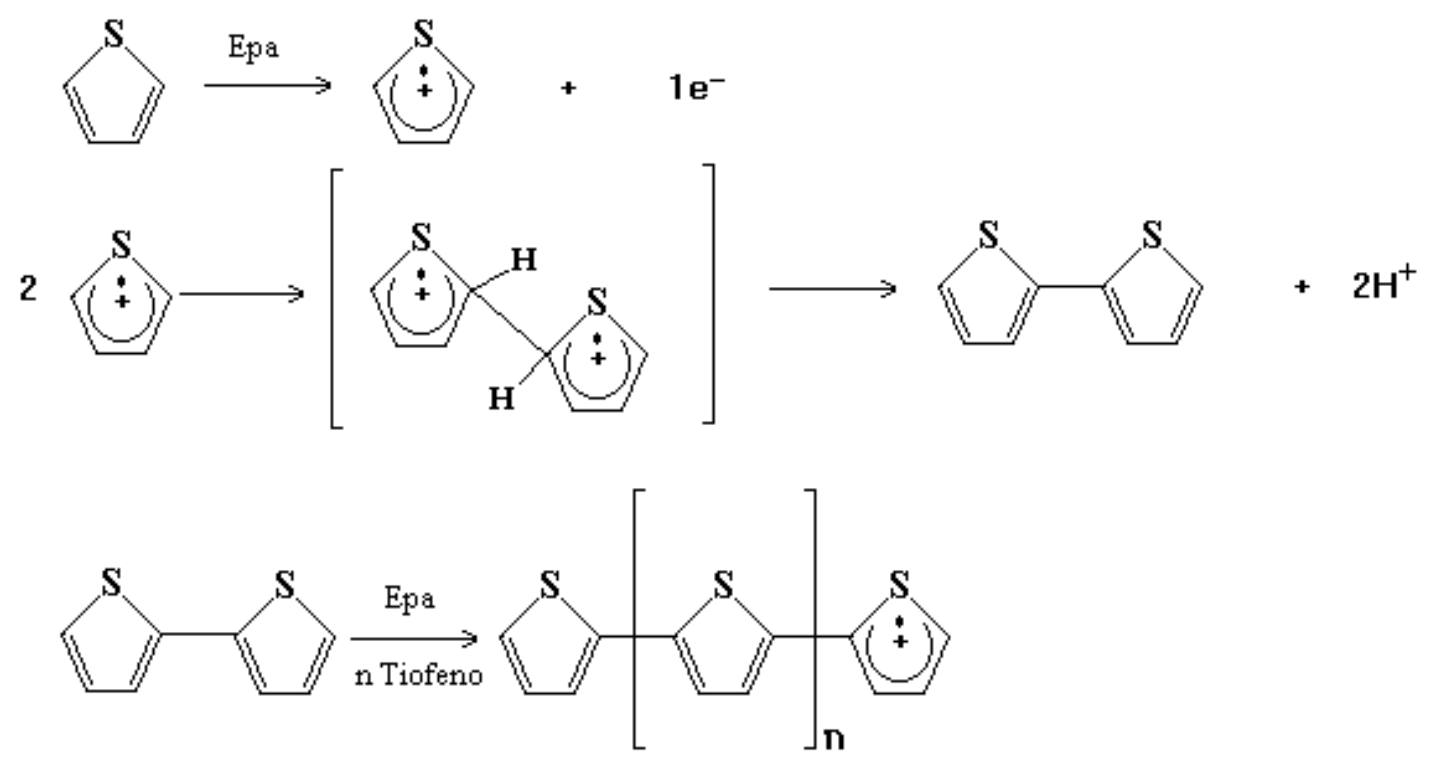

\section{2. Mecanismos de condução}

O processo de oxidação e redução nas cadeias poliênicas envolve a remoção/adição de elétrons e tem como consequência a formação de cargas positivas (ou negativas) deslocalizadas, às quais são neutralizadas pelos ânions (ou cátions) presentes na solução eletrolítica [13-21]. A concentração deste contra-íon varia de 25 a $40 \%$ em massa. A inserção do contra-íon perturba significativamente a estrutura do polímero, não apenas pelo seu tamanho físico, o qual não permite a substituição no 
retículo do polímero, mas também devido à formação do complexo iônico o qual conduz à mudanças na geometria da molécula. A condutividade $(\sigma)$ aumenta em muitas ordens de grandeza, com a "dopagem" do polímero, sendo acompanhada por grandes mudanças nas propriedades espectroscópicas do mesmo [22]. O processo pelo qual um polímero isolante é levado a um estado condutor é comumente chamado de dopagem, em analogia à dopagem de semi-condutores inorgânicos, embora a físico-química desses dois processos mostrarem-se diferentes. Nos semicondutores inorgânicos ocorre um aumento da condutividade pela introdução de impurezas (da ordem de ppm) no retículo cristalino, com alteração na estrutura de banda do sólido [13].

Durante a oxidação eletroquímica de politiofeno em meios orgânicos, a cadeia polimérica neutra é oxidada com remoção de um elétron gerando um radicalcátion conjugado (Figura 1). Este íon radical é deslocalizado sob uma certa porção do esqueleto polimérico, criando um defeito estrutural (Figura 1b). Este defeito, o qual contém tanto cargas positivas como spins (radicais), é comumente denominado "polaron". A partir deste ponto, dois processos podem ocorrer: primeiro, uma segunda oxidação pode diretamente oxidar o polaron para formar o bipolaron dicatiônico (Figura 1c); segundo, uma segunda oxidação pode também ocorrer na cadeia polimérica neutra, em outra localidade, e os dois polarons podem difundir, combinando os spins para formar uma ligação e deixando as espécies bipolarônicas [23]. São essas cargas positivas criadas no esqueleto polimérico que são os transportadores de carga para condução elétrica. Seu transporte ocorre via mobilidade ao longo dos segmentos da cadeia do polímero conjugado e o salto de cargas de cadeia para cadeia. O número destas cargas contidas em um material e sua mobilidade relativa controla a magnitude da condutividade elétrica. 


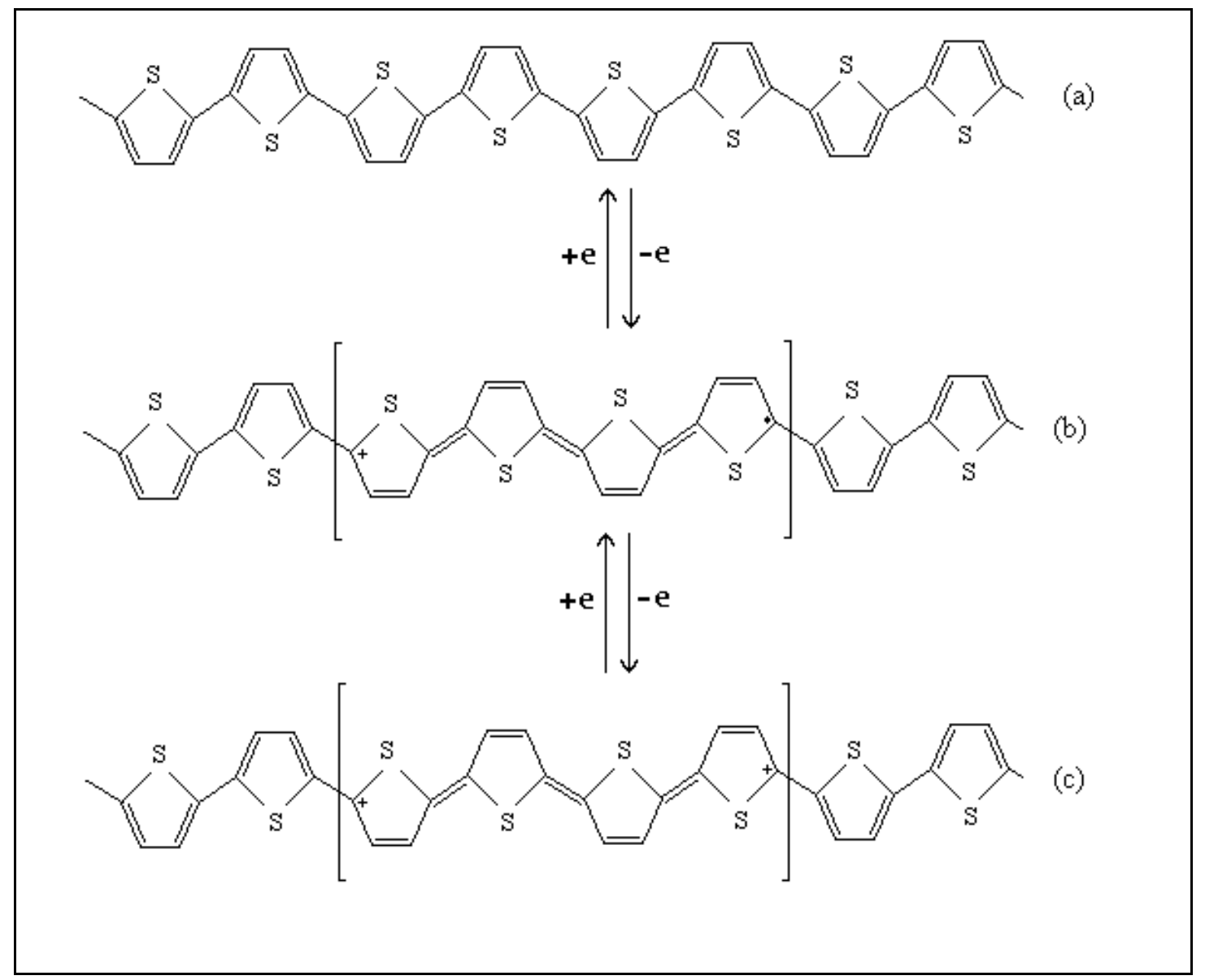

FIGURA 1 - Oxidação eletroquímica do politiofeno. a) a cadeia polimérica neutra é oxidada pela remoção de um elétron; b) o íon radical formado na etapa (a) cria um defeito estrutural e c) ocorre uma segunda oxidação formando um bipolaron dicatiônico.

Um contra-íon (neste caso, um ânion, comumente chamado ânion dopante) estabiliza a carga no polímero, mas a sua mobilidade é em geral muito menor que a da vacância existente na rede polimérica. Deste modo, estes polímeros são condutores verdadeiramente eletrônicos e não-iônicos. A condutividade destes polímeros orgânicos oxidados é tipo-p, quando comparada com semi-condutores, indicando que as espécies móveis são carregadores positivos [23]. 


\section{3. Aplicações como suporte para eletrocatalisadores}

Polímeros condutores podem ser aplicados para várias finalidades, dentre elas estão dispositivos eletrocrômicos e eletrônicos, armazenadores de energia elétrica em baterias recarregáveis, sensores eletroquímicos e suporte para eletrocatalisadores, como mencionado abaixo.

Muitas reações eletroquímicas, como as envolvidas em processos de conversão de energia, tais como células combustíveis, ou aquelas que levam à transformação seletiva de materiais orgânicos, são catalisadas pela superfície do eletrodo e isto constitui um importante campo de pesquisa em eletrocatálise. A maioria das reações eletrocatalíticas é controlada principalmente por um processo de adsorção, cuja velocidade depende fortemente da natureza e da estrutura do eletrodo catalítico. Um bom material eletródico deve apresentar estabilidade mecânica, química e eletroquímica, particularmente em contato com meio eletrolítico agressivo (ácidos ou bases fortes) [24].

Para aumentar a atividade catalítica (a qual é proporcional à área superficial real da interface catalisador-eletrólito), os materiais eletródicos são geralmente dispersos em um substrato condutor eletrônico conveniente, como carbono ou grades metálicas. Um meio de executar esta tarefa é dispersar, a nível molecular ou nanocristalino, o material eletrocatalítico em uma matriz condutora conveniente de tal modo que cada centro catalítico será acessível à molécula reativa, que será assim, eletroativa. Como solução, um polímero condutor eletrônico pode ser utilizado como matriz condutora, por apresentar-se suficientemente estável sob certas condições experimentais, adequadamente condutor para evitar queda ôhmica e poroso, o que minimiza limitações por transferência de massa, facilitando o acesso das espécies 
eletroativas aos sítios catalíticos [24].

O primeiro exemplo de incorporação deste tipo de eletrocatalisadores foi descrito por Noufi [25], que demonstrou a possibilidade de incorporar, em uma matriz de polipirrol, ânions rutenato seguido por sua eletrorredução em partículas de $\mathrm{RuO}_{2}$. No desenvolvimento de materiais alternativos de eletrodos, a incorporação também tem sido feita pela eletrorredução de um íon complexo de platina, tal como $\mathrm{PtCl}_{6}^{-2}$ [26], para formar partículas do metal. Este método pode apresentar certas complicações, tais como a distribuição não-homogênea dos agregados metálicos no interior da matriz polimérica, o fato da condutividade do polímero estar limitada à sua espessura e o descontrole do tamanho dos agregados metálicos. Entretanto, este método tem-se mostrado potencialmente viável para determinados sistemas eletrocatalíticos, principalmente na eletrooxidação de moléculas orgânicas contendo um átomo de carbono [26].

Assim como a Reação de Eletrooxidação de Hidrogênio (ROH), a Reação Eletrocatalítica de Redução de Oxigênio (RRO) está envolvida em todos os tipos de células a combustível e, por isso, seu estudo é de grande interesse. As células a combustível com eletrólitos alcalinos têm grande desvantagem com relação às células com eletrólitos ácidos devido à ocorrência de carbonatação quando o ar é utilizado como agente oxidante [26], daí a importância da investigação da ROH e RRO em meio ácido, principalmente no que se refere à necessidade de se encontrar eletrocatalisadores alternativos aos metais nobres ou de minimizar o seu uso, especialmente a platina (melhor material eletrocatalítico para a $\mathrm{ROH}$ e a RRO conhecido) [27]. Para isso, tem-se realizado vários estudos sobre incorporação de metais e ligas metálicas em matrizes poliméricas, pela possibilidade de obtenção de alta dispersão de partículas catalíticas, com pouca quantidade de metal [24]. 
Alguns trabalhos têm sido realizados com o politiofeno servindo como suporte de micropartículas metálicas para a oxidação de pequenas moléculas como hidrogênio, ácido fórmico e metanol e para redução de oxigênio, por sua faixa de atividade eletroquímica e o controle eletroquímico exercido em sua morfologia e propriedades elétricas tanto por controle de suas condições de eletrossíntese como por modificações estruturais. Estudos mostram que a atividade do eletrodo $\mathrm{PT}-\mathrm{Pt}-\mathrm{Pb}$ foi mantida por mais de $36 \mathrm{~h}$ sem variação e o comportamento do sistema estudado mostra a possibilidade de seu emprego em células combustíveis [28].

O primeiro trabalho sobre a inclusão de partículas metálicas em um derivado de politiofeno se deu pela inclusão de vários metais, tais como $\mathrm{Ag}, \mathrm{Pt}, \mathrm{Cu}, \mathrm{Ni}$ em poli(3-metil-tiofeno), um polímero condutor conjugado altamente condutor $\left(\sigma \approx 10^{2}\right.$ $\mathrm{S} \mathrm{cm}^{-1}$ ) e estável, o qual teve sua permeabilidade controlada através de ajustes nas condições experimentais de síntese [24,29,30]. A eletrodeposição destas partículas metálicas foi estudada por Microscopia Eletrônica de Varredura e Transmissão, Fluorescência de Raio X e Extended X-Ray Absorption Fine Structure (EXAFS). Os resultados mostraram que:

i) uma grande espessura de filmes poliméricos pode ser conseguida, até alguns milímetros, correspondendo a uma densidade de recobrimento de aproximadamente $5 \times 10^{-3}$ mole tiofeno $\mathrm{cm}^{-2}$;

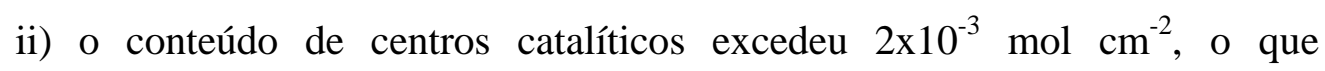
representa um aumento acentuado quando comparado ao caso de polímeros redox;

iii) a dispersão dos agregados metálicos foi muito homogênea ao longo da espessura do filme e;

iv) o tamanho dos agregados metálicos pode ser controlado em uma faixa bem estreita, através da freqüência do pulso usado para a eletrodeposição dos íons 
metálicos; tamanhos da ordem de $1 \mathrm{~nm}$ foram alcançados no caso da Pt, como observado por caracterizações de EXAFS [24,29,30].

Estes fatores estão intimamente relacionados com as propriedades condutoras intrínsecas das cadeias conjugadas, que formam uma rede tri-dimensional de linhas condutoras macromoleculares, onde processos de crescimento-nucleação de nanoagregados metálicos podem ser controlados. As propriedades eletrocatalíticas de platina incluída em politiofenos, em relação à redução de prótons, confirmam a alta condutividade, sendo que densidades de corrente da ordem de $300 \mathrm{~mA} \mathrm{~cm}{ }^{-2}$ são obtidas com cargas de $\mu \mathrm{g} \mathrm{cm}^{-2}$ de Pt [24].

Das várias ligas binárias utilizadas como eletrocatalisadores dispersos em carbono em diferentes eletrodos, em células com membrana de Nafion por exemplo, Pt-Ru, Pt-Sn, Pt-Fe, Pt-Co, Pt-Ni, Pt-Cr, Pt-Mn, e das ternárias (Pt-Cr-Cu), foram as ligas de platina com $\mathrm{Cr}$ que exibiram melhor performance para RRO, sendo que algumas contendo $\mathrm{Sn}$ e Ru apresentam-se tolerantes ao $\mathrm{CO}$ que é um contaminante da reação de oxidação de hidrogênio [31-33]. Em polímeros condutores, sistemas baseados em Pt, Pd, Rh, Co, Cu e também alguns sistemas bimetálicos, Pt-Ag, Pt-Sn, Pt-Rh e Pt-Pd, têm sido desenvolvidos utilizando técnicas similares de eletrodeposição [24]. Nestes trabalhos, devido ao seu importante comportamento eletrocatalítico, partículas de platina foram principalmente consideradas [34-37], mas também sistemas bimetálicos baseados em Pt, como Pt-Ag [38], Pt-Ru [39,40] e PtSn [41] foram analisados. Dispersão de paládio também foi estudada [30], assim como partículas bimetálicas de Pd-Pt [42].

No caso da platina, estudos mostram que o aumento da atividade de RRO poderia ser conseqüência de (i) modificação da estrutura eletrônica da Pt (vacâncias do orbital 5d); (ii) mudanças na estrutura física da Pt (distância da ligação Pt-Pt e 
número de coordenação); (iii) adsorção de espécies contendo oxigênio do eletrólito sobre a platina ou elemento da liga; e/ou (iv) processos tipo redox envolvendo metais da primeira série de transição como elemento da liga.

Uma poderosa técnica analítica que em princípio pode elucidar estas diferentes proposições é a Espectroscopia de Absorção de Raio X (XAS) in-situ, que pode ser utilizada para caracterizar a estrutura dos materiais. O espectro consiste em duas partes, a parte de "near-edge" XANES (X-Ray Absorption Near Edge Structure) que fornece informações químicas e EXAFS (Extended X-Ray Absorption Fine Structure) que fornece informações estruturais [31], sendo estas informações muito importantes para a determinação da estrutura mais eficiente para promover uma determinada reação eletrocatalítica.

\section{4. Mecanismo e Cinética da ROH e RRO}

A Reação de Redução de Oxigênio (RRO) e a Reação de Oxidação de Hidrogênio $(\mathrm{ROH})$ são reações catalíticas muito importantes nos processos de conversão de energia e aqui são apresentados alguns dos fatores envolvidos nestes processos em meio ácido. A RRO pode ser descrita como uma reação complexa, sendo algumas de suas características apresentadas a seguir:

a) Ocorre em faixa de potencial relativamente anódica, onde a maioria dos metais se dissolvem ou formam óxidos passivos, que são cataliticamente inativos. Portanto, em meio ácido, os catalisadores que podem ser utilizados são limitados aos metais nobres e bronze de tungstênio.

b) É uma reação bastante lenta comparada à outras reações eletroquímicas. 
c) A faixa de potenciais onde ocorre pode causar modificações no substrato eletródico, como é o caso da Pt em aproximadamente 1,0 V vs. ERH, o que torna a análise dos dados experimentais mais complicada em relação ao mecanismo de reação.

d) O potencial reversível para a RRO é próximo ao de diversas outras reações paralelas, como a redução de $\mathrm{PtO}_{2}(1,11 \mathrm{~V})$ e $\mathrm{PtO}(0,98 \mathrm{~V})$.

A RRO pode ocorrer por dois mecanismos gerais, um deles levando à formação direta de água e o outro levando à formação de peróxido de hidrogênio e, posteriormente, água:

i. Mecanismo Direto (4 elétrons):

$$
\mathrm{O}_{2}+4 \mathrm{H}^{+}+4 \mathrm{e} \rightarrow 2 \mathrm{H}_{2} \mathrm{O} \quad \mathrm{E}_{\mathrm{o}}=1,229 \mathrm{~V}
$$

ii. Mecanismo Peróxido (2 elétrons):

$$
\mathrm{O}_{2}+2 \mathrm{H}^{+}+2 \mathrm{e} \rightarrow \mathrm{H}_{2} \mathrm{O}_{2} \quad \mathrm{E}_{\mathrm{o}}=0,67 \mathrm{~V}
$$

Eventualmente seguido por:

$$
\mathrm{H}_{2} \mathrm{O}_{2}+2 \mathrm{H}^{+}+2 \mathrm{e} \rightarrow 2 \mathrm{H}_{2} \mathrm{O}
$$

$\mathrm{ou}$

$$
2 \mathrm{H}_{2} \mathrm{O}_{2} \rightarrow 2 \mathrm{H}_{2} \mathrm{O}+\mathrm{O}_{2}
$$


O mecanismo onde os dois processos mencionados acima ocorrem ao mesmo tempo é chamado de Mecanismo Paralelo. Em resumo, o mecanismo da RRO pode ser descrito pelo seguinte diagrama [43]:

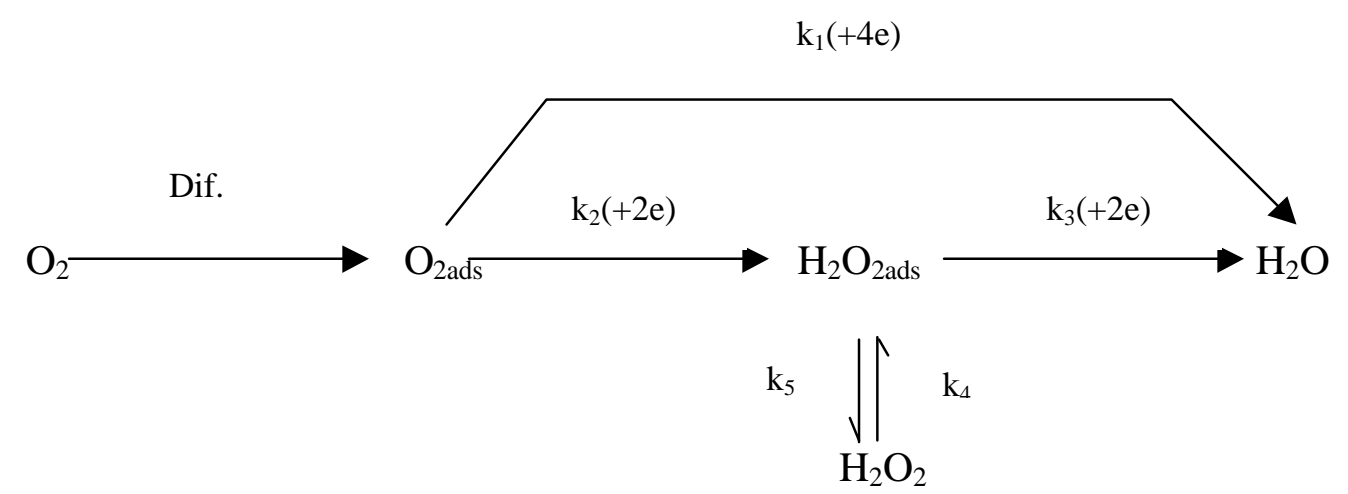

O primeiro passo do processo é a adsorção do oxigênio na superfície do catalisador. Dependendo da natureza do material (por exemplo, em Pt) isto é seguido pelo mecanismo direto de redução gerando água como produto final. Em outros casos (exemplo $\mathrm{Au}$ ), o processo de adsorção é seguido pelo mecanismo peróxido levando à produção de $\mathrm{H}_{2} \mathrm{O}_{2}$. Esta, por sua vez, pode difundir-se para longe do eletrodo tornando-se o produto final da reação; por outro lado, em alguns casos, a decomposição do $\mathrm{H}_{2} \mathrm{O}_{2}$ é um processo relativamente rápido, o que permite sua redução subsequente, também levando à produção de água como produto final.

A ROH envolve a transferência de 2 elétrons por molécula de hidrogênio e pode ocorrer em várias etapas, portanto, através de diferentes mecanismos, sendo os mais prováveis em meio ácido, os seguintes:

i. Descarga Direta de Hidrogênio: 


$$
\mathrm{H}_{2} \rightleftharpoons 2 \mathrm{H}^{+}+2 \mathrm{e}
$$

ii. Mecanismo átomo-átomo:

Envolve uma primeira etapa de adsorção (Tafel), e uma segunda etapa de ionização do átomo adsorvido (Volmer).

$$
\begin{gathered}
\mathrm{H}_{2} \rightleftharpoons 2 \mathrm{H} \quad \text { (Tafel) } \\
\mathrm{H} \rightleftharpoons \mathrm{H}^{+}+\mathrm{e} \quad \text { (Volmer) }
\end{gathered}
$$

iii. Mecanismo átomo-íon:

Envolve uma primeira etapa onde o hidrogênio molecular gera um radical que se adsorve sobre a superfície metálica e um átomo ionizado (Heyrovsky), e uma segunda etapa onde o hidrogênio adsorvido é ionizado (Volmer).

$$
\begin{gathered}
\mathrm{H}_{2} \rightleftharpoons \mathrm{H}+\mathrm{H}^{+}+\mathrm{e} \quad \text { (Heyrovsky) } \\
\mathrm{H} \rightleftharpoons \mathrm{H}^{+}+\mathrm{e} \quad \text { (Volmer) }
\end{gathered}
$$

Os mecanismos átomo-átomo e átomo-íon levam em conta espécies intermediárias adsorvidas, devendo-se, portanto, analisar os vários tipos de isotermas de adsorção (a relação entre a quantidade de espécie adsorvida sobre o eletrodo por unidade de área e a atividade da mesma espécie no seio da solução a uma dada temperatura) das espécies intermediárias formadas durante a reação eletroquímica na superfície eletródica [44,45].

$\mathrm{Na}$ isoterma de Langmuir assume-se que a energia livre de adsorção das espécies intermediárias é independente do grau de recobrimento, o que resulta de 
uma superfície eletródica completamente homogênea com efeitos desprezíveis de interações laterais e heterogeneidades. Além disso, a solução e a interface devem estar em equilíbrio $[44,45]$.

A isoterma de Temkin considera a heterogeneidade da superfície eletródica, ou seja, que diferentes sítios superficiais possuem afinidades intrinsecamente diferentes para o adsorbato, levando a uma variação da energia livre padrão de adsorção com o grau de recobrimento. Uma vez que uma mudança na energia livre padrão de adsorção é geralmente acompanhada por uma variação proporcional na energia livre padrão de adsorção aparente, para os processos de adsorção surgem os processos ativados e não ativados. Nos processos não ativados, a variação de entalpia de adsorção é independente do grau de recobrimento enquanto que, nos processos ativados, a quimissorção dos átomos necessita de energia de ativação [44,45].

Dependendo das condições experimentais ou do material do eletrodo, a ROH pode ocorrer através de um dos mecanismos acima listados. Considerando os mecanismos átomo-átomo ou átomo-íon, qualquer uma das etapas que os compõem podem constituir-se na etapa determinante de velocidade. Assim, tem-se que:

a) no estado estacionário a concentração de hidrogênio adsorvido não varia com o tempo;

b) o coeficiente de transferência de elétrons é o mesmo em ambas as etapas de qualquer um dos mecanismos propostos e possui o valor numérico de 0,5; e,

c) escolhendo-se a isoterma de adsorção apropriada para o cálculo dos devidos valores de grau de recobrimento, pode-se calcular a equação cinética teórica para descrever o comportamento da corrente em função do potencial ou sobrepotencial eletródico. Os resultados finais são normalmente apresentados em 
termos da variação do sobrepotencial com o logaritmo da corrente, ou seja, o coeficiente de Tafel:

$$
(\partial \eta / \partial \operatorname{logi})_{\mathrm{H} 2}=\mathrm{b}
$$

Os valores de b para alguns dos mecanismos e etapas determinantes possíveis podem ser vistos na Tabela 1 [44].

TABELA 1 - Mecanismos mais prováveis para a ROH com os respectivos coeficientes de Tafel (b).

\begin{tabular}{|c|c|c|c|}
\hline Mecanismo & edv & Isoterma de adsorção & $\begin{array}{c}\mathrm{b} \\
(\mathrm{mV} / \mathrm{dec})\end{array}$ \\
\hline Descarga Direta (reversível) & - & - & 30 \\
Descarga Direta (irreversível) & - & - & 60 \\
Átomo-átomo & Tafel & Temkin ativada & 70 \\
Átomo-átomo & Volmer & Langmuir (baixo recobrimento) & 120 \\
Átomo-íon & Heyrovsky & Temkin ativada & 70 \\
Átomo-íon & Volmer & Langmuir (baixo recobrimento) & 40 \\
Átomo-íon & Volmer & Langmuir (alto recobrimento) & 120 \\
\hline
\end{tabular}

\section{5. Objetivos e metodologia empregada}

Conforme observado anteriormente, a síntese do politiofeno tem sido mais freqüentemente realizada em meio não-aquoso. Isto deve-se às várias dificuldades associadas ao emprego de solvente aquoso, entre elas a baixa solubilidade do monômero e o seu alto potencial de oxidação, que em condições normais excede aquele da reação de desprendimento de oxigênio [5]. Estudos em meio aquoso têm 
sido relatados apenas com o uso de ácido perclórico e fosfórico concentrados como eletrólitos [5], os quais em termos gerais, apresentam interesse limitado para fins de aplicação em sistemas de conversão de energia em baixas temperaturas. Para estas aplicações, o uso de ácido sulfúrico tem sido mais amplamente difundido.

Por outro lado, o uso de catalisadores dispersos em politiofeno também tem sido o objeto de vários estudos relativos a aplicação em sistemas de conversão de energia [46], em particular que envolvem a reação de oxidação de ácido fórmico sobre $\mathrm{Pt}$ e $\mathrm{Pt}+\mathrm{Pb}$ [28] e a reação de redução de oxigênio sobre $\mathrm{Pd}$ [30]. No entanto, nenhum estudo sistemático tem sido efetuado sobre as reações de oxidação de hidrogênio e a reação de redução de oxigênio, que estão envolvidas nos processos eletródicos em células a combustível de baixas temperaturas e que utilizam eletrólitos ácidos.

Os objetivos do presente trabalho podem ser agrupados da seguinte forma: (i) estudar a síntese e o comportamento eletroquímico de filmes de politiofeno em solução de ácido sulfúrico, tendo em vista a aplicação como suporte de catalisadores para células a combustível; (ii) estudar os processos de incorporação de partículas de Ag, Pd e Pt sobre filmes deste polímero condutor, bem como caracterizar a estrutura e as propriedades dos materiais resultantes e; (iii) estudar os processos de oxidação de hidrogênio e de redução de oxigênio nos materiais produzidos.

As etapas que acontecem durante a ação catalítica de metais dispersos em polímeros condutores em relação às reações de oxidação de hidrogênio e redução de oxigênio envolvem vários processos simultâneos, como os processos de transferência de carga associados à oxi-redução do polímero, processos de migração-difusão de íons para a compensação de cargas, e as etapas da própria reação eletroquímica de interesse. Levando em conta estes fatos, resulta claro que o comportamento cinético 
que reflete-se sobre os fenômenos da polarização eletródica são em geral de difícil interpretação.

Assim, estudos prévios dos processos envolvidos na síntese e na oxi-redução do polímero são bastante importantes pois fornecem a base para o entendimento do comportamento do polímero contendo partículas catalisadoras frente à reação de interesse. Neste trabalho, este estudo foi realizado utilizando as técnicas de voltametria cíclica, espectroscopia de reflectância na região do infravermelho (FTIR), espectroscopia de ultra-violeta visível (UV-Vis) e microscopia eletrônica de varredura (MEV). Outro passo importante é a caracterização da estrutura e propriedades do compósito formado pelo polímero condutor e as partículas dispersas. Aqui, duas técnicas foram empregadas: a MEV, através da qual a estrutura microscópica do compósito foi analisada, e a espectroscopia de absorção de raios X (XANES e EXAFS), em cujo caso as propriedades eletrônicas e estruturais do elemento metálico que forma a partícula dispersa foram analisadas. Finalmente a última etapa do trabalho consiste na caracterização das propriedades catalíticas dos compósitos em relação às duas reações de interesse. Para tanto, foi empregada a técnica de eletrodo de disco rotatório para a obtenção de curvas de polarização de estado estacionário, as quais foram analisadas tendo como base as equações e modelos da estrutura eletródica conhecidos para esta técnica. 


\section{CAPÍTULO II:}

\section{PARTE EXPERIMENTAL}

\section{1. Reagentes, Soluções, Eletrodos e Células}

\section{1. 1. Reagentes e Soluções}

Os reagentes $\mathrm{H}_{2} \mathrm{SO}_{4}$ (Mallinckrodt $\mathrm{AR}$ ), $\mathrm{H}_{2} \mathrm{PtCl}_{6}$ (Johnson Matthey Electronics), $\mathrm{HClO}_{4}$ (Baker Chemicals), $\mathrm{PdCl}_{2}$ (II) (Alfa Products), $\mathrm{CH}_{3} \mathrm{~N}$ (Aldrich), $\left(\mathrm{C}_{4} \mathrm{H}_{9}\right)_{4} \mathrm{NClO}_{4}\left(\mathrm{TBAClO}_{4}\right)$ (EastMan), $\mathrm{H}_{2} \mathrm{O}-\mathrm{AgClO}_{4}$ (Aldrich) e o $\mathrm{LiClO}_{4}$ (Fluka) foram utilizados como recebidos. O monômero de tiofeno (Aldrich) foi destilado e armazenado em baixas temperaturas (aproximadamente $0{ }^{\circ} \mathrm{C}$ ) em atmosfera inerte e na ausência de luminosidade.

As soluções eletrolíticas de ácido sulfúrico, ácido perclórico, ácido hexacloroplatínico, perclorato de prata e cloreto de paládio foram preparadas com água obtida de sistema de purificação do tipo Milli-Q. A solução de eletrólito suporte utilizada na síntese do polímero era resfriada até a temperatura de aproximadamente $3{ }^{\circ} \mathrm{C}$ (no caso da maioria dos experimentos em meio aquoso) e agitada por $20 \mathrm{~min}$ com gás inerte ( $\mathrm{N}_{2}$ super seco, White Martins) antes da adição do monômero tiofeno para a remoção de todo o oxigênio dissolvido, fatores que diminuem a oxidação 
química do monômero. As soluções do monômero tiofeno foram preparadas pela adição direta de 0,1 ou $0,6 \mathrm{~mL}$ (para meios aquoso e não-aquoso, respectivamente) de tiofeno destilado em $25 \mathrm{~mL}$ do eletrólito suporte a ser utilizado.

As soluções de ácido hexacloroplatínico foram preparadas adicionando-se 0,8 $\mathrm{mL}$ da solução estoque deste reagente já diluído em água (diluição: $5 \mathrm{~g}$ de ácido para $100 \mathrm{~mL}$ de água) em $25 \mathrm{~mL}$ de $\mathrm{H}_{2} \mathrm{SO}_{4}$ 12,5 M.

\section{1. 2. Eletrodos}

O crescimento dos filmes foi realizado em eletrodos constituídos de três tipos de substratos: platina, ouro e carbono vítreo. Esses eletrodos eram formados por cilindros de platina, ouro e carbono vítreo embutidos em Teflon ${ }^{\circledR}$, sendo que as faces expostas apresentavam áreas geométricas de $0,37,0,26$ e $0,29 \mathrm{~cm}^{2}$, respectivamente. Os eletrodos eram polidos com lixas d'água 400, 600, 1000, 2000, 3000 e 4000 e com aluminas 6, 3, 1 e 0,5 $\mu \mathrm{m}$. Após cada etapa do polimento, os eletrodos eram tratados em ultrassom em várias águas de lavagem para remoção de resíduos de lixa e alumina.

Para os experimentos com Luz Síncrotron, foi utilizado eletrodo de tecido de carbono (PWB3 - Stackpole, área geométrica $=3,08 \mathrm{~cm}^{2}$ ) que era recortado na forma de disco de $1,2 \mathrm{~cm}$ de diâmetro em contato com um fio de platina também preso entre duas peças de Teflon $^{\circledR}$ (presas com parafusos uma a outra e com furo central de 1,1 cm de diâmetro), proporcionando o contato elétrico entre o tecido e o circuito externo, como mostra a Figura 2. O tecido, apesar de hidrofóbico, dispensou tratamento prévio porque a solução sendo fortemente ácida, permitia seu rápido 
umidecimento (aproximadamente um minuto após sua imersão na solução). Este eletrodo era inserido verticalmente na célula eletroquímica e fixo próximo a uma barra de Teflon $^{\circledR}$ encaixada no lugar do eletrodo rotatório (RDE) que girava a 1000 rpm.

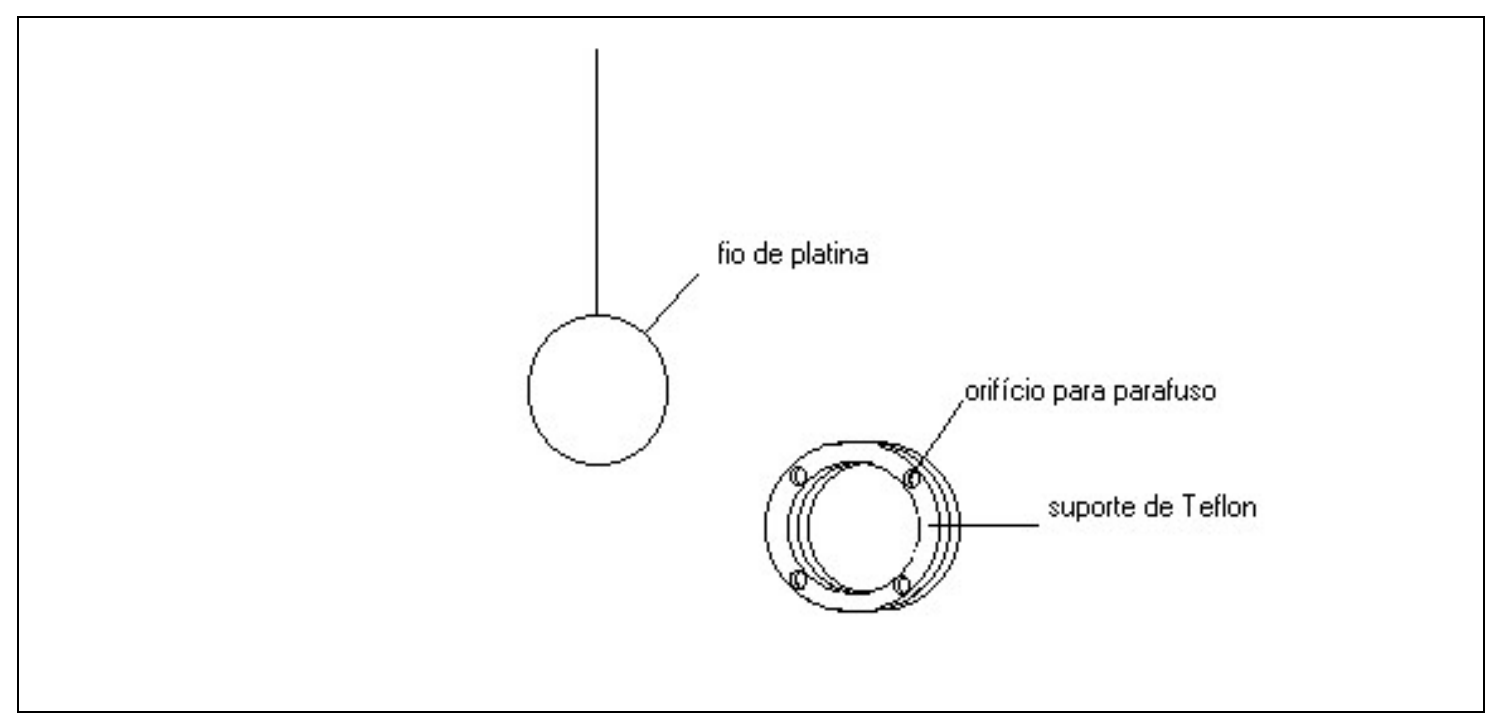

FIGURA 2 - Suporte de Teflon ${ }^{\circledR}$ e fio de platina utilizados para colocar o tecido de carbono em solução e fazer o contato elétrico do mesmo.

O eletrodo de trabalho estacionário (utilizado para as medidas de FTIR apresentadas) consistiu de uma lâmina de platina policristalina retangular ligada a um fio do mesmo material. A área efetiva deste eletrodo $\left(1,73 \mathrm{~cm}^{2}\right)$ foi determinada pelo cálculo da quantidade de hidrogênio adsorvido/dessorvido, segundo resultados apresentados na literatura [47], onde se verifica que a densidade de carga necessária para a formação de uma monocamada de hidrogênio adsorvido sobre platina policristalina é de $210 \mu \mathrm{C} \mathrm{cm}^{-2}$.

Em todos os casos como eletrodo auxiliar, utilizou-se um eletrodo de lâmina de platina ligado a um fio de platina (no caso dos experimentos feitos com eletrodos de trabalho de platina, carbono vítreo e tecido de carbono) e um eletrodo de lâmina 
de ouro ligado a um fio de ouro no caso dos experimentos feitos com eletrodo de trabalho de ouro, porém com área efetiva maior que a do eletrodo de trabalho.

Para meio aquoso ácido, utilizou-se eletrodo reversível de hidrogênio (ERH) como referência (Figura 3) e para os casos de meio não-aquoso e solução de $\mathrm{PdCl}_{2}+$ $\mathrm{HClO}_{4}$, utilizou-se eletrodo de $\mathrm{Ag} / \mathrm{AgCl}$ como referência.

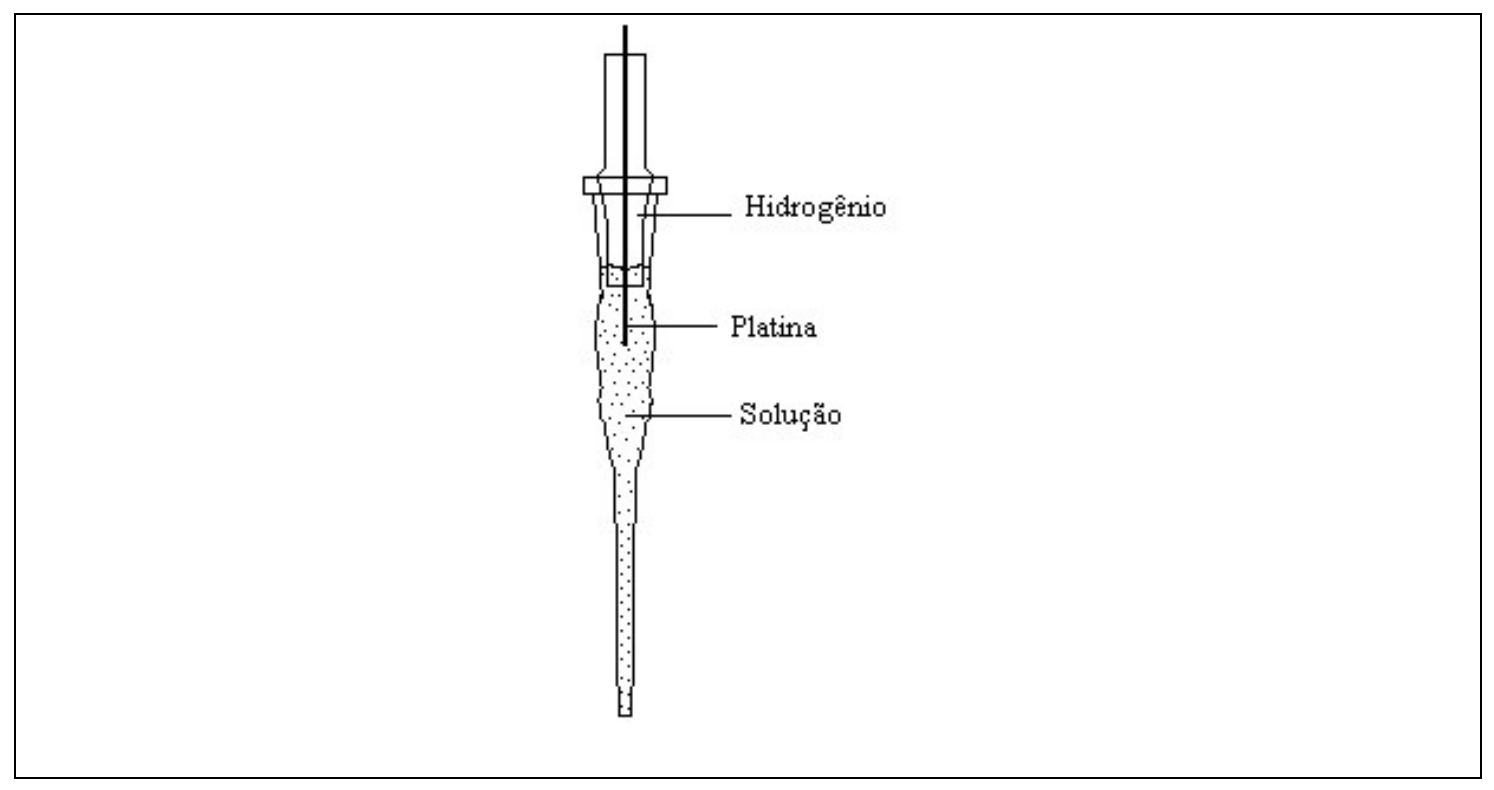

FIGURA 3 - Eletrodo de referência reversível de hidrogênio.

\section{1. 3. Células}

Para o crescimento dos filmes e para as voltametrias cíclicas, utilizou-se uma célula de vidro de $50 \mathrm{~mL}$ de volume com um único compartimento e com uma tampa de Teflon ${ }^{\circledR}$ contendo orifícios para a entrada do eletrodo de trabalho, secundário (lâmina de platina), referência e para entrada e saída de gás inerte.

Para as medidas de UV-Visível in situ, utilizou-se uma célula de vidro com três compartimentos para os três eletrodos (trabalho, referência e secundário), um “trap" e orifícios para entrada de gás (no caso, Ar). No compartimento central havia 
uma tampa com orifício com rosca para a entrada do eletrodo de trabalho e outra peça de Teflon ${ }^{\circledR}$ rosqueada em sua parte inferior também com um orifício onde se colocava uma janela de Quartzo (Figura 4).

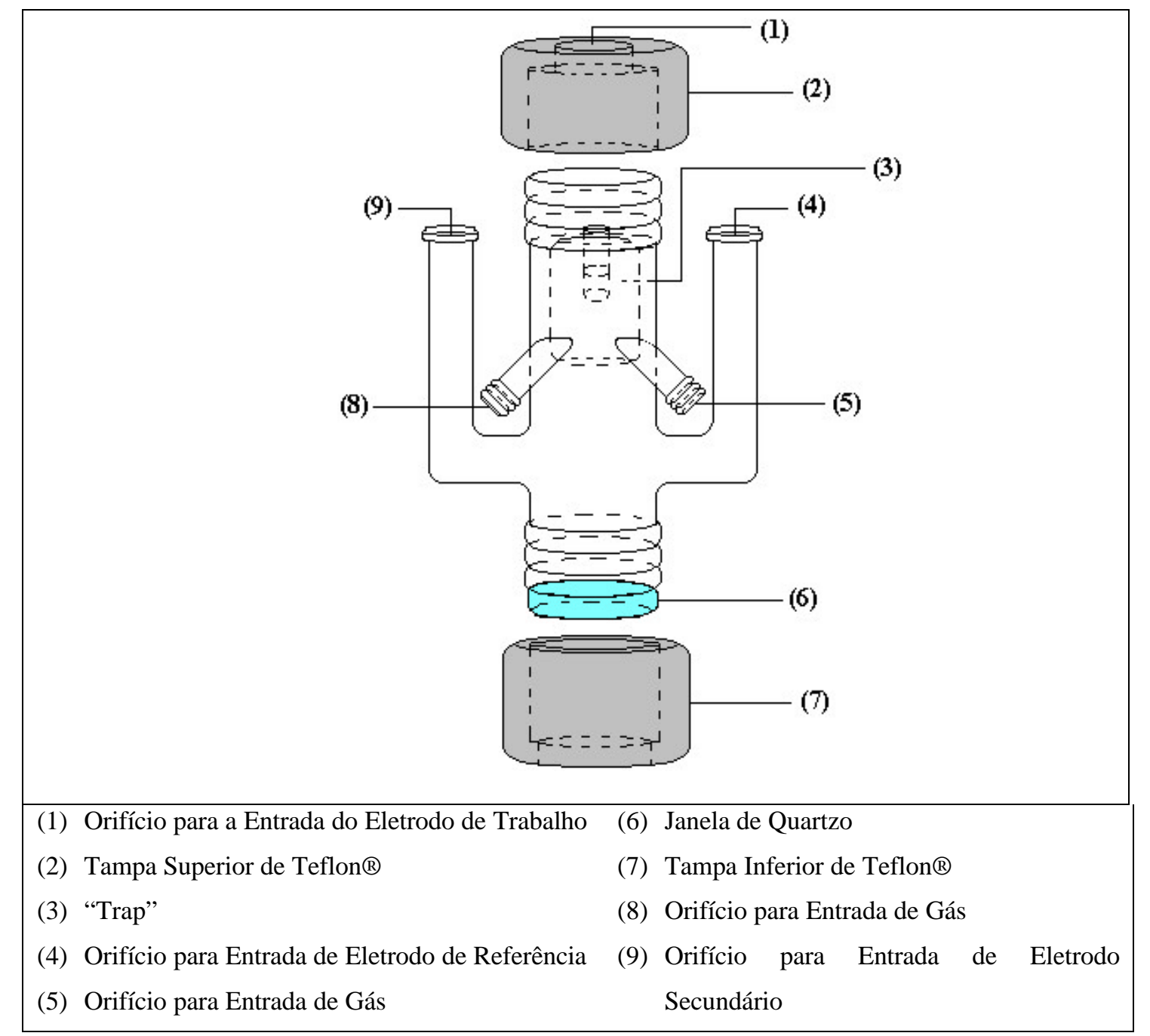

FIGURA 4 - Vista lateral da célula utilizada para medidas de espectroscopia de UV-Visível in situ.

Para as medidas com Luz Síncrotron, utilizou-se uma célula de plexiglas para as medidas in-situ. Esta célula apresentava o contato para o eletrodo de trabalho (fio de $\mathrm{Pt}$ ), contato para o contra-eletrodo (fio de ouro), orifício para eletrodo de 
referência, espaço para ser colocada a amostra umedecida na solução eletrolítica, espaços para disco de carbono usado como eletrodo secundário e para a membrana de Nafion ${ }^{\circledR}$ separando estes dois eletrodos e a janela para medidas de transmissão e fluorescência fechadas com fina camada de plexiglas, como mostra a Figura 5. O eletrólito ácido líquido é imobilizado dentro da estrutura porosa do eletrodo de trabalho. O contato eletrolítico entre os eletrodos de trabalho, secundário e referência é mantido pela membrana de Nafion ${ }^{\circledR}$ (membrana de troca protônica).

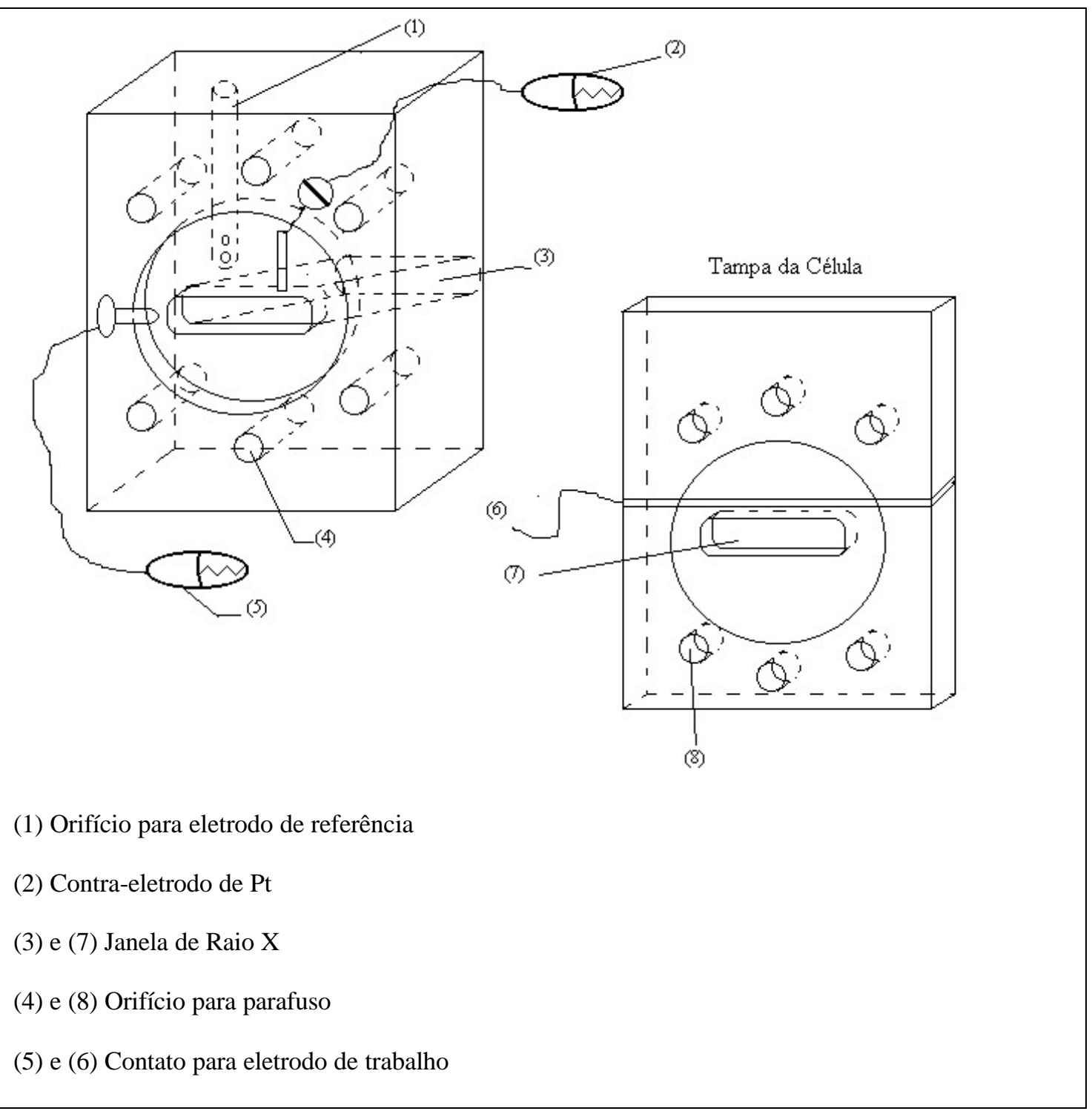

FIGURA 5 - Célula de Plexiglas utilizada para as medidas de raio X. 


\section{2. Aquisição dos Dados Experimentais}

\section{2. 1. Preparação dos Filmes de PT}

Os filmes de politiofeno foram preparados a partir de soluções aquosas de tiofeno (concentração de $0,05 \mathrm{M}$ ) dissolvido em $\mathrm{H}_{2} \mathrm{SO}_{4}$ 12,5 M e soluções de tiofeno (concentração de $3,0 \mathrm{M}$ ) dissolvido em $\mathrm{CH}_{3} \mathrm{CN}+\mathrm{TBAClO}_{4}$ 0,1 M. O processo de deposição do filme sobre a superfície eletródica foi efetuado utilizando-se a técnica de voltametria cíclica. Na maioria dos experimentos em meio aquoso utilizou-se um eletrodo rotatório girando a uma velocidade de $1000 \mathrm{rpm}$. Para o eletrodo de tecido de carbono, a agitação da solução era feita com uma peça de Teflon ${ }^{\circledR}$ colocada no RDE com a velocidade desejada. O número de ciclos de crescimento dos filmes foi de 25 em meio não-aquoso porque com este número o polímero já apresentava-se bastante escuro e aparentemente espesso. Em meio aquoso foram crescidos filmes utilizando variados números de ciclos, dependendo dos estudos a serem realizados, sendo a velocidade de varredura nos dois meios de $75 \mathrm{mV} \mathrm{s}^{-1}$. O crescimento em meio não-aquoso se dava à temperatura ambiente (aproximadamente $23{ }^{\circ} \mathrm{C}$ ) e o crescimento em meio aquoso, na maioria dos casos, foi efetuado à $3{ }^{\circ} \mathrm{C}$.

Para estudar o comportamento redox do polímero sintetizado em $\mathrm{H}_{2} \mathrm{SO}_{4}$ 12,5 M na ausência do monômero, escolheu-se a velocidade de varredura de crescimento mais apropriada e variou-se a concentração do ácido sulfúrico de 12,5 a 1,0 M.

Para o estudo da incorporação de partículas de platina na matriz polimérica, a técnica utilizada foi a redução de ácido hexacloroplatínico no polímero já sintetizado. Após preparado, o filme de politiofeno era estudado em solução de ácido sulfúrico 
(como descrito anteriormente) e depois lavado com água purificada em sistema de Milli-Q em abundância e colocado na solução de ácido hexacloroplatínico (conc. 0,004 M em ácido sulfúrico 12,5 M). Procedia-se à ciclização do eletrodo em um limite de potencial entre 0,0 e $0,7 \mathrm{~V}$ a uma velocidade de varredura de $75 \mathrm{mV} \mathrm{s}^{-1} \mathrm{e}$ rotação de 1000 rpm com variados números de ciclos de crescimento, dependendo do estudo a ser realizado. Os filmes eram então retirados dessas soluções, lavados com água em abundância e colocados na solução onde se realizariam os estudos de voltametria cíclica, absorção de raio X, reação de redução de oxigênio ou reação de oxidação de hidrogênio.

Para a incorporação de partículas de Ag à matriz polimérica, utilizou-se a técnica de potencial controlado $(0,43 \mathrm{~V})$ por tempo determinado $(120 \mathrm{~s})$ em solução de $\mathrm{AgClO}_{4}$ 0,1 M. Após sua síntese, o polímero contendo as partículas de Ag era extensivamente lavado com água purificada.

O estudo da incorporação de partículas de $\mathrm{Pd}$ foi realizado também utilizando-se a técnica de potencial controlado em diferentes tempos, dependendo da quantidade de $\mathrm{Pd}$ desejada. Para isso, utilizou-se solução de $\mathrm{PdCl}_{2}$ 0,05 $\mathrm{M}$ em $\mathrm{HClO}_{4}$ 0,1 M e polarizou-se o eletrodo de trabalho em $0,23 \mathrm{~V}$ ( $v s . \mathrm{Ag} / \mathrm{AgCl}$ ) com tempo variando entre 60 e 240 s. Após a incorporação das partículas de Pd, procedia-se da mesma forma que com o polímero contendo Pt ou Ag, ou seja, o polímero era lavado extensivamente com água purificada em sistema de Milli-Q e colocado na solução onde se realizariam os outros estudos.

O crescimento dos filmes e os estudos voltamétricos foram realizados utilizando-se um Potenciostato-Galvanostato SOLARTRON SI1287 e um Potenciostato-Galvanostato mod. 273 da Princeton Applied Research. 


\section{2. 2. Espectroscopia de Reflectância na Região do Infravermelho}

A espectroscopia na região do infravermelho é uma técnica importante para a investigação dos níveis de energia vibracionais de uma molécula. É necessário saber que uma molécula terá um número de frequiências vibracionais fundamentais e que cada freqüência vibracional fundamental pode ser associada com absorção de radiação de sua própria freqüência. Assim sendo, é possível identificar grupamentos químicos em uma molécula através de absorção em frequências particulares, os quais muitas vezes são improváveis de se verificar através de técnicas alternativas [48].

Foi crescido filme por 55 ciclos em eletrodo de placa de platina de área geométrica $1,73 \mathrm{~cm}^{2}$ em solução de $\mathrm{H}_{2} \mathrm{SO}_{4} 12,5 \mathrm{M}$ a aproximadamente $3{ }^{\circ} \mathrm{C}$. Após o crescimento, o filme foi lavado com água, seco com nitrogênio e então colocado sob o orifício do sistema óptico utilizado para as medidas de FTIR por reflectância. As medidas foram realizadas sob vácuo para remoção de água residual e gás carbônico do seu interior em um aparelho BOMEM DA8 equipado com detector de Telureto de Mercúrio e Cádmio (MCT) resfriado com nitrogênio líquido. As medidas foram realizadas com 256 varreduras e $4 \mathrm{~cm}^{-1}$ de resolução.

Os resultados dos experimentos de espectroscopia de reflectância na região do infravermelho foram obtidos tendo-se como referência o espectro do eletrodo de platina lisa. Assim, a razão $\mathrm{R} / \mathrm{R}_{\mathrm{o}}$ onde $\mathrm{R}$ é o espectro obtido para o eletrodo modificado (Pt/politiofeno) e $\mathrm{R}_{\mathrm{o}}$, o espectro de platina lisa, é o espectro resultante dos fenômenos que acontecem no filme polimérico. 


\section{2. 3. Espectroscopia de UV-Visível}

A absorção molecular na região do ultravioleta e do visível do espectro depende da estrutura eletrônica da molécula. A absorção de energia é quantizada e conduz à passagem dos elétrons de orbitais do estado fundamental para orbitais de maior energia em um estado excitado. Há uma vantagem na seletividade da absorção no ultravioleta visível: grupos característicos podem ser reconhecidos em moléculas de complexidade bastante variável. Como uma grande porção de uma molécula relativamente complicada pode ser transparente no ultravioleta visível, pode-se obter espectro semelhante ao de moléculas muito mais simples [49,50].

No caso de polímeros $\pi$-conjugados, como é o caso do politiofeno, pode-se sumarizar seu comportamento espectroscópico da seguinte forma: conforme mostra o esquema da Figura 6, eles possuem uma interbanda de transição (Banda de Valência/Banda de Condução $\left.\left(\pi-\pi^{*}\right)\right)$ com "gap" de energia em aproximadamente $450 \mathrm{~nm}$ e duas meia bandas de transição com "gap" de energia em aproximadamente 750 e $1500 \mathrm{~nm}$. Este comportamento é típico de espécies bipolarônicas conforme descrito por Fesser et al. [51]. Segundo estes autores, existem 4 características espectroscópicas da adsorção bipolarônica: 1) duas transições óticas são observadas nos "gap" das bandas; 2) a soma de energias para estas duas transições é igual a energia de "gap" das bandas; 3) a transição em baixa energia, isto é, $1500 \mathrm{~nm}$ deve ter uma força de oscilação mais forte do que na mais alta energia, ou seja, $750 \mathrm{~nm}$, por aproximadamente 4 vezes e 4) o "gap" da banda de transição passa a ocorrer na cor azul sob forte dopagem [24]. 


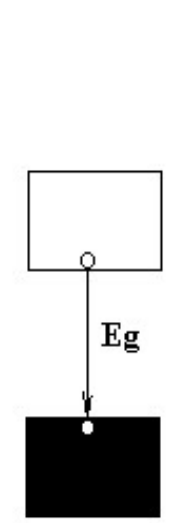

(A)

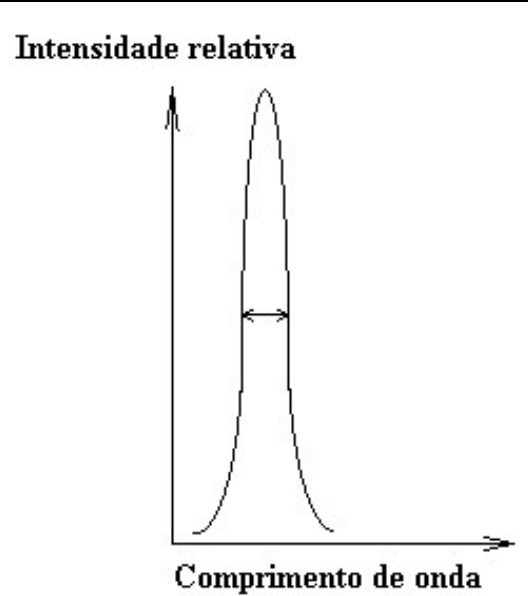

(B)

FIGURA 6: (A) O retorno de um elétron da Banda de Condução para a Banda de Valência pode liberar um fóton com energia igual a energia de "gap" da banda. O elétron pode também retornar sem liberar a luz por vibrações atômicas no material. (B) Um espectro de emissão típico correspondendo à transição eletrônica mostrada em (A) [52].

Foram realizadas medidas de UV-Visível de soluções de ácido sulfúrico 12,5 M, ácido perclórico 8,0 M e acetonitrila na ausência e na presença de monômero (concentração de monômero: 0,05 M). As medidas em meio aquoso foram realizadas em duas temperaturas: $3^{\circ}$ e $23^{\circ} \mathrm{C}$. Todas as medidas foram realizadas em função do tempo após a adição do monômero (que variou de 5 a aproximadamente 1320 min).

Foram realizadas medidas de UV-Visível in situ de filmes de politiofeno crescidos sobre Pt a uma velocidade de varredura de $75 \mathrm{mV} \mathrm{s}^{-1}$ por 35 ciclos e somente do eletrodo de Pt nas mesmas condições do politiofeno, ou seja, em $\mathrm{H}_{2} \mathrm{SO}_{4}$ 12,5 $\mathrm{M}$ e polarizado em $0,1,0,3$ e $0,6 \mathrm{~V}$ para que se descontasse o efeito da platina nos resultados e se obtivesse somente os resultados relativos ao polímero. O polímero foi crescido do mesmo modo que para os estudos eletroquímicos, em célula e eletrodo já apresentados anteriormente e nas condições mais eficientes de síntese (1000 rpm, $\mathrm{H}_{2} \mathrm{SO}_{4} 12,5 \mathrm{M}$, tiofeno $0,05 \mathrm{M}, 3^{\circ} \mathrm{C}, 75 \mathrm{mV} \mathrm{s}^{-1}$ ). Depois de crescidos, os 
filmes eram lavados com água purificada em sistema Milli-Q em abundância e colocado na célula específica para esses estudos (Figura 4).

Para estas medidas utilizou-se um Espectrofotômetro de UV-Visível HITACHI U-3501.

\section{2. 4. Microscopia Eletrônica de Varredura (MEV)}

A MEV é um dos mais versáteis instrumentos disponíveis para exame e análise de características microestruturais de objetos sólidos. A primeira razão para isso é a alta resolução que pode ser obtida quando objetos volumosos são examinados, com instrumentos comerciais sendo encontrados com valores de resolução da ordem de 2 a $5 \mathrm{~nm}(20$ - $50 \AA$ Å). Outro aspecto importante da MEV é a aparência tridimensional da imagem da amostra, um resultado direto da grande profundidade do campo.

Análises químicas no $\mathrm{MEV}$ são baseadas na emissão de raios $\mathrm{X}$ pelos elementos da amostra após interação com o feixe eletrônico. Cada elemento tem suas raias de emissão muito características, o que permite sua identificação. A técnica de EDX (Espectroscopia de Dispersão de Energia de Raios X) está baseada na medida da energia do fóton emitido [53,54].

O polímero foi sintetizado nos três materiais eletródicos (platina, ouro e carbono vítreo), nas condições mais eficientes de síntese com velocidade de varredura de crescimento 100 e $75 \mathrm{mV} \mathrm{s}^{-1}$ e 15, 35 ou 65 ciclos de crescimento. Após a síntese os filmes eram lavados com bastante água e secos com gás $\mathrm{N}_{2}$. 
Foram realizadas medidas dos eletrodos na ausência do polímero e antes e após a incorporação de partículas de platina na matriz polimérica. Também foram realizadas medidas de Dispersão de Energia de Raios X (EDX) em alguns casos.

Utilizou-se um Microscópio Eletrônico de Varredura LEO 400 e Detetor Oxford mod. 7060 com Resolução de $133 \mathrm{eV}$ para estas medidas.

\section{2. 5. Espectroscopia Absorção de Raio X}

A luz síncrotron foi acidentalmente observada pela primeira vez em 1946 no laboratório General Electric Synchrotron, em Schenectady nos EUA [55]. A teoria da emissão de radiação por cargas em movimentos circulares data de 1898, com o trabalho de Liénard, e a partir da observação da radiação em 1946, muitas outras máquinas e pesquisas foram desenvolvidas na área.

Luz Síncrotron ou Radiação Síncrotron é a radiação eletromagnética emitida por partículas carregadas se movendo em órbitas circulares com velocidades relativísticas. O espectro emitido se estende do infra-vermelho, visível, atravessando o ultravioleta e a faixa de raios $\mathrm{X}$ moles e duros, fazendo com que esta seja uma técnica muito importante para pesquisa em diversas áreas.

O grande interesse em radiação síncrotron se deve ao fato dela proporcionar 5 ordens de magnitude a mais de intensidade nas regiões do ultra-violeta (VUV) e da radiação $\mathrm{X}$ do que as fontes convencionais, tais como os tubos de raios $\mathrm{X}$.

Utilizando cristais monocromadores, um comprimento de onda específico pode ser selecionado na contínua e intensa radiação síncrotron, ao contrário das 
fontes convencionais que fornecem alta intensidade em determinado comprimento de onda e fraca nos demais [55-57].

Resumidamente, pode-se descrever uma fonte de luz síncrotron sendo composta pelos seguintes principais componentes:

i. Sistema de Aceleração: Local onde pulsos de radiofreqüência aceleram os elétrons até velocidade próxima à da luz $\left(300000 \mathrm{~km} \mathrm{~s}^{-1}\right)$. A energia final dos elétrons varia de equipamento para equipamento.

ii. Linha de Transporte: É a seção intermediária entre o sistema de aceleração e o anel de armazenamento de elétrons, onde se localizam os componentes que fazem o processo de injeção de elétrons do anel.

iii. Anel de Armazenamento de Elétrons: É o componente principal da fonte de luz síncrotron.

Neste trabalho os experimentos foram realizados no National Synchrotron Light Source (NSLS), que foi um dos primeiros anéis de armazenamento de elétrons a ser dedicado a gerar luz síncrotron para propósitos científicos. Começou a funcionar em 1982 no Brookhaven National Laboratory (BNL - Upton, USA). O esquema geral do arranjo experimental usado em tais medidas é ilustrado na Figura 7 para medidas de transmissão. A fonte de raio $\mathrm{X}$ fornece radiação contínua. Esta passa por um cristal monocromador que seleciona os valores desejados de energia do espectro contínuo. Após a monocromatização, o feixe atravessa um detetor que monitora o fluxo total de fótons $\left(\mathrm{I}_{0}\right)$ do feixe que irá incidir na amostra. O feixe passa então pela célula eletroquímica contendo a amostra e o fluxo transmitido (I) é medido por um segundo detetor. O feixe transmitido ainda passa por uma folha metálica utilizada como referência do material em estudo e por um terceiro detetor que mede o fluxo de fótons transmitido ( $\left.\mathrm{I}_{\text {ref }}\right)$ após atravessar a amostra de referência. 


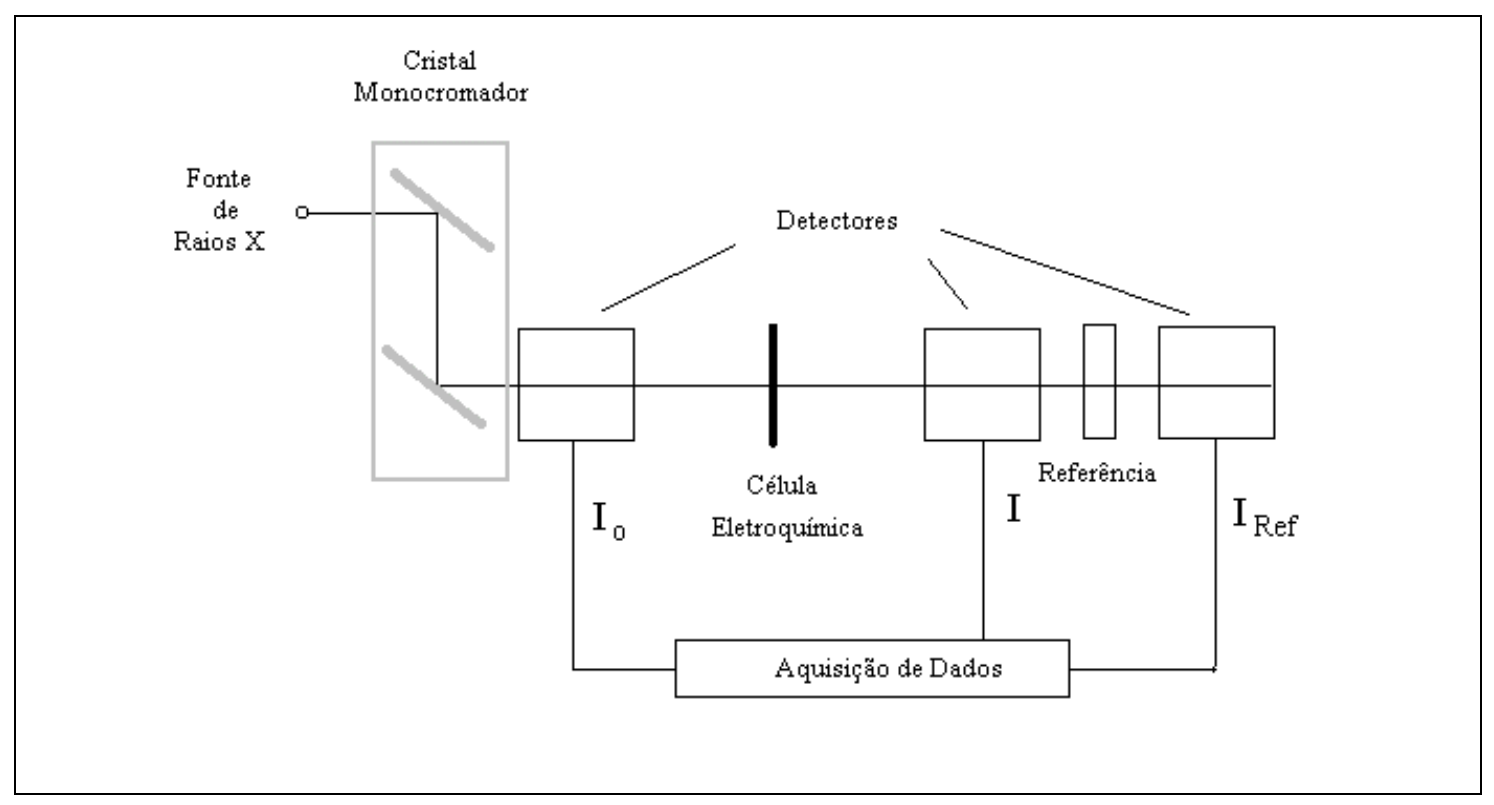

FIGURA 7 - Arranjo experimental para medidas de absorção de raios X (esquema da célula mostrado na Figura 5).

A Espectroscopia de Absorção de Raios X (XAS) foi utilizada para obter informações sobre o ordenamento atômico, números de coordenação e estrutura eletrônica dos materiais eletródicos. Em processos eletrocatalíticos estas propriedades podem ser correlacionadas com a energia livre e a geometria dos adsorbatos. As medidas são efetuadas utilizado-se um arranjo experimental conforme descrito na Figura 7, afim de se obter o coeficiente de absorção de raios X em função da energia do fóton incidente, em um intervalo abaixo e acima da borda de absorção de um ou mais dos elementos metálicos que formam o catalisador.

Em uma medida de transmissão, com o aumento de energia, há o decréscimo do coeficiente de absorção até atingir um valor crítico de energia. Após atingir este valor, o coeficiente cresce abruptamente e volta a diminuir até atingir outro valor crítico de energia. Estes fenômenos correspondem a ejeção de um elétron de uma das 
diferentes camadas eletrônicas do átomo e são conhecidos por bordas de absorção [58].

A região do espectro de absorção de raios $\mathrm{X}$ localizada perto da borda de absorção do metal (Figura 8) é denominada de XANES “do inglês, X-Ray Near-Edge Structure", enquanto que a oscilação que se inicia cerca de $50 \mathrm{eV}$ acima da borda é conhecida como EXAFS “do inglês, Extended X-Ray Absorption Fine Structure” (EXAFS). A estrutura na região XANES pode ser explicada em termos de (a) transição de um fotoelétron ejetado das camadas eletrônicas internas do átomo para um estado eletrônico desocupado localizado nas proximidades do nível de Fermi, e (b) ao múltiplo espalhamento do fóton-elétron ejetado pelo átomo excitado. O formato do espectro na região XANES fornece informações sobre o tipo e a simetria dos ligantes localizados ao redor do átomo excitado. Por outro lado, mudanças de energia da borda de absorção causadas por interações do tipo "elétron-buraco" são indicativas de mudanças no estado de oxidação, que é importante por exemplo para identificar a formação de óxidos. Na região EXAFS o processo pode ser explicado por um mecanismo de retro-espalhamento. Após a absorção de fóton de raios X por um átomo central, é criado o fóto-elétron, que é representado por uma onda esférica que se propaga a partir do absorvedor e é espalhada pelos átomos vizinhos, retornando ao átomo central e interferindo com a onda inicial. As oscilações observadas na região EXAFS são conseqüência direta da natureza ondulatória do fóto-elétron, sendo o formato da oscilação EXAFS fortemente dependente da natureza, do número de átomos e da desordem dos átomos que formam as esferas vizinhas do átomo excitado [59,60].

A Figura 8 mostra um exemplo de um espectro bruto obtido na borda $\mathrm{L}_{\mathrm{III}}$ de amostra diretamente obtido da linha de absorção de Raios X no modo de 
Fluorescência. A análise dos resultados obtidos experimentalmente envolve um método relativamente complexo de processamento dos dados o qual, neste trabalho, foi efetuado utilizando o programa UWXAFS [60] desenvolvido na University of Washington, USA. Para a região XANES, próxima à borda de absorção do elemento analisado (Figura 8), os passos principais de processamento dos dados são:

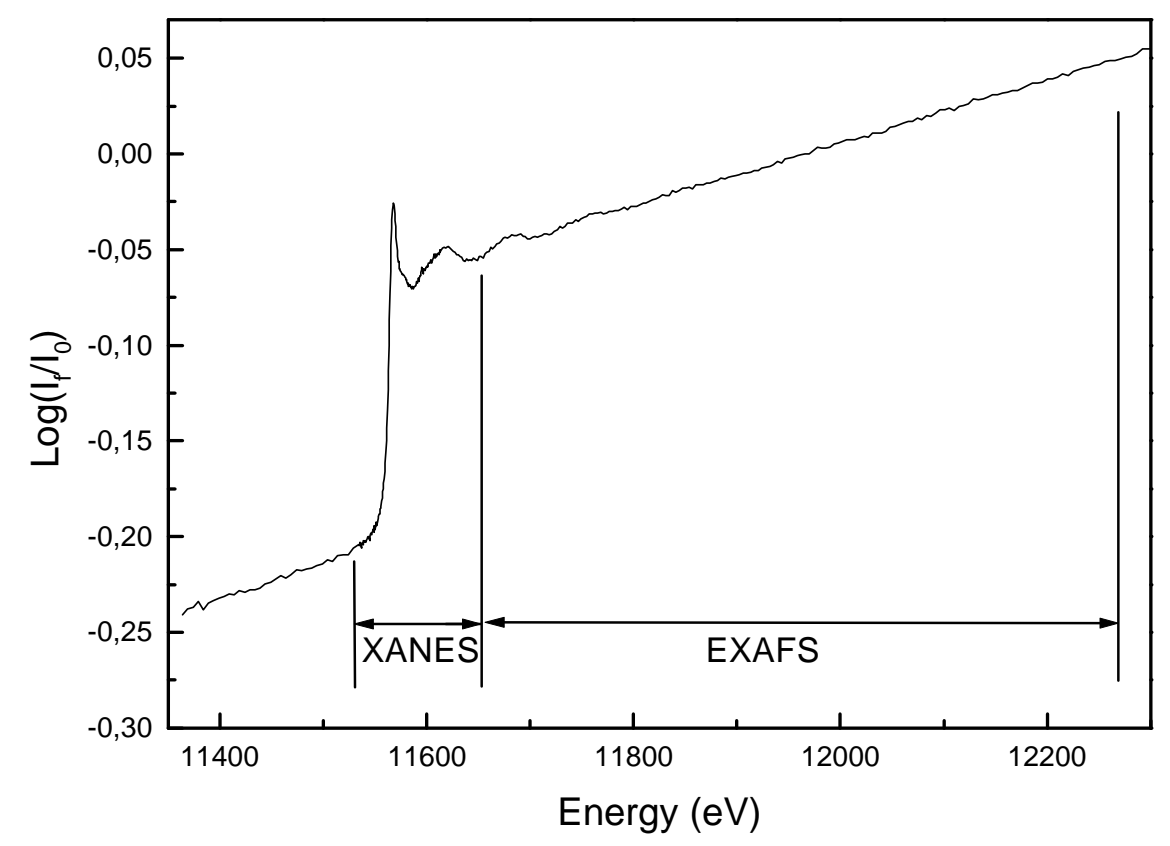

II. XANES

(X-ray absorption near edge structure)

\section{Base Física:}

\section{EXAFS}

(Extended X-ray absorption fine structure)

Espalhamento múltiplo de foto-elétrons de baixa energia.

\section{Base Física:}

Espalhamento simples de foto-elétrons de alta

\section{Informações:} energia.

- Determinação de estados de oxidação e Informações: simetria de coordenação;

- Estrutura Eletrônica;

- Determinação do ordenamento atômico (distância de ligação, número de vizinhos e desordem estrutural).

- Extensão de corrosão

FIGURA 8: Espectro bruto de politiofeno em $\mathrm{H}_{2} \mathrm{SO}_{4}$ 2,0 M contendo platina obtido na borda $\mathrm{L}_{\text {III }}$ da Pt, polarizado em 0,0 V (vs. ERH). Modo de fluorescência. 
- O espectro experimental é primeiramente corrigido pela absorção de fundo (resposta do detetor, elétrons mais externos e absorção de outros elementos), pelo ajuste da curva obtida abaixo da borda $(-200 \mathrm{a}-40 \mathrm{eV})$ a uma fórmula do tipo linear. Gera-se uma linha de base que é subtraída do espectro original.

- O espectro é calibrado quanto à posição da borda (eixo X). Para isto localiza-se o ponto de inflexão da borda, usando a segunda derivada do espectro experimental da amostra de referência;

- Finalmente o espectro é normalizado tomando-se como referência o ponto de inflexão de uma das oscilações EXAFS.

Para a região EXAFS (Extended X-Ray Absorption Fine Structure), os passos principais requeridos para a interpretação dos dados experimentais podem ser resumidos da seguinte forma:

- A função EXAFS é dada por

$$
\chi(k)=\frac{\mu(E)-\mu_{0}(E)}{\mu_{0}(E)}
$$

onde $\mu$ e $\mu_{0}$ são os coeficientes de absorção de raio $X$ do átomo absorvente no material de interesse e no estado livre, respectivamente. A diferença $\mu-\mu_{o}$ depende da estrutura local do átomo absorvente e representa o EXAFS. A divisão por $\mu_{0}$ normaliza o EXAFS para a base de um átomo;

- EXAFS é separado do espectro experimental, primeiramente por subtração da linha de base e depois por filtragem do ruído e outras oscilações de fundo usando-se uma função spline cúbica ou quadrada, sendo a escolha feita com base nos resultados obtidos, ou seja, utilizando-se as duas funções e comparando-as; 
- É realizada conversão da energia espacial (E) em vetor de onda espacial $(\mathrm{k})$ usando a relação,

$$
k=\left[\left(2 m / \hbar^{2}\right)\left(E-E_{0}\right)\right]^{1 / 2}
$$

onde,

$\mathrm{h}=h / 2 \pi$

$\mathrm{m}=$ massa do elétron

$\mathrm{E}_{0}=$ energia da borda de absorção

$\mathrm{h}=$ constante de Plank

A oscilação EXAFS contém as contribuições do retro-espalhamento em várias esferas de coordenação. A onda final é a somatória de todas as contribuições:

$$
\chi\left(\overrightarrow{k)}=\sum_{j} A_{j}(\vec{k}) \operatorname{sen}\left[2 \overrightarrow{k R_{j}}+\phi_{j}(\overrightarrow{k)}]\right.\right.
$$

onde $\mathrm{j}$ é a esfera de coordenação, $\mathrm{R}_{\mathrm{j}}$ é sua distância do átomo central, $\phi_{\mathrm{j}}(\mathrm{k})$ é o deslocamento de fase da onda devida ao espalhamento. $A_{j}$ é uma função amplitude dada por:

$$
A_{j}\left(\overrightarrow{k)}=\frac{N_{j}}{k R_{j}^{2}} S_{o}^{2}(\vec{k}) F_{j} \overrightarrow{(k)} \exp \left[-2\left(R_{j}-\Delta\right) / \lambda-\sigma_{j}^{2} / \overrightarrow{k^{2}}\right]\right.
$$

onde:

$F_{j}, S_{o}, \Delta, \lambda$ : termos relacionados com a amplitude do retro-espalhamento e o caminho livre do fotoelétron. Parâmetros obtidos com padrões ou teoricamente; $N_{j}=$ número médio de coordenação; 
$\mathrm{R}_{\mathrm{j}}=$ distância da esfera de coordenação ao átomo central;

$\sigma^{2}=$ termo de Debye-Waller relacionado com a desordem estática e térmica do material.

A função EXAFS corresponde a superposição da contribuição de várias esferas de coordenação. Assim, a contribuição das esferas de coordenação individuais ao sinal EXAFS é isolada fazendo-se a transformada de Fourier:

$$
M T(r)=\frac{1}{\sqrt{2 \pi}} \int_{k_{\min }}^{k_{\max }} k^{n} \chi(k) e^{2 i k r} d k
$$

onde $M T(r)$ é a magnitude da transformada em função da coordenada radiana. Neste caso os picos presentes na transformada de Fourier em função da coordenada radiana correspondem à contribuição das várias camadas individuais de coordenação ao redor do átomo metálico sob investigação.

Finalmente, o sinal EXAFS de uma camada única é obtido efetuando-se a transformação inversa da função $M T(r)$, no domínio de $r$ correspondente. A partir da comparação com modelos teóricos ou com a transformada inversa de resultados obtidos com padrões, é possível determinar os parâmetros importantes relativos ao átomo sob investigação, ou seja, os valores de $\Delta \mathrm{E}_{0}, \mathrm{~N}, \mathrm{R}$ e $\sigma$ [60]. 


\section{CAPÍTULO III:}

\section{RESULTADOS E DISCUSSÃO}

\section{1. Síntese e Propriedades morfológicas dos Filmes de Politiofeno}

\section{1. 1. Efeito da Natureza do Eletrólito}

Para fins comparativos, inicialmente foram realizados estudos da síntese de politiofeno em meio não-aquoso. Os experimentos foram efetuados por varredura cíclica de potencial à temperatura ambiente (aproximadamente $23^{\circ} \mathrm{C}$ ) com o eletrodo de referência de $\mathrm{Ag} / \mathrm{AgCl}$, porém todos os gráficos aqui apresentados foram convertidos para potenciais relativos ao eletrodo de referência reversível de hidrogênio (ERH).

Os experimentos foram realizados em soluções de $\mathrm{CH}_{3} \mathrm{CN}+\mathrm{TBAClO}_{4} 0,1 \mathrm{M}$ contendo tiofeno 3,0 M, até 25 ciclos de crescimento. A Figura 9 apresenta vários ciclos voltamétricos de crescimento de politiofeno em meio não-aquoso. Nota-se que o comportamento voltamétrico altera-se bastante durante o crescimento, com deslocamento de picos e aumento de carga. As correntes acima de 1,7 V, consideradas de oxidação do monômero, apresentam um aumento com o número de ciclos, não muito pronunciado no início porque a oxidação do monômero 
sobre o substrato eletródico é menos efetiva do que sobre a camada de polímero em formação [5,11]. Por outro lado, os picos que são formados logo após o primeiro ciclo (em aproximadamente 1,0 e 0,5 V), crescem e se deslocam com o aumento do número de ciclos e correspondem aos picos de oxidação/redução do polímero. Isto é atribuído ao progressivo aumento da quantidade de polímero e a efeitos de queda ôhmica que se acentuam nos filmes mais espessos.

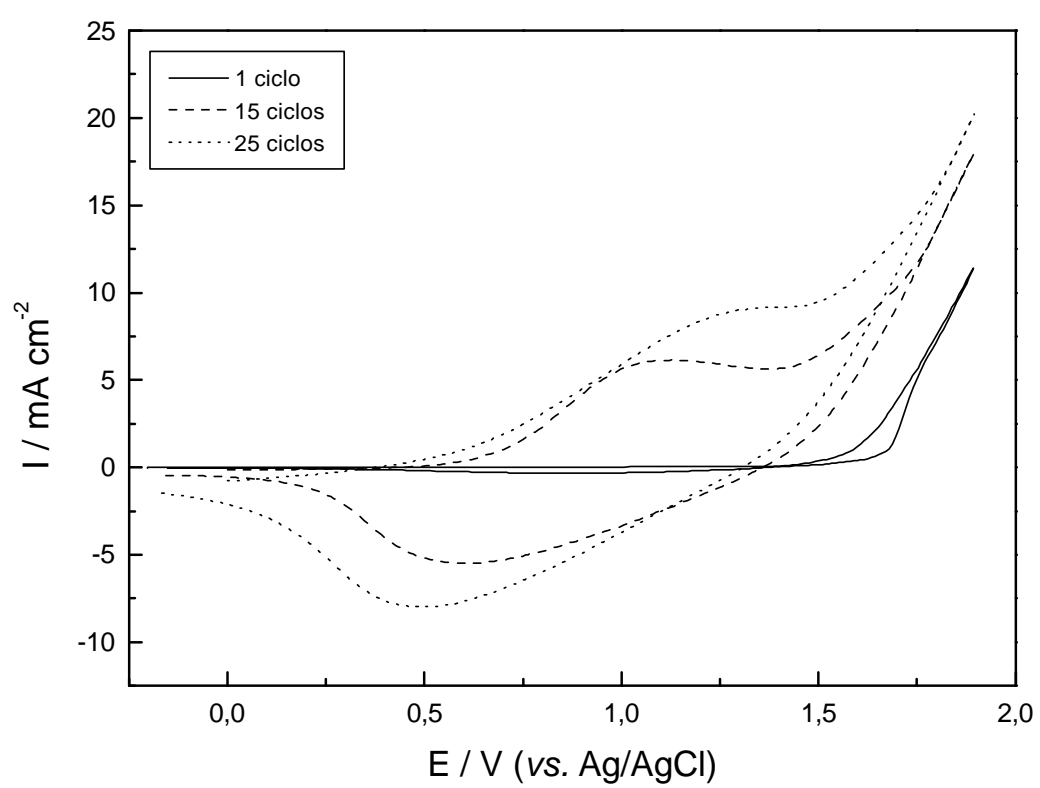

FIGURA 9 - Voltamogramas de crescimento de politiofeno em acetonitrila $+\mathrm{TBAClO}_{4} 0,1$ M e tiofeno 3,0 M a temperatura ambiente, em eletrodo de carbono vítreo. Velocidade de varredura: $75 \mathrm{mV} \mathrm{s}^{-1}$.

Após 25 ciclos de crescimento, o polímero (já lavado com acetonitrila para que não restassem resíduos de monômero) foi colocado em solução de acetonitrila + $\mathrm{TBAClO}_{4} \quad 0,1$ M sem monômero e estudado voltametricamente. A Figura 10 apresenta estes resultados para o polímero sintetizado como mostrado na Figura anterior. 
Observa-se que o voltamograma não apresenta o pico anódico observado durante o crescimento, pois o mesmo situa-se em potenciais mais elevados que o abrangido na Fig. 10. Por outro lado, um pico largo de redução na direção catódica é claramente observado. Tanto o comportamento de crescimento apresentado na Figura 9 como o de voltametria cíclica (Figura 10) assemelham-se aos encontrados na literatura $[28,61]$. Nestes trabalhos observa-se que a carga anódica é maior que a catódica, indicando que juntamente com o processo aniônico de dopagem do polímero, ocorre um processo eletroquímico degradativo do filme em que a corrente cresce exponencialmente com o potencial e que se inicia a partir de $0,6 \mathrm{~V}$.

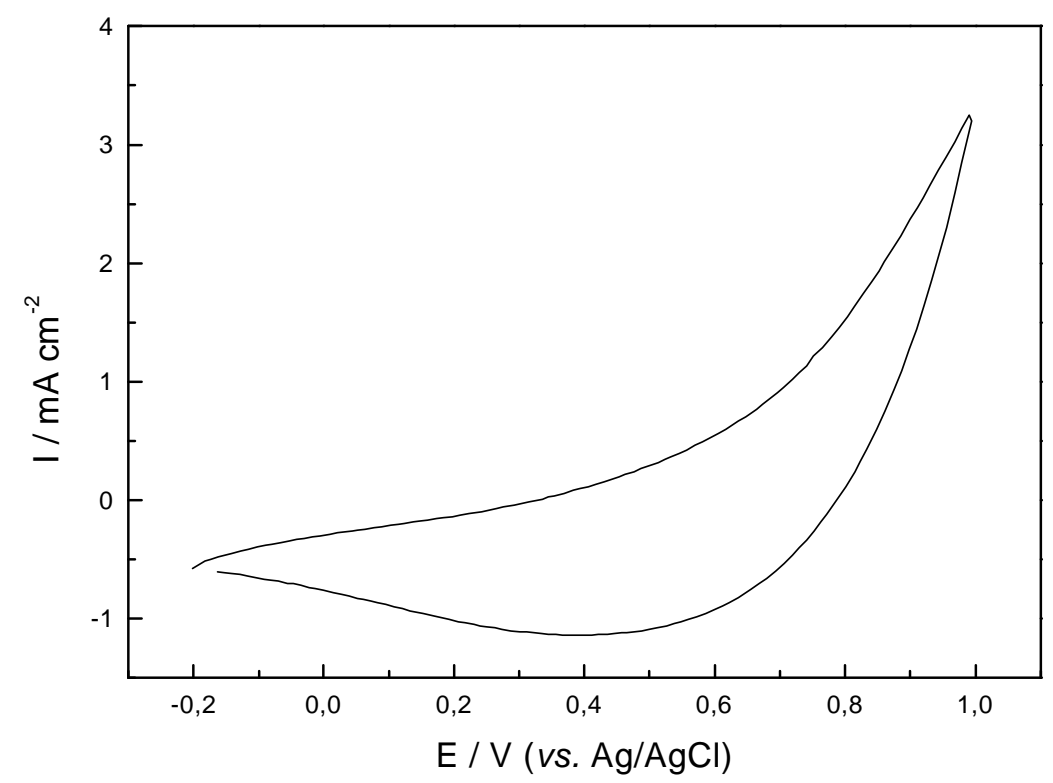

FIGURA 10 - Voltamograma cíclico de politiofeno crescido por 25 ciclos em acetonitrila + $\mathrm{TBAClO}_{4}$ 0,1 M e tiofeno 3,0 M e ciclado na mesma solução na ausência de monômero. $\mathrm{v}=$ $100 \mathrm{mV} \mathrm{s}^{-1}$.

Em meio aquoso, foram estudados os processos de preparação de filmes de politiofeno em soluções de ácido sulfúrico. A Figura 11 mostra alguns ciclos de crescimento de politiofeno em ácido sulfúrico $12,5 \mathrm{M}$ a uma temperatura de $\sim 3^{\circ} \mathrm{C}$. O 
aumento de corrente que ocorre acima de 1,0 V é referente à oxidação do monômero e o ombro em aproximadamente $0,4 \mathrm{~V}$ deve-se à oxidação do polímero durante os ciclos voltamétricos. Assim, nota-se que o comportamento voltamétrico de crescimento em meio aquoso difere daquele em meio não-aquoso, com correntes de crescimento mais baixas e sem o par de picos que aparecem à medida que o polímero vai crescendo.

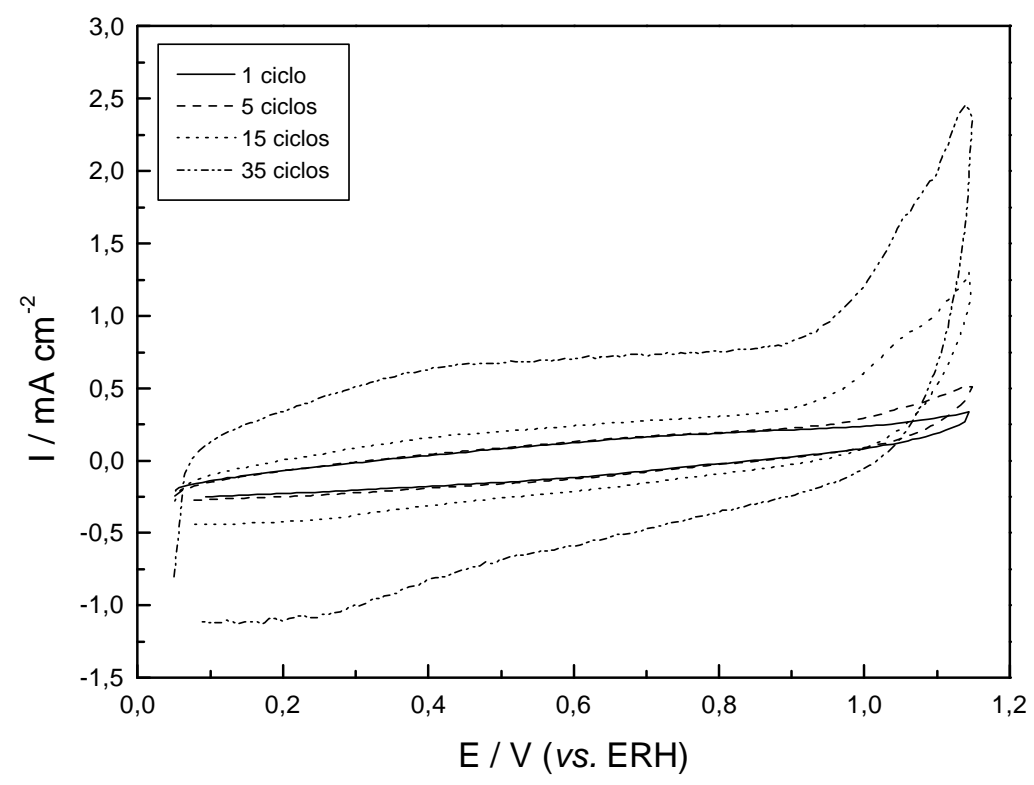

FIGURA 11 - Voltamogramas de crescimento de politiofeno sobre platina em solução de $\mathrm{H}_{2} \mathrm{SO}_{4} 12,5 \mathrm{M}$ e tiofeno $0,05 \mathrm{M}, 3^{\circ} \mathrm{C}$, velocidade de varredura de $75 \mathrm{mV} \mathrm{s}^{-1}$ e rotação de $1000 \mathrm{rpm}$.

A Figura 12 mostra o voltamograma cíclico em $\mathrm{H}_{2} \mathrm{SO}_{4} 12,5 \mathrm{M}$, do polímero crescido a aproximadamente $3{ }^{\circ} \mathrm{C}$ com 35 ciclos. O comportamento voltamétrico é bastante similar ao do polímero sintetizado em ácido perclórico concentrado [5], o que indica que em ambos os eletrólitos são produzidos materiais com propriedades redox equivalentes. Também nesta Figura observa-se que o comportamento redox é mais próximo ao tipicamente encontrado para alguns outros polímeros condutores 
eletrônicos, particularmente o polipirrol [62] em meio aquoso. Provavelmente o tipo de perfil observado esteja relacionado com um certo grau de protonação das cadeias poliméricas que certamente é função da força ácida do meio eletrolítico, conforme será discutido mais adiante.

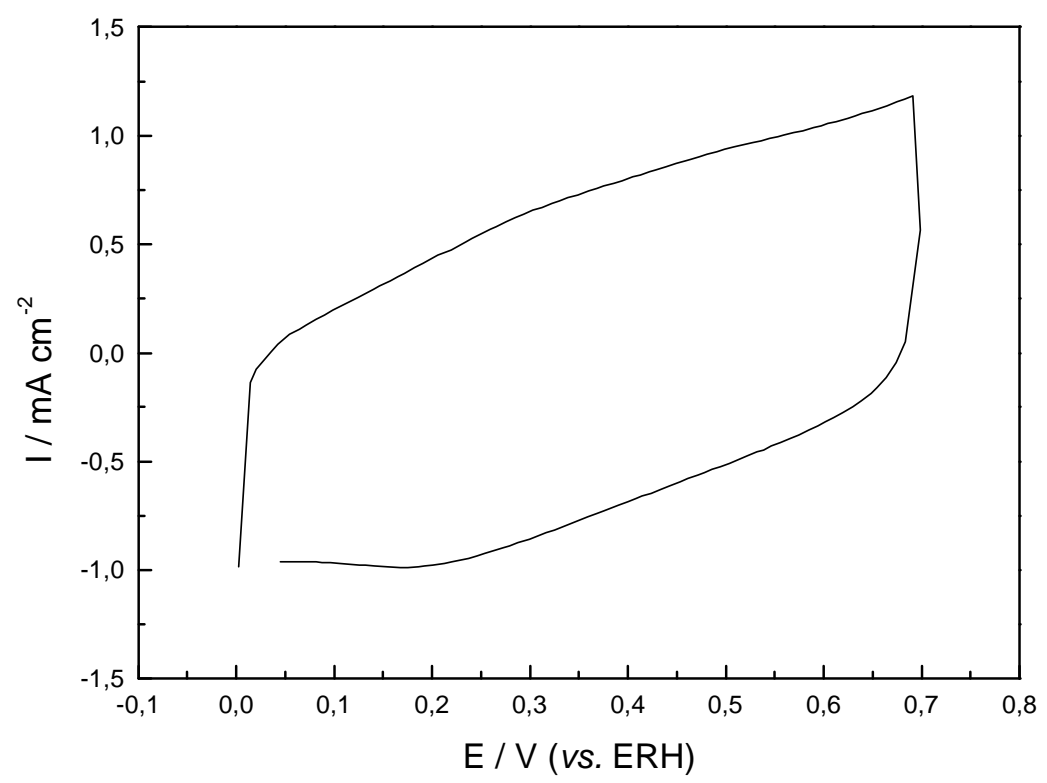

FIGURA 12 - Voltamograma cíclico de politiofeno sintetizado sobre platina em $\mathrm{H}_{2} \mathrm{SO}_{4} 12,5$ M, tiofeno 0,05 M e ciclado na mesma solução na ausência do monômero. Velocidade de varredura: $75 \mathrm{mV} \mathrm{s}^{-1}$.

Comparando-se os resultados nos dois meios estudados (aquoso e nãoaquoso), observou-se que em meio não-aquoso o polímero apresenta-se menos estável, indicando uma possível degradação do mesmo durante a ciclagem eletroquímica. O perfil voltamétrico do material neste caso é característico de sistemas fracamente condutores. Em meio aquoso, o comportamento eletroquímico apresentou-se mais estável e, portanto, mais adequado à aplicação em sistemas catalíticos. 


\section{1. 2. Efeito da Concentração e Temperatura de $\mathrm{H}_{2} \mathrm{SO}_{4}$}

Observou-se que o processo de polimerização é bastante dependente de uma reação que ocorre em solução envolvendo o monômero. Tendo como base trabalho prévio em $\mathrm{HClO}_{4}$ [5], os estudos de polimerização em ácido sulfúrico foram iniciados em concentração de 5,5 M que foi aumentada gradativamente para 8,0; 10,$0 ; 11,5 ; 12,0 ; 12,5 ; 13,0 ; 13,5 ; 14,0$ e $18,0 \mathrm{M}$ para estabelecer em que intervalo de concentrações a polimerização pode ocorrer com mais eficiência. Nestas experiências, a concentração de tiofeno foi mantida em $0,05 \mathrm{M}$, uma vez que não se observou um efeito significativo desta variável. Notou-se também que nenhum efeito qualitativo significativo é introduzido quando a janela de potencial é variada $100 \mathrm{mV}$ abaixo do limite catódico ou acima do limite anódico tipicamente empregados, os quais correspondem a 0,0 e $1,17 \mathrm{~V}$, respectivamente.

Na Figura 13, é apresentado um gráfico da densidade de corrente em potencial igual a $0,5 \mathrm{~V}$ para o $5^{\mathrm{o}}$ e o $25^{\circ}$ ciclos de crescimento em função da concentração de ácido sulfúrico. Por estes resultados observa-se que, em termos gerais, a densidade de corrente de oxidação do polímero varia com a concentração do ácido sulfúrico sendo que a mesma atinge um valor máximo próximo a 12,5 M. Em razão do fato de que a magnitude da corrente de oxidação do polímero é proporcional a quantidade de material formado, estes resultados mostram que a eficiência da síntese é um pouco maior em solução 12,5 M do ácido.

Estes resultados podem ser explicados considerando que a reação de polimerização deve ocorrer a partir da oxidação de um produto formado por uma reação do ácido com o tiofeno, cuja concentração é tanto maior quanto maior é a concentração de sulfúrico. Acima de 12,5 M, a eficiência da síntese decresce, 
possivelmente porque os oligômeros gerados durante a oxidação do agente ativo devem ser solúveis, o que dificulta sua precipitação sobre o substrato eletródico.

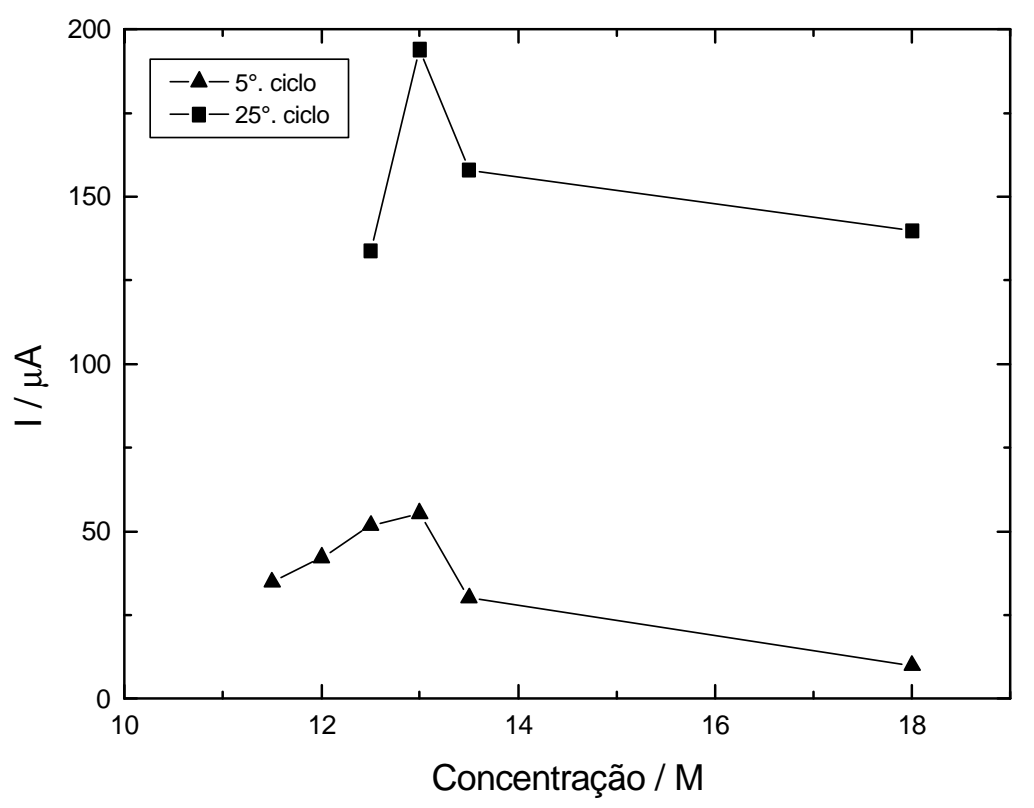

FIGURA 13 - Gráfico da densidade de corrente em potencial igual a 0,5 V (vs. ERH) para o $5^{\circ}$ e o $25^{\circ}$ ciclos de crescimento do politiofeno em função da concentração de ácido sulfúrico.

Medidas de UV-Visível foram realizadas em soluções de $\mathrm{H}_{2} \mathrm{SO}_{4}, \mathrm{HClO}_{4}$ e acetonitrila contendo monômero para verificar a possibilidade de ocorrência de reações em solução. Os resultados obtidos são apresentados nas Figuras 14 a 18. Em solução de acetonitrila à temperatura ambiente, a adição de tiofeno (concentração igual a 0,05 M) origina uma banda centrada em aproximadamente 220-230 nm (região abrangida nas Figuras 14 a 18) que se deve a transições eletrônicas $\pi$ - $\pi^{*}$ no tiofeno [5] e que não se altera com o tempo (consistentemente nota-se que a solução permanece incolor). Na Figura 15, observa-se que após 5 min da adição de tiofeno à solução de $\mathrm{H}_{2} \mathrm{SO}_{4} 12,5 \mathrm{M}$ (temperatura $23{ }^{\circ} \mathrm{C}$ ), aparece um ombro em cerca de 300$320 \mathrm{~nm}$ e um pico mais bem definido em aproximadamente $430 \mathrm{~nm}$, além da banda 
$\pi-\pi^{*}$ do tiofeno em aproximadamente $230 \mathrm{~nm}$. Segundo referências encontradas na literatura [10], a presença de uma banda de absorção em $310 \mathrm{~nm}$ indica a presença de bi-tiofeno e uma banda em $430 \mathrm{~nm}$ é característica da presença de $\alpha, \alpha^{\prime}$-sexi-tiofeno $[5,10,63]$ ou de outros oligômeros com maior número de átomos de tiofeno. Assim conclui-se que este último é um produto relativamente importante da reação de ataque ácido ao tiofeno.

A Figura 16, que corresponde ao resultado obtido para tiofeno 0,05 $\mathrm{M} \mathrm{em}$ $\mathrm{H}_{2} \mathrm{SO}_{4} 12,5 \mathrm{M}$ a $3{ }^{\circ} \mathrm{C}$, possui as mesmas bandas da Figura 15 , porém não há aumento tão pronunciado de intensidade das mesmas com o tempo, o que concorda com os resultados das voltametrias cíclicas de crescimento dos filmes e com as mudanças de coloração da solução que neste caso resultaram menos intensas.

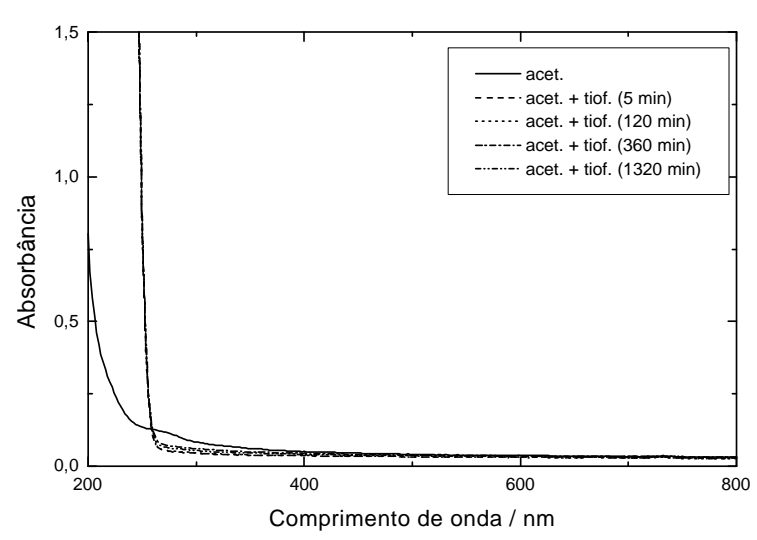

FIGURA 14 - Espectro de UV-visível de acetonitrila e acetonitrila + tiofeno em diferentes tempos a $23^{\circ} \mathrm{C}$.

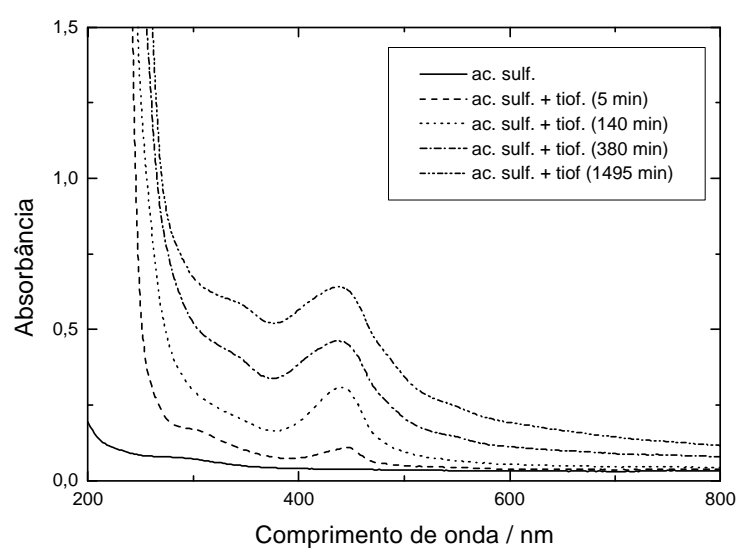

FIGURA 15 - Espectros de UV-visível de ácido sulfúrico $12,5 \mathrm{M}$ e ácido sulfúrico 12,5 $\mathrm{M}+$ tiofeno em diferentes tempos a $23{ }^{\circ} \mathrm{C}$. 


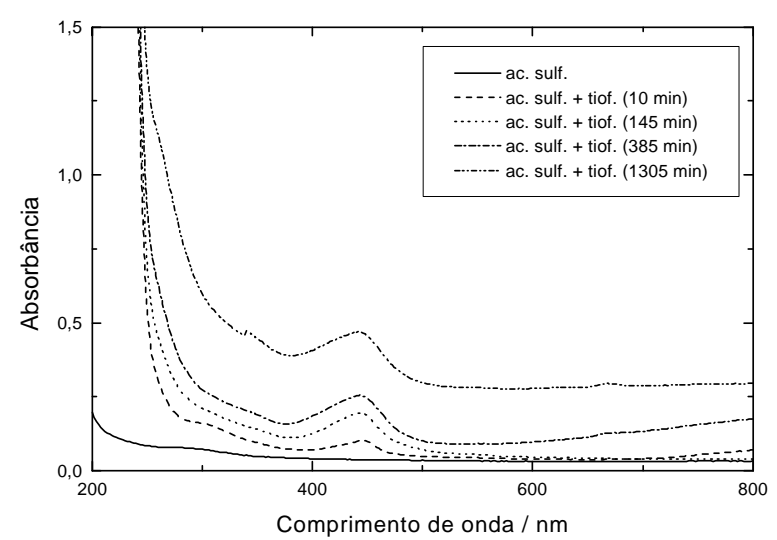

FIGURA 16 - Espectros de UV-visível de ácido sulfúrico 12,5 M e ácido sulfúrico 12,5 M + tiofeno em diferentes tempos a $3{ }^{\circ} \mathrm{C}$.

Os espectros do tiofeno em $\mathrm{HClO}_{4}$ 8,0 $\mathrm{M}$ (Figuras 17 e 18) apresentam os mesmos perfis dos obtidos em $\mathrm{H}_{2} \mathrm{SO}_{4}$ (Figuras 15 e 16), porém nota-se para $\mathrm{T}=23$ ${ }^{\circ} \mathrm{C}$ (Figura 17) que o crescimento da banda em aproximadamente $430 \mathrm{~nm}$ é mais rápido que em $\mathrm{H}_{2} \mathrm{SO}_{4} \quad 12,5 \mathrm{M}$, indicando que a formação de oligômeros é mais significativa. Além disso, em tempos maiores há o surgimento de uma pequena banda em aproximadamente $480 \mathrm{~nm}$, provavelmente devido a transições eletrônicas decorrentes da presença de oligômeros modificados. Os mesmos espectros evidenciam a presença de mais duas bandas, em aproximadamente 290 e $350 \mathrm{~nm}$ que também aumentam com o passar do tempo e talvez se devam à presença de bitiofeno e $\alpha, \alpha^{\prime}$-ter-tiofeno cujos processos de transição eletrônica $\pi$ - $\pi^{*}$ se verificam ao redor destes comprimentos de onda [6]. Já em $\mathrm{HClO}_{4}$ a T $=3{ }^{\circ} \mathrm{C}$ (Figura 18) a banda máxima em $430 \mathrm{~nm}$ é da mesma ordem de magnitude do que a encontrada em $\mathrm{H}_{2} \mathrm{SO}_{4}$ na mesma temperatura, porém o seu aparecimento se dá em tempos menores. Também ocorre o surgimento de uma banda em aproximadamente $290 \mathrm{~nm}$, provavelmente devida a formação de bi-tiofeno, cuja magnitude, descontados os 
efeitos de acréscimo da linha de base, permanece aproximadamente invariável com o tempo.

A seguir estão apresentadas as estruturas citadas,<smiles>c1cc2cc[se]c2s1</smiles>

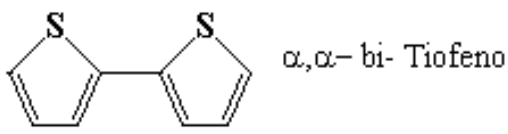

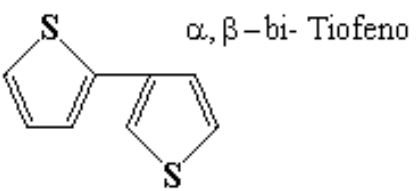<smiles>CCCCCOc1ccc(-c2ccc(-c3cccs3)s2)s1</smiles><smiles>CCCCCCOc1ccc(-c2ccc(-c3ccc(-c4ccc(-c5ccc(-c6cccs6)s5)s4)s3)s2)s1</smiles>

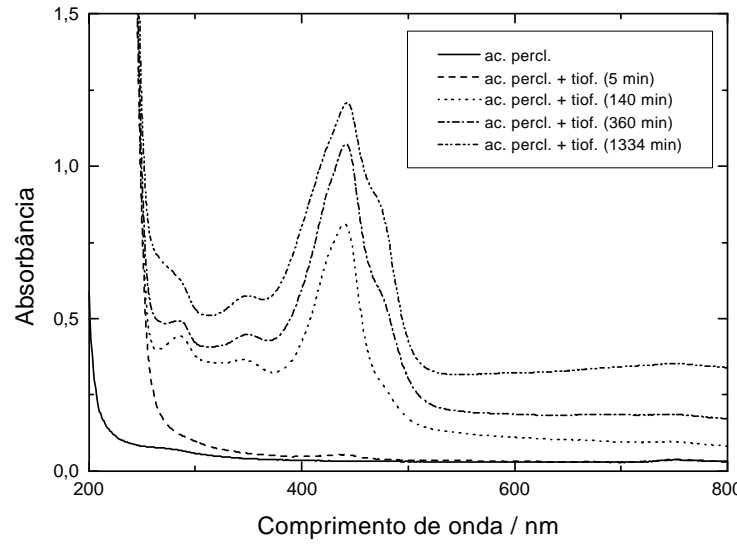

FIGURA 17 - Espectros de UV-Visível de ácido perclórico 8,0 M e ácido perclórico 8,0 $\mathrm{M}+$ tiofeno em diferentes tempos a $23{ }^{\circ} \mathrm{C}$.

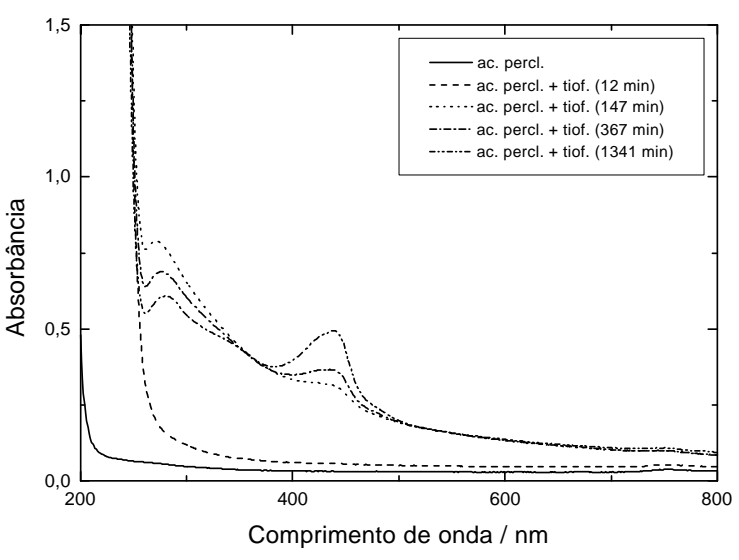

FIGURA 18 - Espectros de UV-Visível de ácido perclórico 8,0 M e ácido perclórico 8,0 $\mathrm{M}+$ tiofeno em diferentes tempos a $3{ }^{\circ} \mathrm{C}$.

Pode-se concluir, por estes estudos, que a formação de oligômeros solúveis em solução ocorre mais rapidamente e em maior escala na solução de $\mathrm{HClO}_{4}$, fato que dificulta a síntese neste meio. Os estudos voltamétricos conduzidos em $\mathrm{HClO}_{4}$ 
[5] motraram uma situação bastante complexa quanto ao processo de oxidação das espécies em solução e quanto ao mecanismo de precipitação dos oligômeros responsáveis pela formação dos filmes poliméricos. Em ácido sulfúrico a $3{ }^{\circ} \mathrm{C}$ os estudos realizados indicam a formação de $\alpha, \alpha$ '-sexi-tiofeno, o qual eventualmente pode ser um precursor importante envolvido no processo de formação do polímero. No entanto, nota-se que as magnitudes dos picos característicos observados a $3{ }^{\circ} \mathrm{C}$ são pequenas, indicando que a concentração deste precursor é pequena em comparação com a de tiofeno.

\section{1. 3. Efeito da Rotação do Eletrodo}

Durante a síntese eletroquímica do politiofeno em condições estacionárias observou-se que, quanto mais polido era o eletrodo, mais uniforme era o crescimento do filme. Notou-se também que no caso de um eletrodo estacionário de lâmina de $\mathrm{Pt}$ inserido verticalmente em solução, o filme produzido era mais espesso próximo à interface solução/ar, significando que ali deveria haver um acúmulo da quantidade do agente eletroquimicamente ativo, ou indicando que os oligômeros formados (provavelmente em grande parte o $\alpha, \alpha^{\prime}$-sexi-tiofeno) formam uma camada sobrenadante na solução [5]. Em função destas observações, foi estudado o crescimento de politiofeno através de voltametria cíclica em eletrodo rotatório de forma que a solução em constante agitação mantivesse a concentração do agente ativo sempre homogênea.

Nas Figuras 19 e 20 são comparados os voltamogramas cíclicos de crescimento de politiofeno em $\mathrm{H}_{2} \mathrm{SO}_{4} 12,5 \mathrm{M}$ e $3{ }^{\circ} \mathrm{C}$ com e sem a rotação do 
eletrodo. Observa-se que as densidades de correntes são maiores para os polímeros sintetizados em eletrodo rotatório (Figura 19), do que no eletrodo estacionário usado no crescimento de politiofeno mostrado na Figura 20 e que estas diferenças se acentuam com o número de ciclos. Estes fatos estão relacionados com os processos de transporte de massa que são favorecidos no eletrodo rotatório e com a menor segregação do agente ativo presente em solução. Assim estes experimentos são consistentes com a proposta de que o precursor envolvido na formação do polímero, gerado pelo ataque ácido ao tiofeno, está presente em concentrações relativamente baixas.

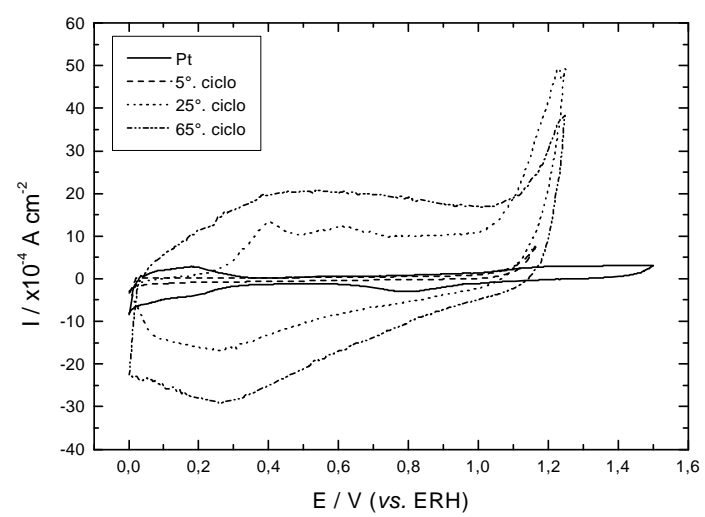

FIGURA 19 - Voltametria cíclica de crescimento de politiofeno em eletrodo de Pt em ácido sulfúrico $12,5 \mathrm{M}$ a $3{ }^{\circ} \mathrm{C}$ com rotação do eletrodo (1000 rpm). v = $100 \mathrm{mV}$ $\mathrm{s}^{-1}$.

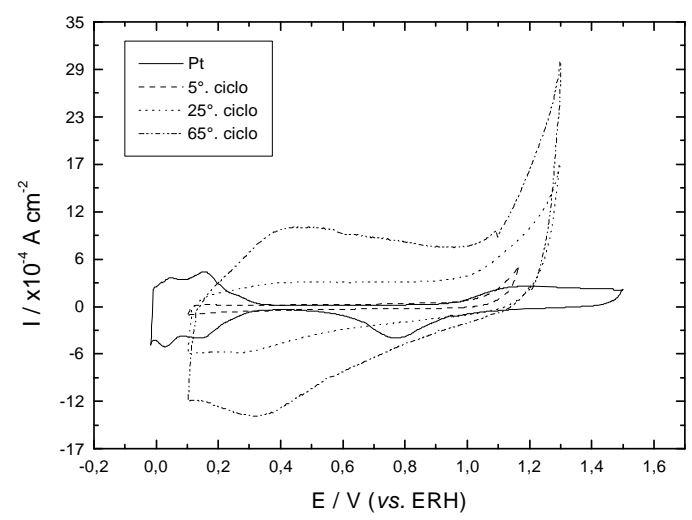

FIGURA 20 - Voltametria cíclica de crescimento de politiofeno em eletrodo de $\mathrm{Pt}$ em ácido sulfúrico $12,5 \mathrm{M}$ a $3{ }^{\circ} \mathrm{C}$ sem rotação do eletrodo. $\mathrm{v}=100 \mathrm{mV} \mathrm{s}^{-1}$.

\section{1. 4. Síntese em Diferentes Materiais Eletródicos}

A Figura 21 apresenta voltamogramas cíclicos do politiofeno sintetizado em ácido sulfúrico nos três eletrodos lisos estudados ( $\mathrm{Pt}$, $\mathrm{Au}$ e $\mathrm{C}$ vítreo) a uma 
velocidade de varredura de síntese de $75 \mathrm{mV} \mathrm{s}^{-1}$ utilizando-se 35 ciclos de crescimento. O perfil voltamétrico dos filmes é praticamente o mesmo independentemente do material eletródico estudado, sendo que as pequenas diferenças encontradas podem decorrer de pequenas diferenças nas condições de síntese (temperatura ou concentração do monômero) do filme polimérico.

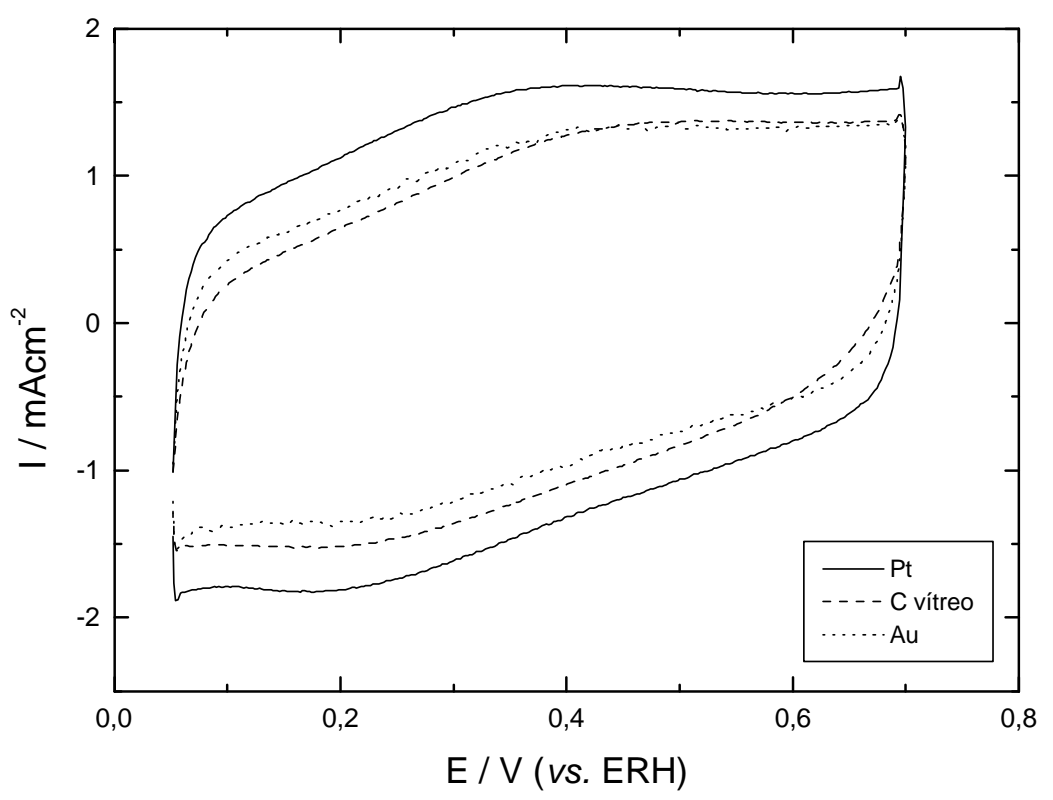

FIGURA 21 - Comparação entre a síntese de politiofeno em $\mathrm{H}_{2} \mathrm{SO}_{4} 12,5 \mathrm{M}, 1000 \mathrm{rpm}, 3{ }^{\circ} \mathrm{C}$, $\mathrm{v}=75 \mathrm{mV} \mathrm{s}^{-1}$, com 35 ciclos de crescimento sobre os três eletrodos estudados: platina, carbono vítreo e ouro. Voltametrias realizadas em $\mathrm{H}_{2} \mathrm{SO}_{4} 12,5 \mathrm{M}$ com v $=100 \mathrm{mV} \mathrm{s}^{-1}$.

A síntese de politiofeno em eletrodo de tecido de carbono, foi efetuada tendo em vista a realização de experimentos com luz síncrotron. O crescimento do filme em tecido de carbono se deu nas mesmas condições que em carbono vítreo, sendo que o polímero foi depositado nos dois lados do tecido. Na Figura 22, estão apresentados os voltamogramas de crescimento obtidos até o $65^{\circ}$ ciclo. Nota-se que o comportamento voltamétrico de crescimento do filme se assemelha bastante ao 
observado em carbono vítreo, sendo que as cargas voltamétricas são também similares para um mesmo número de ciclos.

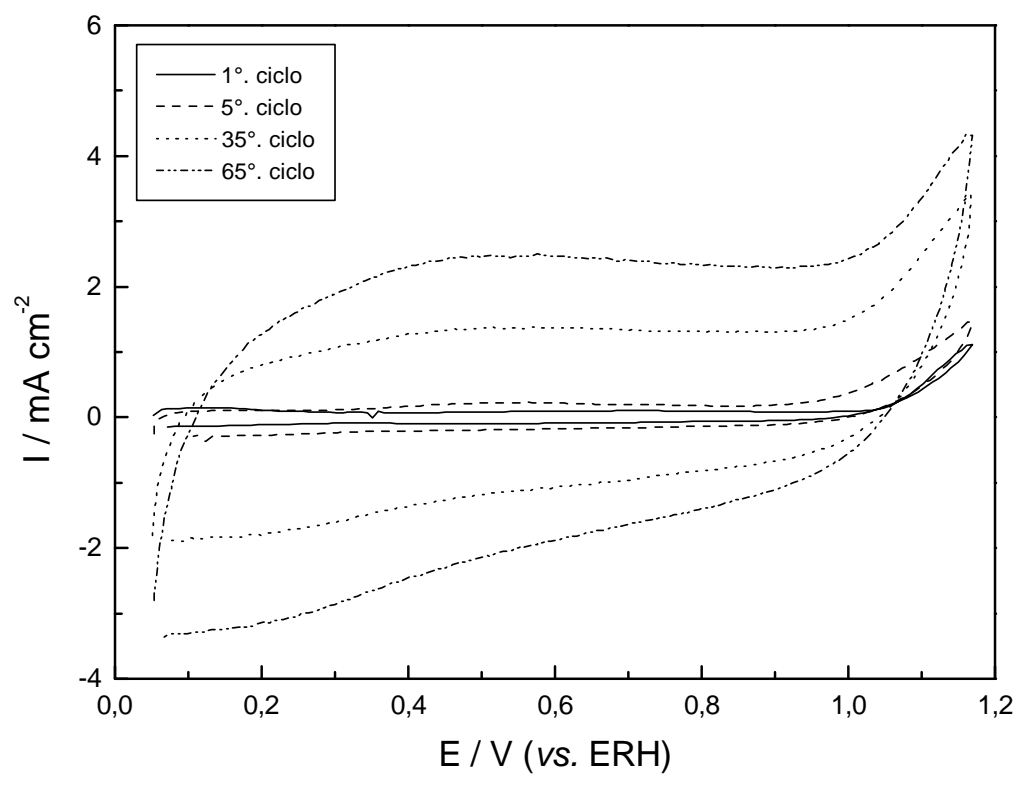

FIGURA 22 - Voltamogramas cíclicos de crescimento de politiofeno em eletrodo de tecido de carbono em $\mathrm{H}_{2} \mathrm{SO}_{4} 12,5 \mathrm{M}$ e tiofeno 0,05 M. Temperatura de $3^{\circ} \mathrm{C}$, velocidade de $75 \mathrm{mV}$ $\mathrm{s}^{-1}$, rotação de $1000 \mathrm{rpm}$.

A conclusão geral é que o politiofeno pode ser sintetizado em variados materiais eletródicos, como é o caso da platina, ouro, carbono vítreo e do tecido de carbono, sendo que o comportamento voltamétrico apresentado pelo polímero resulta bastante similar indicando a formação de produtos com propriedades bastante similares.

\section{1. 5. Propriedades Morfológicas dos filmes formados}

Medidas de MEV foram realizadas nos filmes de politiofeno sintetizados em 
platina, carbono vítreo e ouro em diferentes números de ciclos, portanto, várias espessuras. Também foram realizadas medidas de microscopia dos substratos eletródicos para fins comparativos. As Figuras 23-28 mostram alguns dos resultados obtidos.

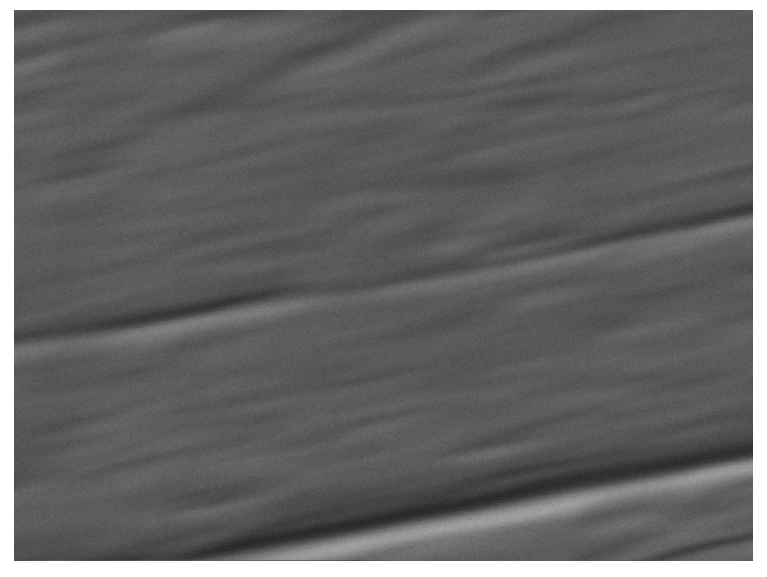

FIGURA 23 - MEV de eletrodo de platina sem presença de filme de PT. Aumento de 20000 vezes.

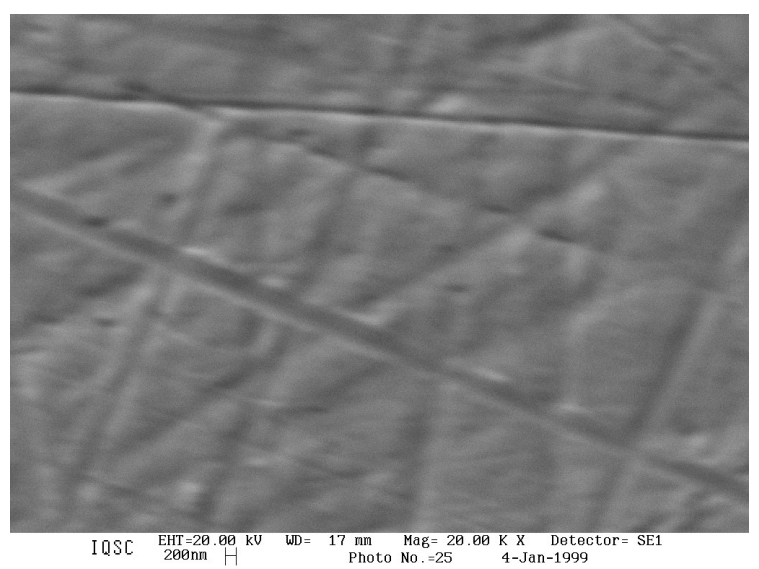

FIGURA 25 - MEV de eletrodo de ouro sem presença de filme de PT. Aumento de 20000 vezes.

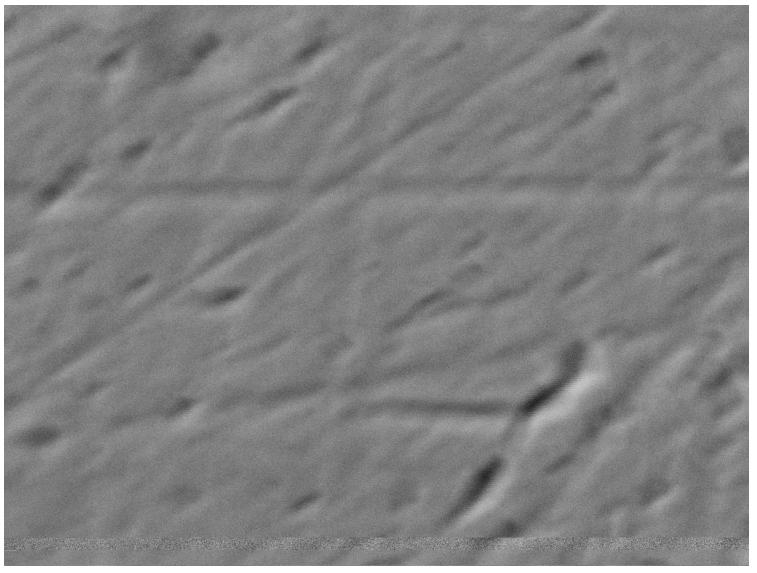

FIGURA 24 - MEV de filme de PT sintetizado em $\mathrm{H}_{2} \mathrm{SO}_{4} 12,5 \mathrm{M}, 3{ }^{\circ} \mathrm{C}, 1000 \mathrm{rpm}, \mathrm{v}=75 \mathrm{mV}$

$\mathrm{s}^{-1}$ por 15 ciclos sobre eletrodo de platina.

Aumento de 25000 vezes.

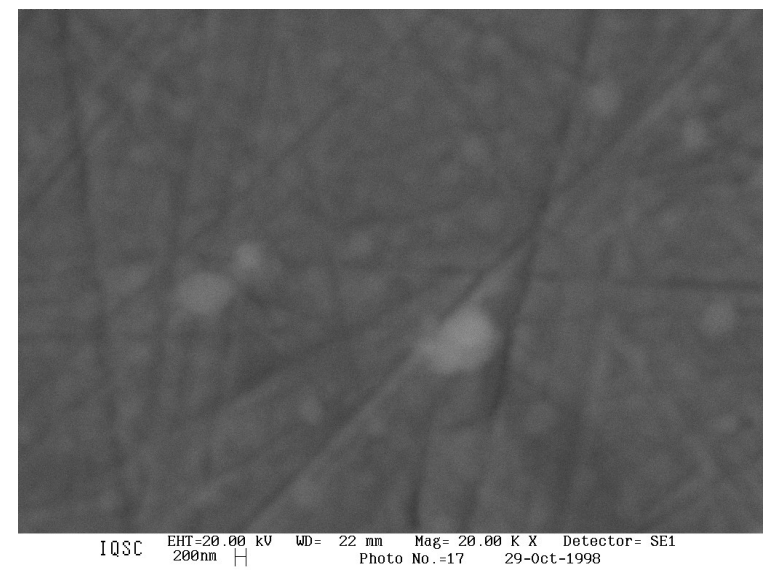

FIGURA 26 - MEV de filme de PT sintetizado em $\mathrm{H}_{2} \mathrm{SO}_{4} 12,5 \mathrm{M}, 3{ }^{\circ} \mathrm{C}, 1000 \mathrm{rpm}, \mathrm{v}=75 \mathrm{mV}$ $\mathrm{s}^{-1}$ por 35 ciclos sobre eletrodo de ouro.

Aumento de 20000 vezes. 

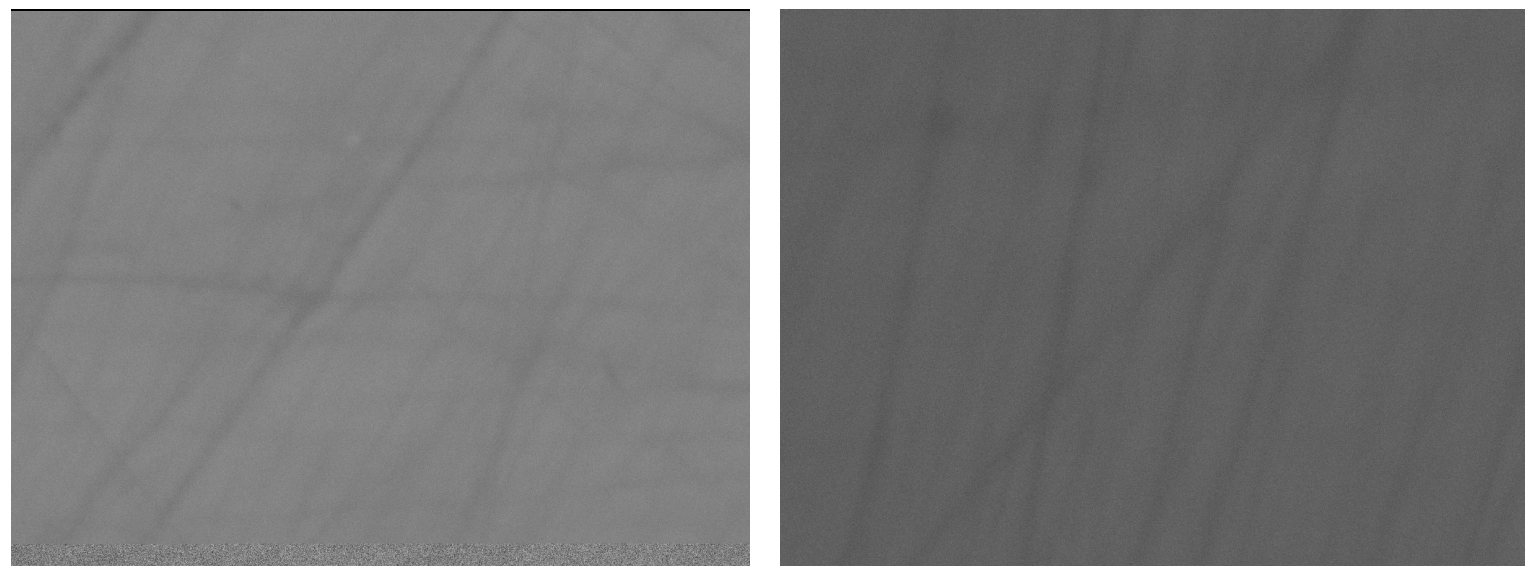

FIGURA 27 - MEV de eletrodo de carbono vítreo sem presença de filme de PT. Aumento de 20000 vezes.
FIGURA 28 - MEVde filme de PT sintetizado em $\mathrm{H}_{2} \mathrm{SO}_{4} 12,5 \mathrm{M}, 3{ }^{\circ} \mathrm{C}, 1000 \mathrm{rpm}, \mathrm{v}=100$ $\mathrm{mV} \mathrm{s}^{-1}$ por 15 ciclos sobre eletrodo de carbono vítreo. Aumento de 20000 vezes.

Uma análise dos resultados das Figuras 23-28 mostra que não é possível visualizar defeitos na morfologia do filme de politiofeno nas condições estudadas. Parece que o filme é extremamente homogêneo e sem falhas, sendo que o mesmo se adere perfeitamente sobre a superfície do eletrodo. Isto contrasta significativamente com a estrutura observada para outros polímeros condutores como polipirrol e polianilina [64-66] onde estruturas superficiais do tipo globular são observadas.

Para que não houvesse dúvidas sobre a presença do politiofeno sobre o eletrodo, realizou-se medida de EDX em politiofeno sintetizado por 65 ciclos sobre $\mathrm{Au}$ e os elementos $\mathrm{S}$ e $\mathrm{C}$ foram detectados, confirmando a presença dos mesmos sobre o metal (Figura 29). Também em um experimento independente a superfície do filme foi sulcada com uma lâmina fina criando-se assim externamente uma falha no filme polimérico após sua síntese. Realizou-se medidas de MEV do mesmo, como é mostrado na Figura 30. A presença do sulco criado externamente é facilmente observada no resultado obtido, o que comprova a existência do filme polimérico 
sobre o substrato. Considerando-se a profundidade do sulco, estima-se que a espessura do filme com 15 ciclos de crescimento é da ordem de $1 \mu \mathrm{m}$.

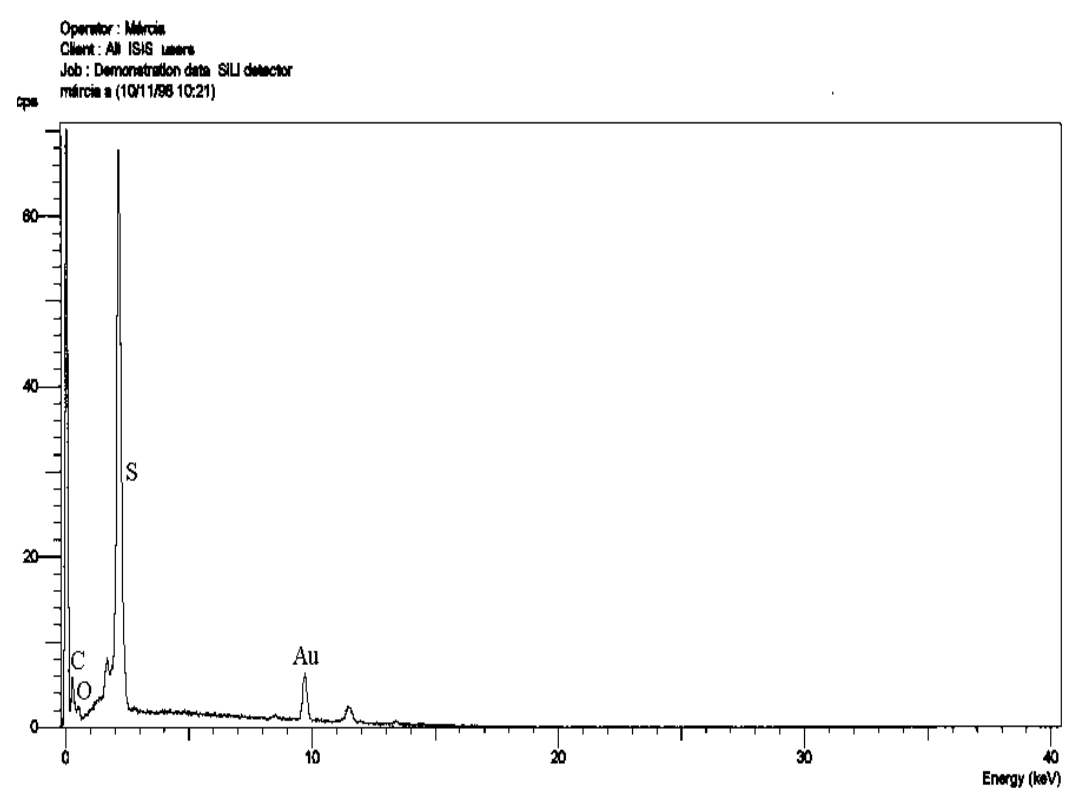

FIGURA 29 - EDX de filme de PT sintetizado em $\mathrm{H}_{2} \mathrm{SO}_{4} 12,5 \mathrm{M}, 3{ }^{\circ} \mathrm{C}, 1000 \mathrm{rpm}, \mathrm{v}=75$ $\mathrm{mV} \mathrm{s}^{-1}$ por 65 ciclos sobre eletrodo de Au.

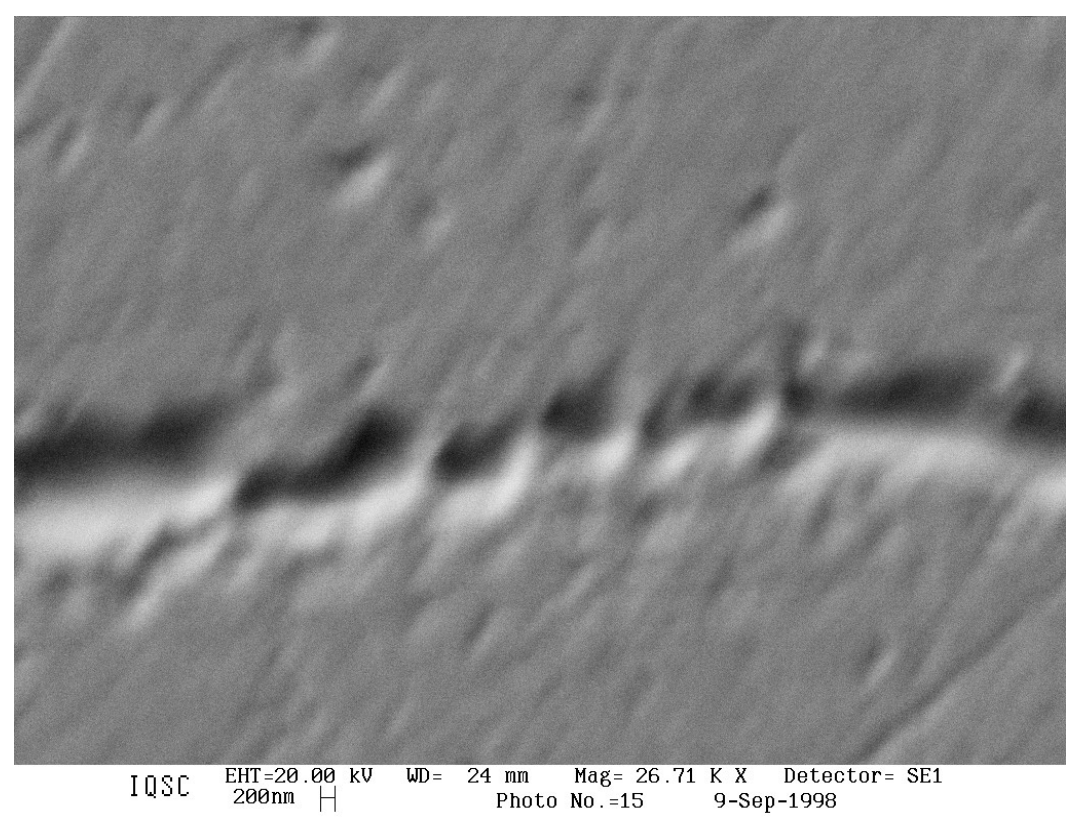

FIGURA 30 - MEV de filme de politiofeno sintetizado em $\mathrm{H}_{2} \mathrm{SO}_{4} 12,5 \mathrm{M}, 3^{\circ} \mathrm{C}, 1000 \mathrm{rpm}$, v $=100 \mathrm{mV} \mathrm{s}^{-1}$ por 15 ciclos sobre eletrodo de platina. Aumento de 26710 vezes. 


\section{1. 6. Espectro de FTIR}

Foram realizadas medidas de FTIR em substrato de Pt do politiofeno crescido por 55 ciclos em $\mathrm{H}_{2} \mathrm{SO}_{4} 12,5 \mathrm{M}$ a $3{ }^{\circ} \mathrm{C}$, sendo os resultados apresentados na Figura 31. Comparando-se o espectro do filme com resultado da literatura, encontram-se essencialmente os mesmos picos [5]. As bandas em aproximadamente 1447, 1272 e $1169 \mathrm{~cm}^{-1}$ se devem às ligações $\alpha, \alpha^{\prime}$ características de poli-2,5-tiofeno [5]; a banda em $806 \mathrm{~cm}^{-1}$ pode ser devida estiramento em ângulo de C-H fora do plano [7,67,68]. Já a banda em $1736 \mathrm{~cm}^{-1}$ foi também observada para o polímero preparado em ácido perclórico e tem sido atribuída a presença de grupos $\mathrm{OH}$ de água residual aprisionada na matriz polimérica [5]. Este fato é um tanto quanto surpreendente, porém tem sido também observado em alguns sólidos contendo água de cristalização [5]. Esta também pode ser devida à presença de grupos $\mathrm{C}=\mathrm{O}$ na cadeia [68] que pode indicar a presença de porções degradadas na cadeia polimérica [69], como explicado pelo mecanismo apresentado mais adiante.

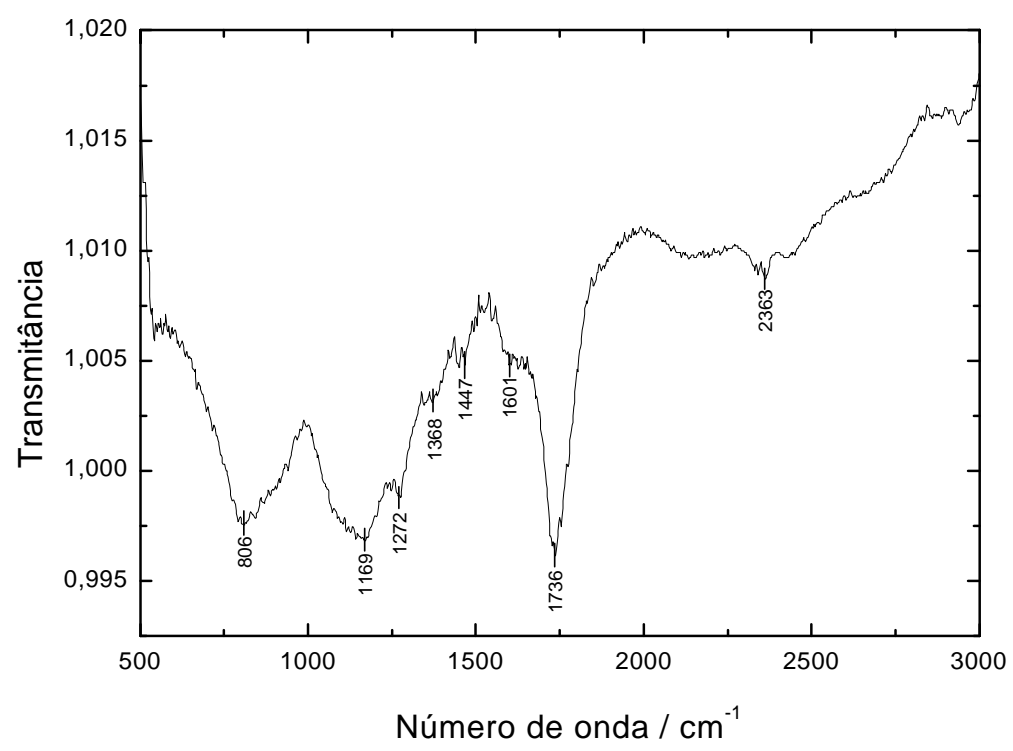

FIGURA 31 - Espectro de FTIR de politiofeno crescido em ácido sulfúrico $12,5 \mathrm{M}$ a $3{ }^{\circ} \mathrm{C} \mathrm{e}$ velocidade de varredura de $100 \mathrm{mV} \mathrm{s}^{-1}$. 


\section{1. 7. Mecanismo de Síntese}

A partir das observações feitas pode-se dizer que, assim que o monômero tiofeno é adicionado à solução ácida, pode ser polimerizado levando à formação de bi-tiofeno, ter-tiofeno, sexi-tiofeno e ainda oligômeros com cadeias maiores. Isto acontece porque a solução fortemente ácida leva à formação de um complexo $\pi$ ou complexo $\sigma$, como no caso de polímeros como o PPP [5,70], onde o monômero é protonado pelo ácido forte. Estes monômeros podem expontaneamente serem polimerizados em solução e formar oligômeros, como mencionado anteriormente. Também por analogia ao caso do poli-para-fenileno $[5,70]$ pode-se propor que a síntese eletroquímica ocorre com o envolvimento direto dos complexos $\pi$ ou $\sigma$.

Assim, tendo em vista os resultados dos estudos realizados e com base em resultados da literatura [5] é possível propor o seguinte mecanismo para o processo de síntese eletroquímica do polímero envolvendo complexo $\pi$ :

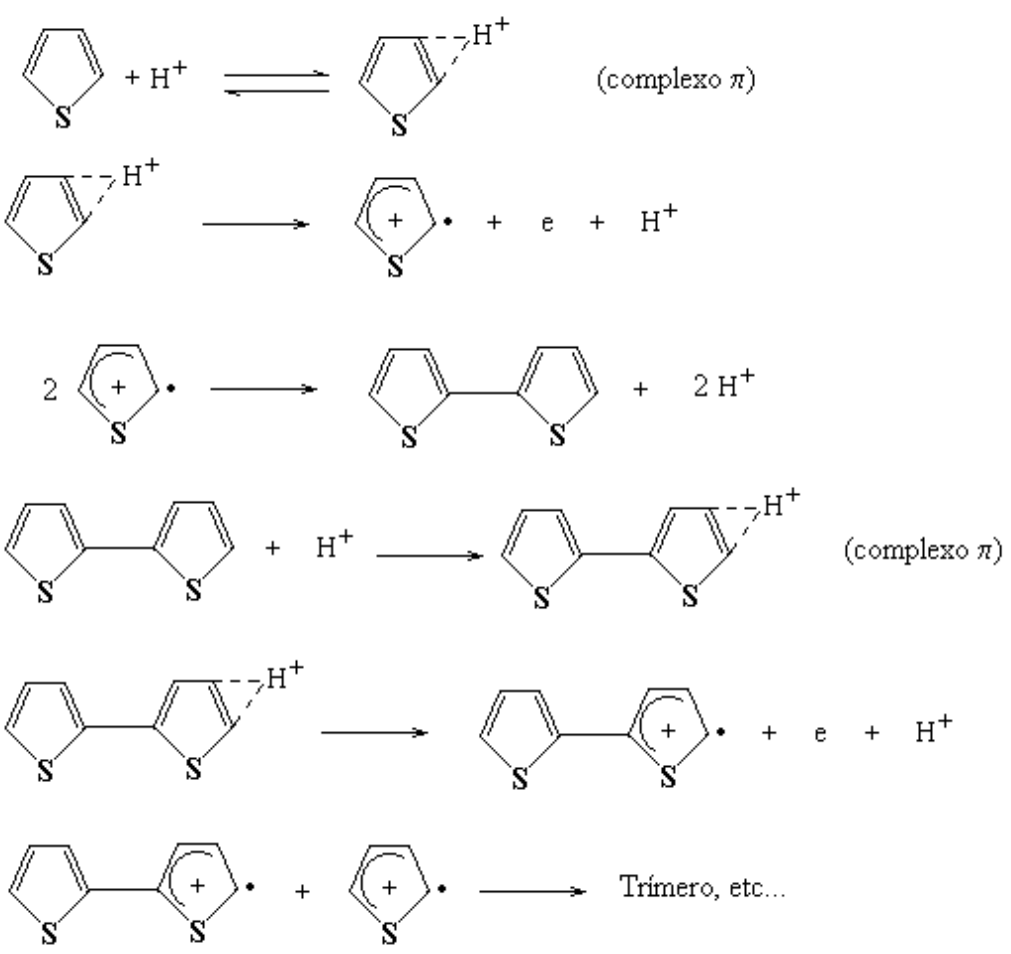


Os dados de FTIR indicam que com a contínua oxidação da cadeia polimérica, parte dela pode sofrer superoxidação com a entrada de oxigênio em sua constituição como mostra o esquema proposto a seguir [71,72]:

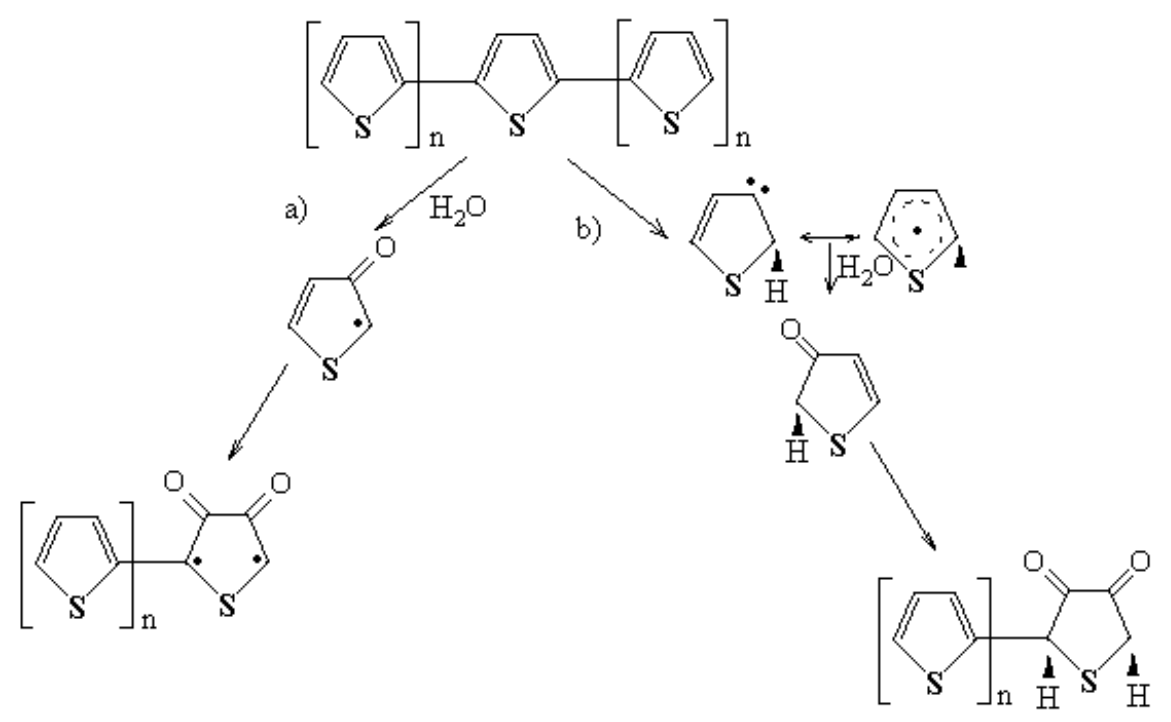

\section{2. Propriedades REDOX dos Filmes de PT}

3. 2. 1. Estudo do Comportamento Voltamétrico do PT em várias Concentrações de $\mathrm{H}_{2} \mathrm{SO}_{4}$

Foram realizadas voltametrias cíclicas de politiofeno sintetizado em platina em solução de $\mathrm{H}_{2} \mathrm{SO}_{4}$ 12,5 M com velocidade de crescimento igual a $75 \mathrm{mV} \mathrm{s}^{-1} \mathrm{em}$ várias concentrações de ácido sulfúrico para verificar a influência desta variável sobre o comportamento redox do polímero.

As Figuras 32a e 32b apresentam essas curvas voltamétricas. Em relação à concentração $12,5 \mathrm{M}$, observa-se uma grande queda de corrente quando se diminui a 
concentração do ácido para 10,0 M, e novamente quando esta é diminuída para 8,0 M, porém o perfil voltamétrico não se altera. Abaixo desta concentração de ácido sulfúrico $(8,0$ M) não há muita alteração na corrente voltamétrica, porém o perfil passa a se alterar quando a concentração é mudada de 6,0 M para valores inferiores. As curvas nestas condições não mostram tão claramente as características voltamétricas típicas de polímeros condutores [73-75] indicando que o polímero apresenta-se menos ativo nestas concentrações.
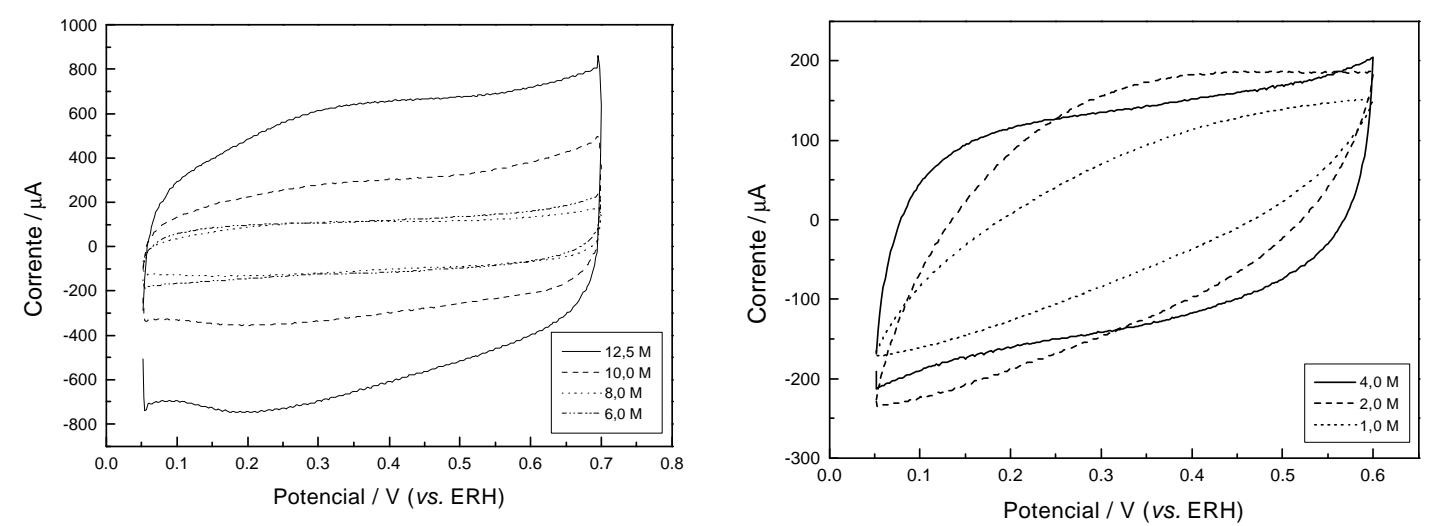

FIGURAS 32a e 32b - Curvas voltamétricas de PT sintetizado em $\mathrm{H}_{2} \mathrm{SO}_{4}$ 12,5 M, $1000 \mathrm{rpm}$,

$3{ }^{\circ} \mathrm{C}, \mathrm{v}=75 \mathrm{mV} \mathrm{s}^{-1}$, com 65 ciclos de crescimento sobre eletrodo de Pt em diversas concentrações de $\mathrm{H}_{2} \mathrm{SO}_{4}$ (concentrações apresentadas nas próprias figuras). $\mathrm{v}=100 \mathrm{mV} \mathrm{s}^{-1}$.

Estes efeitos podem ser explicados considerando que nas concentrações ácidas mais elevadas o polímero encontra-se protonado (equilíbrio ácido/base) sendo que o fenômeno principal responsável pela compensação das cargas formadas durante o processo eletroquímico de oxidação da cadeia polimérica deve ser a saída de prótons do interior do filme. Com a diminuição da protonação da cadeia polimérica [76] resultante da diminuição da concentração ácida há uma diminuição da participação do próton no processo de compensação de cargas, ao mesmo tempo em que se observa uma diminuição da concentração de centros reativos. 


\section{2. 2. Estudos Espectroscópicos de UV-Visível}

Espectros de UV-Visível de filme de politiofeno crescido por 35 ciclos em eletrodo de Pt em solução de $\mathrm{H}_{2} \mathrm{SO}_{4} 12,5 \mathrm{M}$ com o eletrodo polarizado em diferentes potenciais são mostrados na Figura 33. São observadas quatro bandas de absorção em 290, 430, 550 e $900 \mathrm{~nm}$ para o polímero no estado menos oxidado (0,1 V). O aumento do potencial aplicado (ou do estado de oxidação) não leva à nenhuma mudança na intensidade das bandas em 290 e 430 nm. Entretanto, há um decréscimo na intensidade das bandas em 550 e $900 \mathrm{~nm}$, ao mesmo tempo que um ombro surge na faixa $600-800 \mathrm{~nm}$ e uma nova e larga banda centrada em aproximadamente 1050 nm se desenvolve.

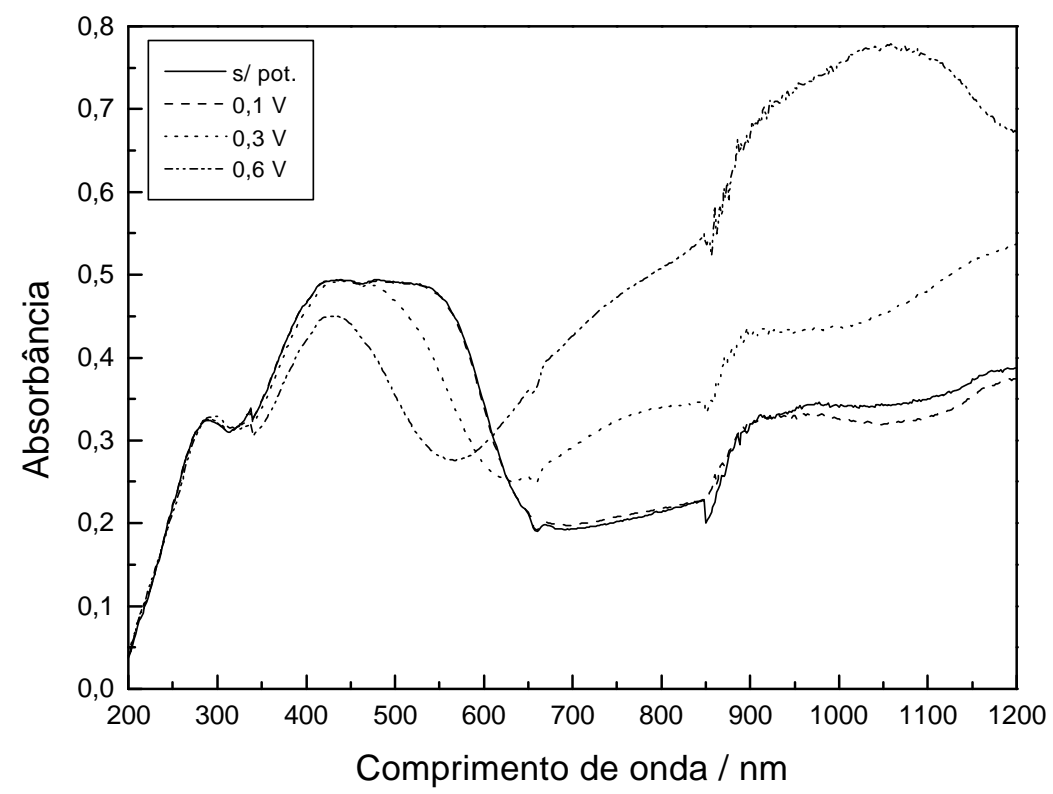

FIGURA 33 - Espectros de UV-Visível de politiofeno sintetizado sobre platina em $\mathrm{H}_{2} \mathrm{SO}_{4}$ 12,5 M por 35 ciclos, com $1000 \mathrm{rpm}, 3{ }^{\circ} \mathrm{C} \mathrm{e} \mathrm{v}=75 \mathrm{mV} \mathrm{s}{ }^{-1}$. Solução utilizada: $\mathrm{H}_{2} \mathrm{SO}_{4} 12,5 \mathrm{M}$ Potenciais aplicados mostrados na própria figura (vs. ERH). 
A presença de quatro centros cromóforos pode ser inferida para os filmes de politiofeno nos estados mais e menos oxidados. As absorbâncias em 290 e 430 nm permanecem inalteradas com a oxidação do polímero, indicando que eles representam a contribuição dos centros cromóforos que são invariantes com o potencial do eletrodo. A primeira pequena banda em $290 \mathrm{~nm}$ é muito próxima àquela de dímeros de tiofeno em meio orgânico, e deve corresponder às transições eletrônicas $\pi-\pi^{*}$ [5]. Isto indica a presença de algum resíduo do material precursor não-polimerizado aprisionado na cadeia polimérica. A outra banda em $430 \mathrm{~nm}$ é provavelmente devida à transições similares envolvendo a cadeia polimérica ou de oligômeros com cadeias contendo um número maior que 6 monômeros, a qual é deslocada para menores energias em relação ao monômero/dímero devido ao largo comprimento da cadeia, como já proposto para este [77] e outros polímeros condutores [78].

Do mesmo modo que para outros polímeros condutores, particularmente polipirrol [78], as outras bandas de absorção podem ser analisadas em termos de modelo polarônico/bipolarônico. De acordo com este, as bandas em 550 e 900 nm observadas para os potenciais eletródicos mais baixos, podem ser atribuídas à presença de polarons ou também de centros protonados. Por outro lado, o ombro em 600-800 nm e a banda de absorção centrada em 1050 nm, que aparece mais claramente em altos potenciais, pode ser atribuída à formação de bipolarons.

A Figura 34a mostra a evolução das intensidades de absorção em 530 e 670 nm, para o mesmo filme de politiofeno mostrado na Figura 33, como função do potencial do eletrodo. A derivada de tais curvas proporciona uma idéia da taxa de formação/destruição dos centros cromóforos correspondentes (polarons e bipolarons) como função do potencial do eletrodo. Estes resultados são mostrados na Figura 34b, 
para a varredura anódica em ambos os comprimentos de onda. Nesta Figura é interessante observar que os picos da derivada da absorção nos dois comprimentos de onda se encontram aproximadamente no mesmo potencial de oxidação do politiofeno observado em suas voltametrias cíclicas. Os resultados nas Figuras 34a e 34b mostram claramente que os polarons (ou centros protonados) estão presentes nos potenciais mais baixos de oxidação e são oxidados à bipolarons ao longo da varredura anódica.

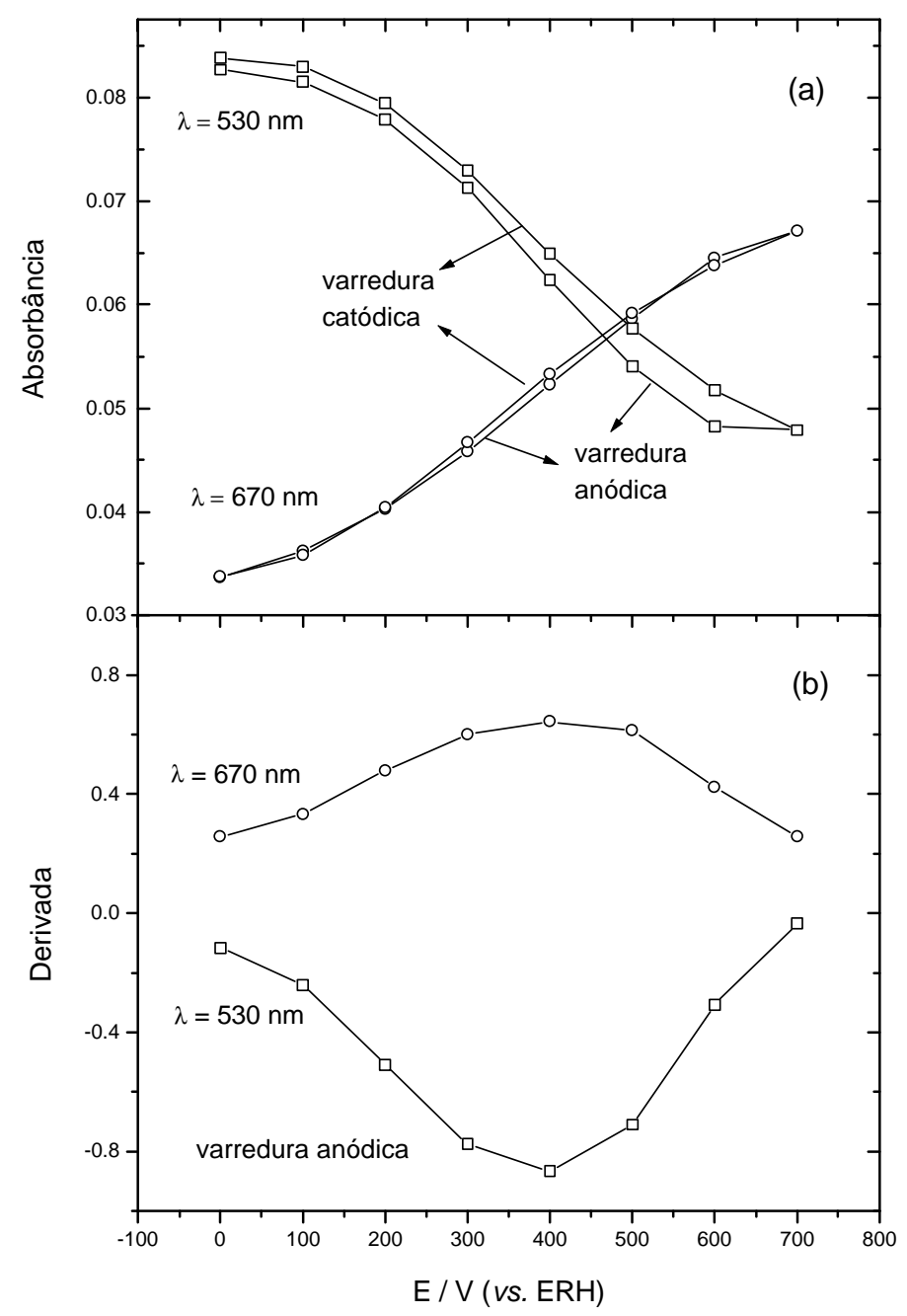

FIGURA 34 - Espectros de UV-Visível do politiofeno apresentado na figura anterior em comprimentos de onda fixos de 530 e $670 \mathrm{~nm}$ durante voltametria cíclica a $50 \mathrm{mV} \mathrm{s}^{-1}$. 
Por estes resultados, pode-se propor que as formas encontradas nesses potenciais são:

- Forma protonada:

$$
\begin{aligned}
(\mathrm{PT})_{\mathrm{n}}+\mathrm{nH}^{+}+\mathrm{nHSO}_{4}^{-} \rightleftharpoons & \left(\mathrm{PTH}^{+}\left(\mathrm{HSO}_{4}^{-}\right)\right)_{\mathrm{n}} \\
& (\text { centros protonados })
\end{aligned}
$$

- Polímero em 0,1V (oxidação dos centros protonados):

$$
\begin{gathered}
\mathrm{PTH}^{+}\left(\mathrm{HSO}_{4}^{-}\right)_{\mathrm{n}} \rightleftharpoons \\
\left(\mathrm{PT}^{\bullet+} \mathrm{HSO}_{4}^{-}\right)_{\mathrm{n}}+\mathrm{nH}^{+}+\mathrm{ne} \\
(\text { polaron })
\end{gathered}
$$

- Polímero entre 0,1 e 0,6 V (oxidação do polaron):

$$
\left(\mathrm{PT}^{\bullet+}\left(\mathrm{HSO}_{4}^{-}\right)\right)_{\mathrm{n}}+\mathrm{nHSO}_{4}^{-} \rightleftharpoons\left(\mathrm{PT}^{+2}\left(\mathrm{HSO}_{4}^{-}\right)_{2}\right)_{\mathrm{n}}+\mathrm{ne}
$$

$\mathrm{ou}$

$$
\begin{aligned}
\left(\mathrm{PT}^{\bullet+}\left(\mathrm{HSO}_{4}^{-}\right)\right)_{\mathrm{n}} \rightleftharpoons & \left(\mathrm{PT}^{+2}\left(\mathrm{SO}_{4}^{-2}\right)\right)_{\mathrm{n}}+\mathrm{nH}^{+}+\mathrm{ne} \\
& \text { (bipolaron) }
\end{aligned}
$$

\section{3. Propriedades Catalíticas dos Filmes Contendo Catalisadores Dispersos}

\section{3. 1. Caracterização dos Catalisadores}

Os voltamogramas cíclicos apresentados na Figura 35 mostram o comportamento de politiofeno crescido por 35 ciclos em solução de $\mathrm{H}_{2} \mathrm{SO}_{4} 12,5 \mathrm{M}$ 
antes e após a eletrodeposição da platina no mesmo. Nota-se que há um crescimento bastante pronunciado da corrente na região de oxidação/redução do hidrogênio após a adição de Pt na cadeia polimérica, indicando que o polímero incorporou tais partículas e que estas apresentam atividade eletroquímica.

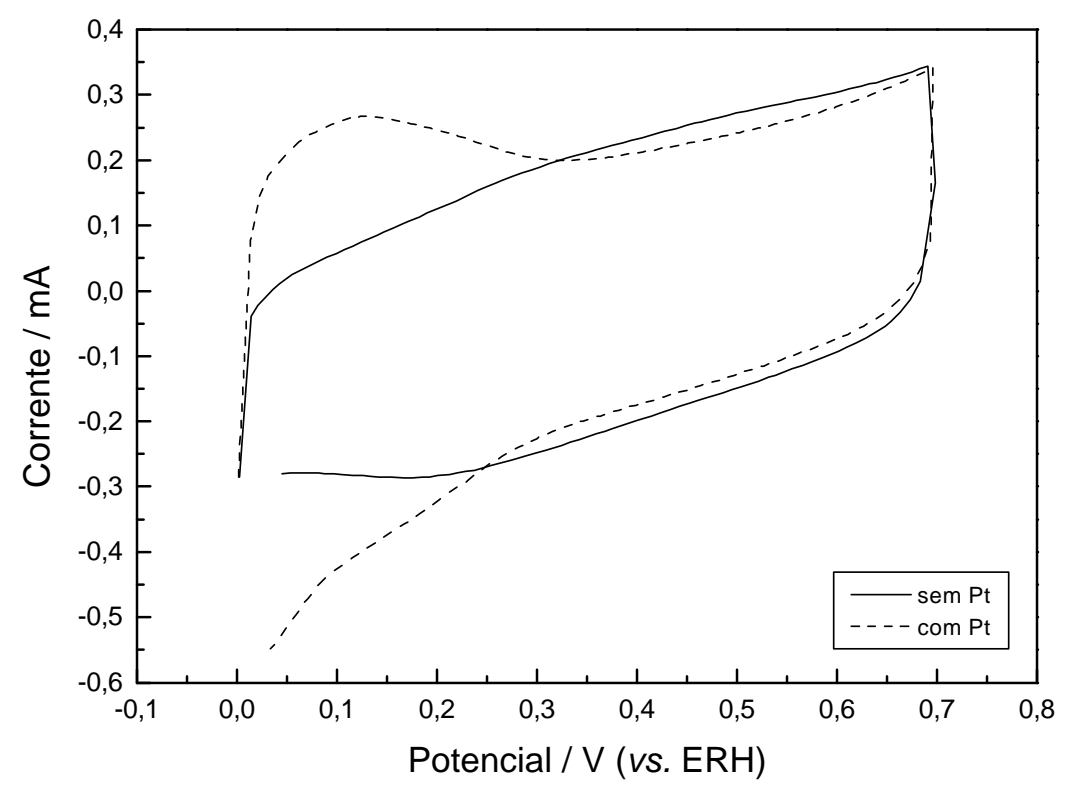

FIGURA 35 - Voltamogramas cíclicos de politiofeno crescido sobre eletrodo de C vítreo por 35 ciclos contendo platina e não contendo platina em solução de $\mathrm{H}_{2} \mathrm{SO}_{4} 12,5 \mathrm{M}$. Velocidade de varredura: $75 \mathrm{mV} \mathrm{s}^{-1}, 40$ ciclos de incorporação de platina.

As Figuras 36 e 37 mostram as voltametrias cíclicas em $\mathrm{H}_{2} \mathrm{SO}_{4}$ 0,05 M de politiofeno contendo partículas de prata e paládio, respectivamente. Observa-se que, no caso da prata (Figura 36), os picos de oxidação presentes em aproximadamente 0,6 V diminuem rapidamente com o número de ciclos. No primeiro ciclo, o pico está bem definido e no terceiro, já praticamente não se observa mais a presença do mesmo. Também observa-se a diminuição da magnitude do pico de redução encontrado em $0,25 \mathrm{~V}$. O pico em $0,6 \mathrm{~V}$ é atribuído à formação de $\mathrm{Ag}(\mathrm{OH})$ e o pico em $0,25 \mathrm{~V}$ pode ser atribuído à redução de $\mathrm{Ag}_{2} \mathrm{O}$ [79]. A diminuição e posterior 
desaparecimento desses picos, indica que a prata pode estar se dissolvendo na solução ácida, o que explicaria o comportamento voltamétrico e a inatividade do eletrodo observada frente a Reação de Redução de Oxigênio.

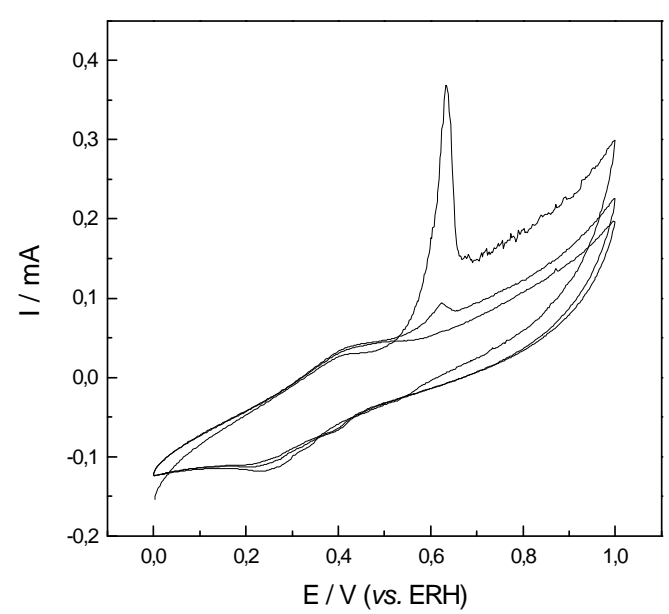

FIGURA 36 - Voltamogramas cíclicos de PT contendo prata em solução de $\mathrm{H}_{2} \mathrm{SO}_{4} 0,05 \mathrm{M}$. $\mathrm{v}=20 \mathrm{mV} \mathrm{s}^{-1}, 60 \mathrm{~s}$ de polarização do eletrodo em potencial de $0,54 \mathrm{~V}$ para incorporação de Ag. Eletrodo utilizado: C vítreo.

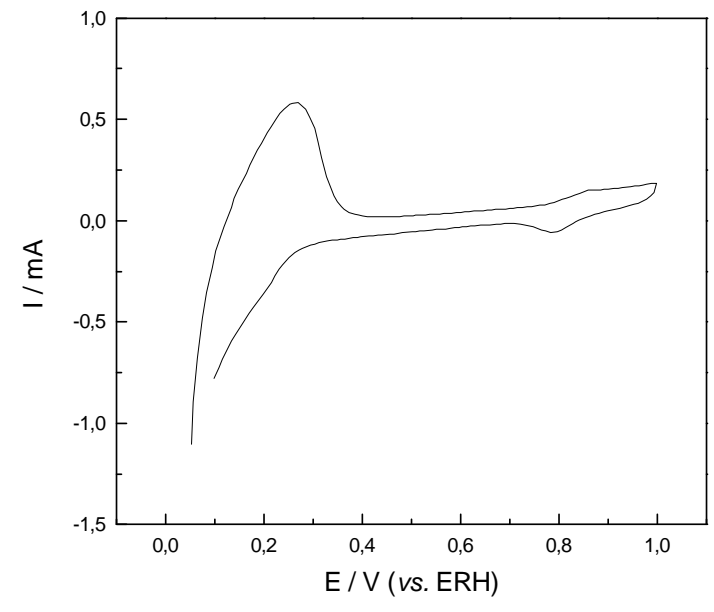

FIGURA 37 - Voltamogramas cíclicos de PT contendo paládio em solução de $\mathrm{H}_{2} \mathrm{SO}_{4} 0,05$ M. $v=75 \mathrm{mV} \mathrm{s}^{-1}, 120 \mathrm{~s}$ de polarização do eletrodo em potencial de $0,43 \mathrm{~V}$ para incorporação de Pd. Eletrodo utilizado: C vítreo.

A Figura 37 mostra o voltamograma cíclico do politiofeno contendo partículas de paládio em $\mathrm{H}_{2} \mathrm{SO}_{4}$ 0,05 M. Observa-se a presença de grandes picos redox na região de oxidação/redução de hidrogênio, como também picos de oxidação/redução em aproximadamente $0,8 \mathrm{~V}$ similares aos que são encontrados para a platina em meio ácido. Estes resultados mostram que, assim como no caso da Pt, as partículas incorporadas apresentam atividade eletroquímica. O par redox centrado ao redor de $0,2 \mathrm{~V}$ refere-se aos processo de absorção/dessorção de hidrogênio atômico 
no retículo do paládio [80]. Já o par ao redor de $0,8 \mathrm{~V}$ corresponde aos processos de formação e redução de óxidos superficiais hidratados [81].

Também foram incorporadas partículas catalisadoras em eletrodo de tecido de carbono e o voltamograma do polímero após a incorporação de Pt é mostrado na Figura 38. Novamente, como no eletrodo de carbono vítreo, nota-se o crescimento das cargas na região de oxidação/redução do hidrogênio, indicando que o polímero incorporou tais partículas e que estas apresentam atividade eletroquímica.

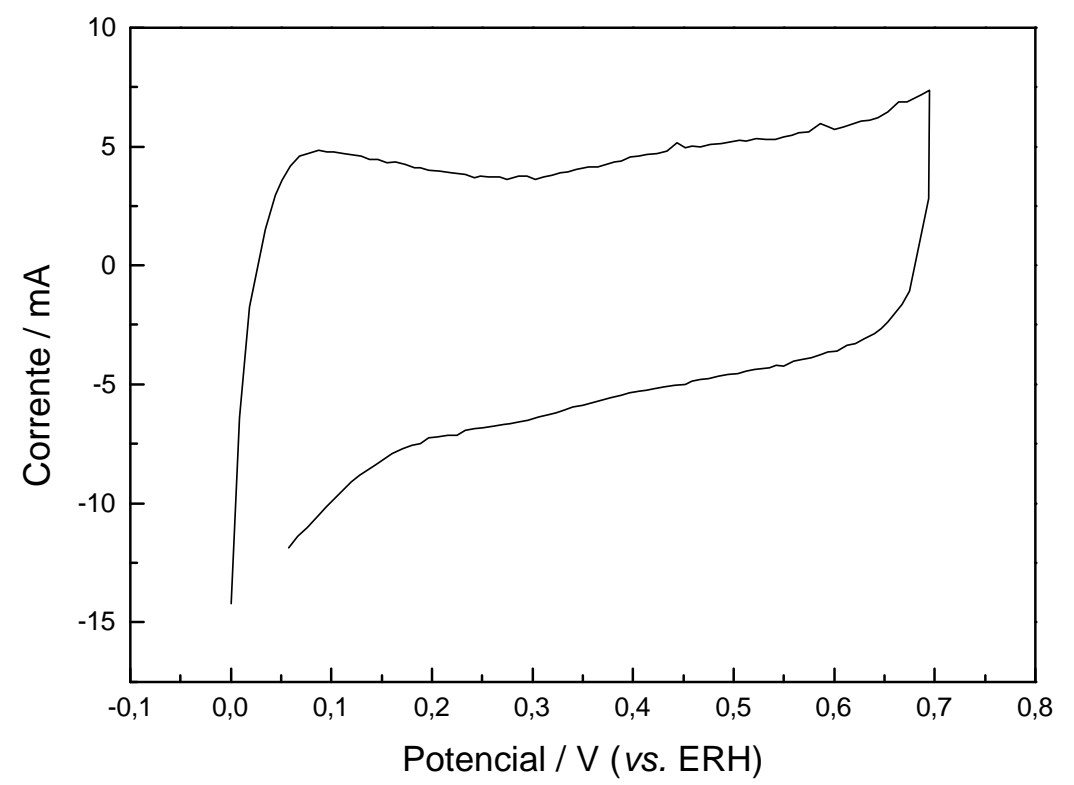

FIGURA 38 - Voltamograma cíclico de politiofeno contendo platina em solução de $\mathrm{H}_{2} \mathrm{SO}_{4}$ 12,5 M, 65 ciclos de crescimento de politiofeno sobre eletrodo de C vítreo. Velocidade de varredura: $75 \mathrm{mV} \mathrm{s}^{-1}, 40$ ciclos de incorporação de platina.

Para os filmes de PT contendo partículas eletrocatalisadoras de Pt, duas técnicas auxiliares foram utilizadas para confirmar a presença dessas partículas na matriz polimérica: MEV e EDX. As Figuras 39a e 39b apresentam os resultados que confirmam a presença do catalisador sobre o eletrodo. Além disso, a olho nu o eletrodo passou a apresentar coloração cinza ao invés de verde, que é a coloração 
típica do polímero a circuito aberto. Nota-se na Figura 39a que o catalisador apresenta-se na forma de partículas esféricas ou de aglomerados de partículas com diâmetros da ordem de 200 - 400 nm. Já na Figura 39b, nota-se que, embora haja certa superposição dos picos de EDX da Pt e do S, a presença das partículas de Pt é confirmada pelos picos em aproximadamente 9,4 e 11,1 keV.

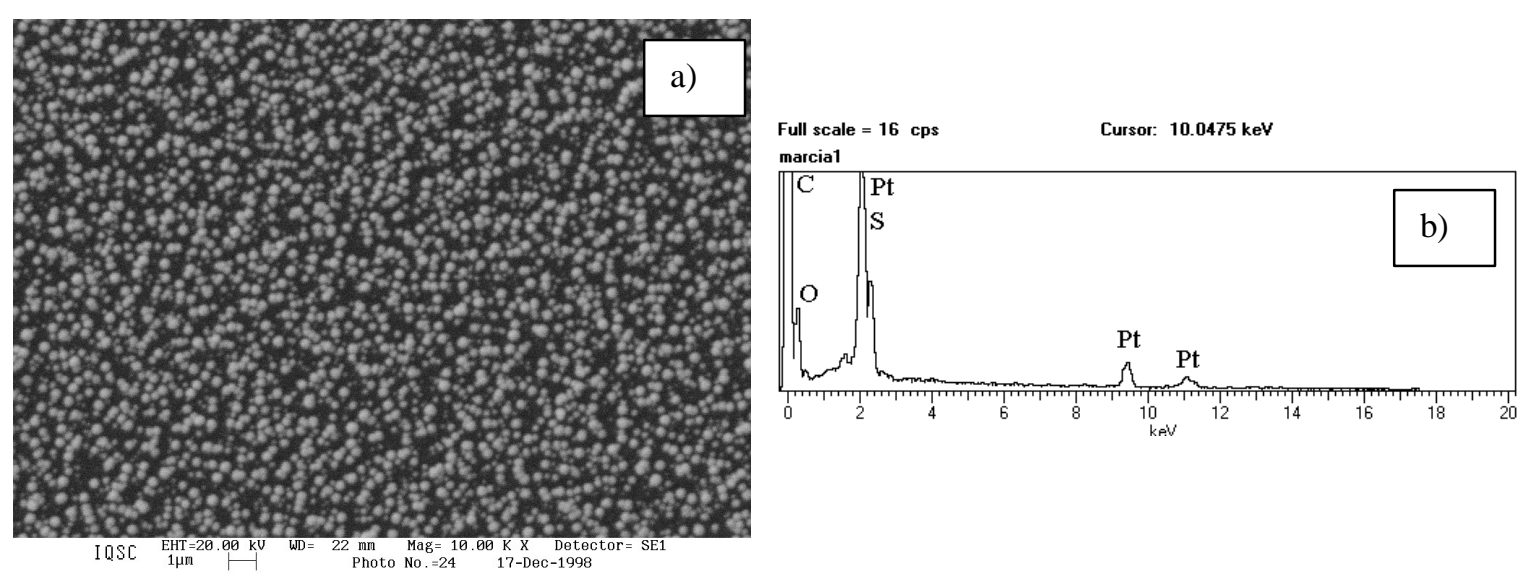

FIGURA 39 - Filme de PT sintetizado em $\mathrm{H}_{2} \mathrm{SO}_{4} 12,5 \mathrm{M}, 3{ }^{\circ} \mathrm{C}, 1000 \mathrm{rpm}, \mathrm{v}=75 \mathrm{mV} \mathrm{s}{ }^{-1}$ por 65 ciclos sobre eletrodo de carbono vítreo, com posterior incorporação de partículas de Pt através de ciclização do eletrodo em $\mathrm{H}_{2} \mathrm{PtCl}_{6}$ por 20 ciclos: a) MEV.Aumento de 10000 vezes; b) EDX.

Foram também realizados experimentos com Luz Síncrotron com os filmes poliméricos modificados por partículas catalisadoras. Para tanto, foram crescidos filmes de politiofeno com 65 ciclos em tecido de carbono e foram incorporadas partículas de $\mathrm{Pd}$ e Pt, conforme procedimentos descritos previamente. As medidas foram realizadas in situ em solução 2,0 M de ácido sulfúrico, em quatro diferentes potenciais de polarização, 0,$05 ; 0,2 ; 0,5$ e $0,84 \mathrm{~V}$. Os espectros XANES e os sinais EXAFS foram extraídos dos espectros de absorção de raios $\mathrm{X}$ experimentais utilizando-se o procedimento descrito em detalhes na Seção Experimental. 
Na Figura 40 estão apresentados os espectros XANES obtidos no modo de transmissão na borda $\mathrm{K}$ do $\mathrm{Pd}\left(\mathrm{E}_{0}=24350 \mathrm{eV}\right)$ depositado sobre o PT com 60 s de eletrorredução. Para fins comparativos, inclui-se nesta Figura o correspondente resultado obtido para o Pd em uma folha metálica. A absorção de raios X na borda K do Pd é devida a promoção de elétrons do nível energético 1s para níveis eletrônicos desocupados com energia próxima a do nível de Fermi, no caso, $1 \mathrm{~s} \rightarrow 5 \mathrm{p}$, que resulta no degrau de absorção característico do espectro XANES [82,83].

Em termos gerais, diferenças nos espectros de XANES nas regiões próximas a borda $( \pm 20 \mathrm{eV})$ podem ser associadas a diferenças na estrutura (energia) e ocupação dos orbitais eletrônicos do elemento absorvente, bem como a mudanças na sua simetria de coordenação. Por exemplo, um óxido de um metal de transição apresenta uma estrutura cristalina diferente do correspondente metal puro, o que pode levar ao favorecimento ou impedimento de algumas transições eletrônicas em comparação ao metal base, de forma que as características do espectro XANES de ambas as amostras podem se diferenciar. Neste mesmo exemplo, a mudança no estado de oxidação do elemento (como é o caso do óxido) leva a um esvaziamento dos orbitais d em comparação com o metal puro, sendo esta mudança observada através de um aumento na intensidade da correspondente banda de absorção.

Os resultados da Figura 40 mostram que há uma grande semelhança nos espectros XANES para a borda K do Pd na folha metálica e no material disperso em todos os potenciais eletródicos, particularmente na região de energias abaixo de 20 eV. Este fato é indicativo de que os átomos que compõem as partículas dispersas apresentam estrutura eletrônica similar à do Pd na folha metálica, confirmando tratarse de cristalitos com propriedades metálicas (não oxidados). Deve ser notado que esta conclusão também aplica-se para o potencial eletródico de $0,05 \mathrm{~V}$ em cujo caso 
as partículas de Pd estão preenchidas com hidrogênio atômico absorvido, conforme discutido anteriormente. No entanto, neste caso, observa-se um pequeno deslocamento na posição dos picos localizados acima de $20 \mathrm{eV}$, que correspondem ao início das oscilações EXAFS. Este fato, deve estar relacionado com alterações no ordenamento atômico introduzidas pelo hidrogênio absorvido, sendo isto discutido com mais detalhes mais adiante.

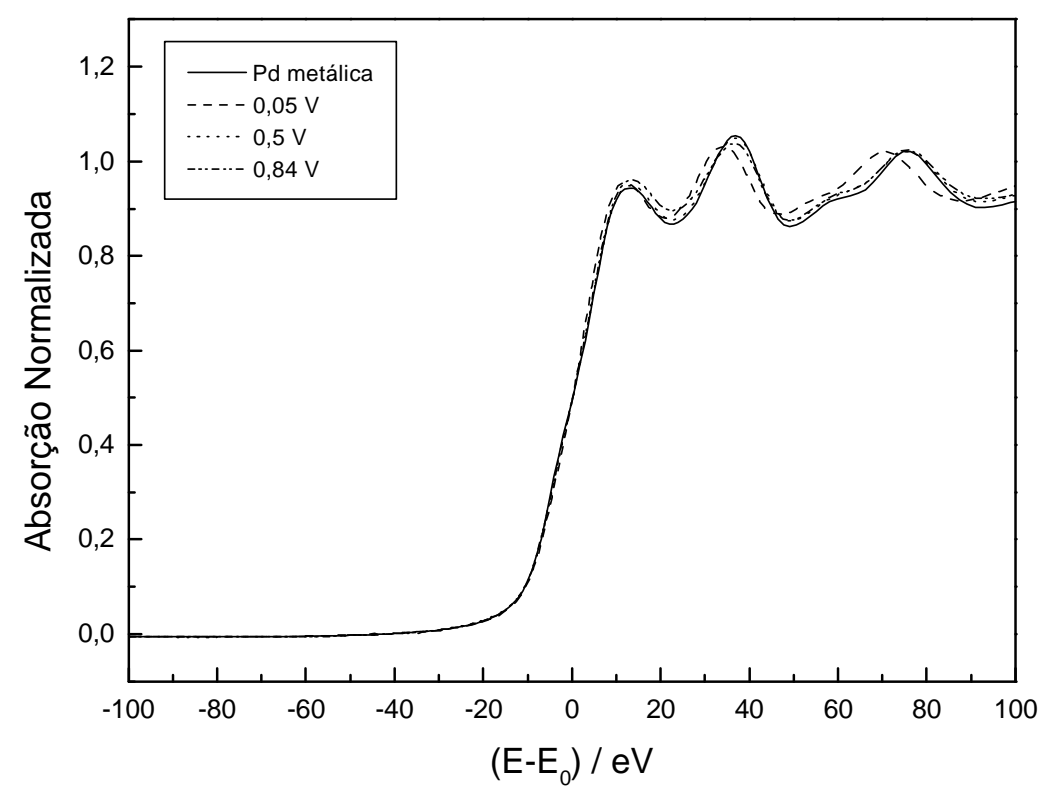

FIGURA 40 - Espectros de XANES do Pd incorporado no politiofeno sintetizado em $\mathrm{H}_{2} \mathrm{SO}_{4}$ 12,5 M e com 60 s de eletrorredução, em solução de ácido sulfúrico 2,0 M à temperatura ambiente e polarizado em 0,05; 0,5 e 0,84 V (vs. ERH) sobre eletrodo de tecido de carbono.

E do paládio metálico utilizado como referência em condições ex situ.

Na Figura 41 estão apresentados os gráficos de XANES obtidos no modo de fluorescência para a borda $\mathrm{L}_{\mathrm{III}}$ da Pt incorporada no politiofeno sintetizado em $\mathrm{H}_{2} \mathrm{SO}_{4}$ 12,5 M por 40 ciclos de eletrorredução em sua cadeia polimérica. A absorção de raios $\mathrm{X}$ na borda $\mathrm{L}_{\mathrm{III}}$ corresponde a transições dos elétrons de subníveis $3 \mathrm{p}$ para subníveis 4d vazios [60]. Observa-se que as diferenças entre os espectros obtidos nos 
diferentes potenciais são muito pequenas e que as características são muito semelhantes ao da platina metálica. Isto indica que as partículas incorporadas no polímero estão preponderantemente na forma metálica, com os átomos apresentando o mesmo ordenamento atômico (cfc) que na folha metálica.

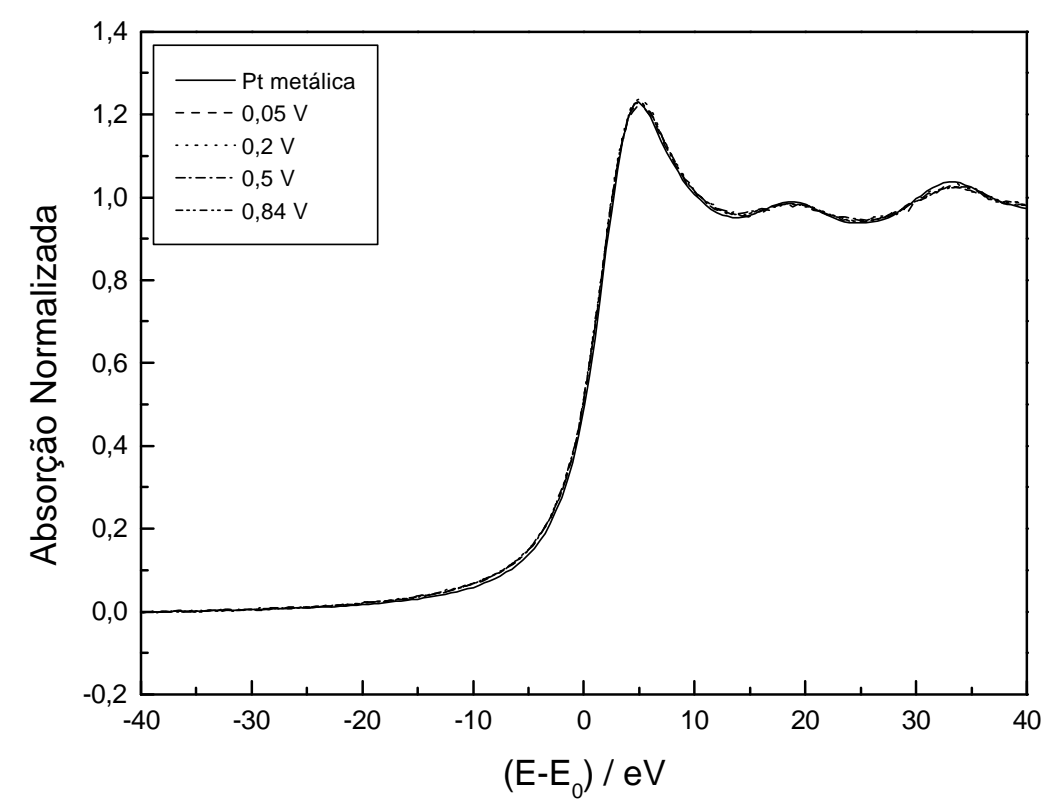

FIGURA 41 - Espectros de XANES da Pt incorporada no politiofeno sintetizado em $\mathrm{H}_{2} \mathrm{SO}_{4}$

$12,5 \mathrm{M}$ e com 40 ciclos de eletrorredução, em solução de ácido sulfúrico 2,0 M à temperatura ambiente e quatro potenciais de polarização $(0,05 ; 0,2 ; 0,5$ e $0,84 \mathrm{~V} v s$. ERH) sobre eletrodo de tecido de carbono. E da platina metálica utilizada como referência em condições ex situ.

Informações adicionais sobre a estrutura e propriedades das partículas incorporadas nos filmes de politiofeno foram obtidas a partir das análises dos sinais EXAFS das diversas amostras. Exemplos dos dados EXAFS obtidos experimentalmente são apresentados na Figura 42. Os sinais EXAFS contêm contribuições de várias esferas de coordenação, de forma que sua análise direta é extremamente complexa. Este problema é minimizado fazendo-se a Transformada de 
Fourier do mesmo, no sentido de separar as contribuições das esferas individuais, conforme já mencionado anteriormente (Seção Experimental).

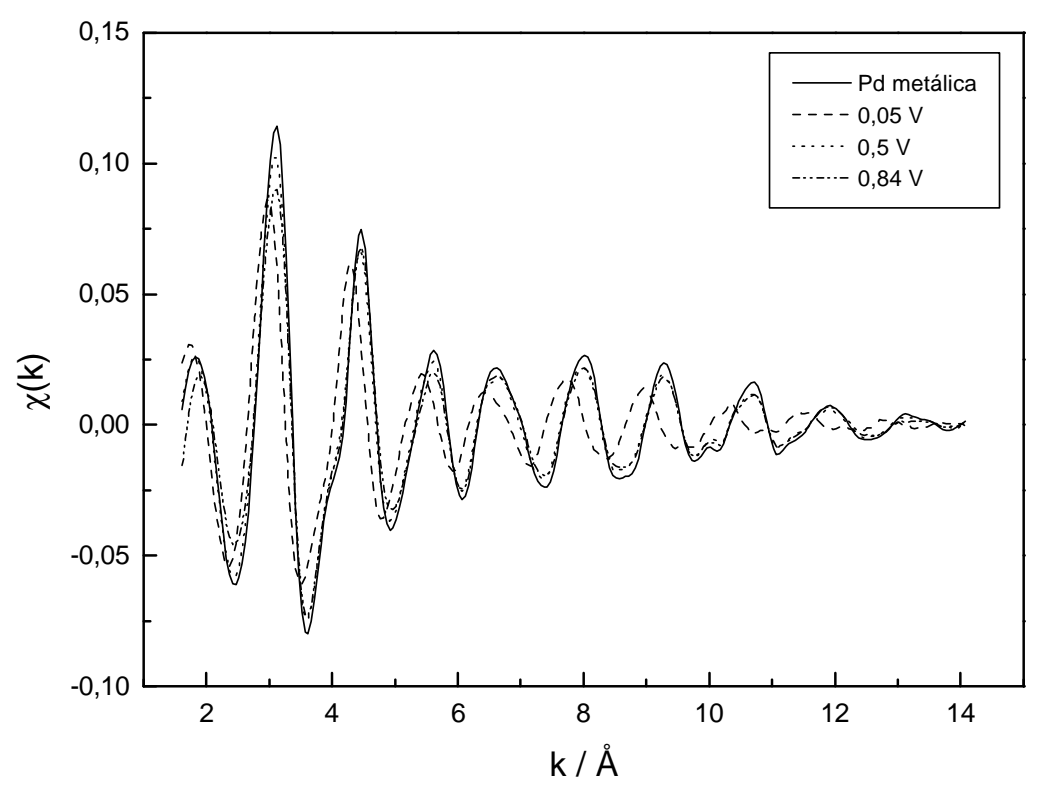

FIGURA 42 - Gráficos de sinais de EXAFS do Pd incorporado no PT sintetizado em $\mathrm{H}_{2} \mathrm{SO}_{4}$ 12,5 M e com 60 s de eletrodeposição e do Pd metálico utilizado como referência em condições ex situ.

Os gráficos da Transformada de Fourier (TF) do sinal EXAFS das amostras contendo Pd são apresentados na Figura 43. Os diferentes picos contidos na TF representam as contribuições das esferas individuais que se localizam em diferentes coordenadas. A magnitude de cada pico é dependente do número de coordenação e do grau de ordenamento dos arranjos atômicos. Por outro lado, os valores das coordenadas relacionam-se com as distâncias das diferentes esferas de coordenação em relação ao átomo central e a uma mudança de fase que pode ser introduzida por diferenças nas energias da borda de absorção do átomo nas diferentes amostras. Comparando-se os resultados da Figura 43, observa-se que a magnitude dos picos que aparecem em $\sim 2,6 \AA$ para o paládio nos potenciais de 0,5 e $0,84 \mathrm{~V}$ possuem 
magnitudes próximas, porém menores que a do $\mathrm{Pd}$ na folha metálica. Isto indica que os números de coordenação dos átomos de Pd nas partículas apresentam-se menores que no paládio metálico, o que pode ser devido ao fato de que as partículas depositadas são bastante pequenas. Observa-se também que estes picos apresentamse aproximadamente na mesma posição de coordenadas radiais que na folha metálica, indicando que o paládio incorporado apresenta-se com a mesma estrutura cristalina. No potencial de $0,05 \mathrm{~V}$ há um decréscimo na magnitude dos picos e um deslocamento para maiores valores de coordenada radial em relação aos demais resultados. Estes fenômenos são consistentes com um aumento nas distâncias da ligação Pd-Pd, que certamente decorre da presença dos átomos de hidrogênio contidos no interior do retículo cristalino.

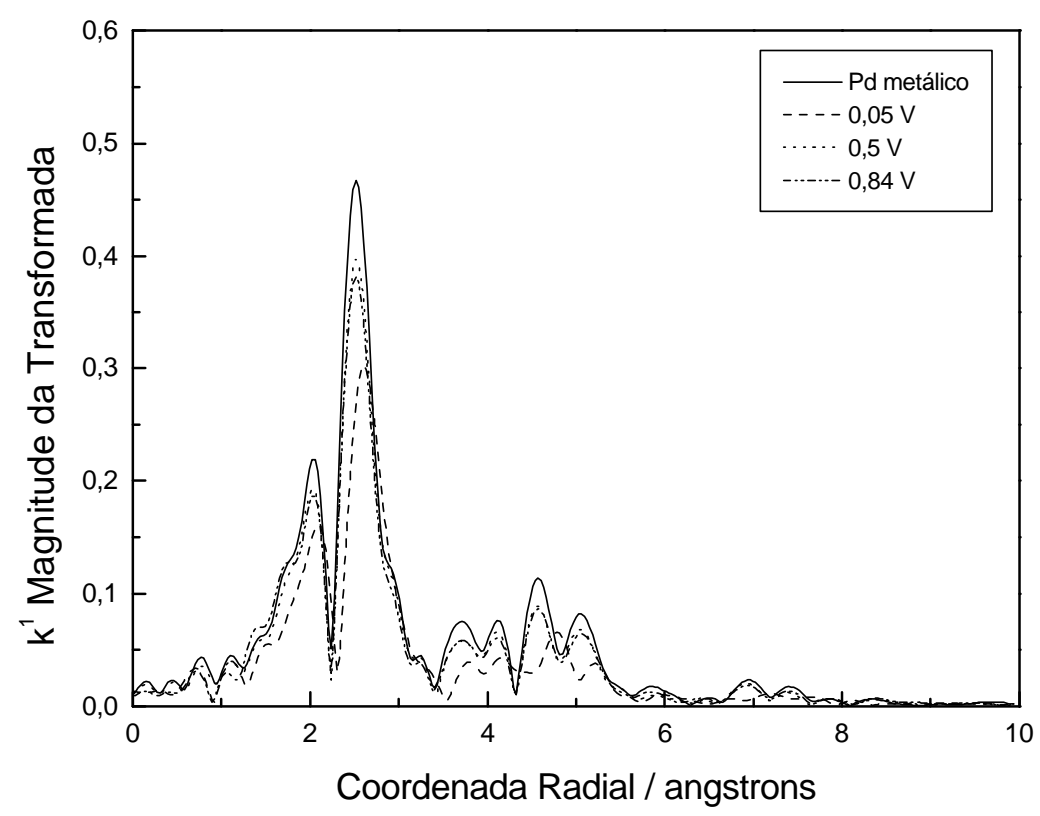

FIGURA 43 - Gráficos de Transformada de Fourier do Pd incorporado no PT sintetizado em $\mathrm{H}_{2} \mathrm{SO}_{4} 12,5 \mathrm{M}$ e com $60 \mathrm{~s}$ de eletrodeposição, em $\mathrm{H}_{2} \mathrm{SO}_{4}$ 2,0 M à temperatura ambiente e 3 potenciais de polarização $(0,05 ; 0,5$ e $0,84 \mathrm{~V} v s$. ERH) e do Pd metálico utilizado como referência em condições ex situ. k peso $1, \Delta \mathrm{k}=2,70-13,00 \AA^{-1}$. 
Os gráficos de Transformada de Fourier do sinal EXAFS do filme contendo partículas de platina em vários potenciais eletródicos são mostrados na Figura 44. Nota-se que, ao contrário da observação feita em outros trabalhos da literatura com Pt dispersa em carbono [32], poucas diferenças na magnitude da Transformada são encontradas para a $\mathrm{Pt}$ dispersa no filme polimérico nos diferentes potenciais aplicados. Comparando-se os picos desse gráfico, observa-se que a magnitude dos picos que aparecem em $\sim 3 \AA$ para a platina dispersa são próximas umas das outras, porém bastante menores que a da Pt metálica. Isto indica que as partículas devem ser bastante pequenas, o que será discutido mais adiante. Outra observação que pode ser feita é que estes mesmos picos, encontram-se na mesma posição de coordenadas radiais que o da platina na folha metálica, confirmando que os átomos na platina dispersa estão arranjados com a mesma estrutura que na folha metálica.

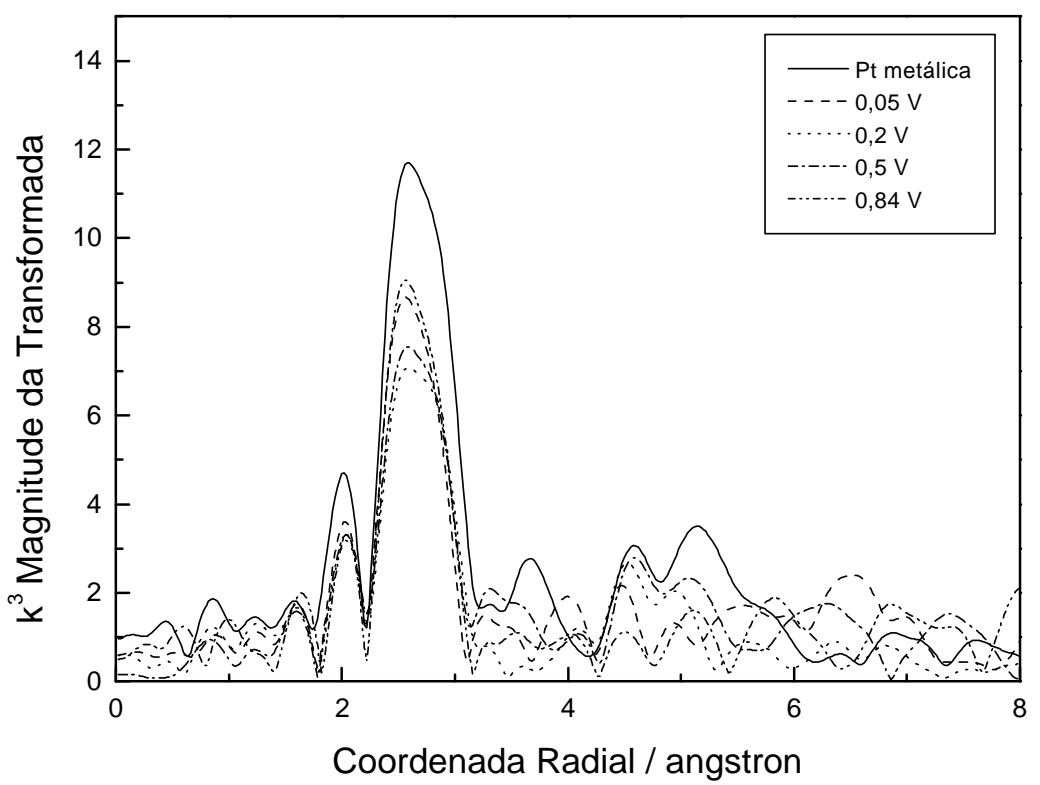

FIGURA 44 - Gráficos de Transformada de Fourier da Pt incorporada no PT sintetizado em $\mathrm{H}_{2} \mathrm{SO}_{4} 12,5 \mathrm{M}$ e com 40 ciclos de eletrorredução, em $\mathrm{H}_{2} \mathrm{SO}_{4}$ 2,0 M à temperatura ambiente e 4 potenciais de polarização $(0,05 ; 0,2 ; 0,5$ e $0,84 \mathrm{~V} v s$. ERH). E da Pt metálica utilizada como referência em condições ex situ. $\mathrm{K}$ peso $3, \Delta \mathrm{k}=2,70-12,5 \AA^{-1}$. 
A obtenção dos parâmetros relativos ao arranjo das partículas metálicas dispersas no filme polimérico foi feita através da geração do sinal EXAFS da primeira esfera de coordenação, o que foi realizado fazendo-se a transformada inversa dos dados das Figuras 42 e 43 nos correspondentes intervalos de coordenada radial. Os números de coordenação $(\mathrm{N})$, as distâncias inter-atômicas $(\mathrm{R})$, o efeito de Debye-Waller $(\Delta \sigma)$ e os deslocamentos da energia de borda $\left(\Delta \mathrm{E}_{0}\right)$ foram obtidos por ajustes dos dados das transformadas inversas obtidas para as amostras e os correspondentes resultados para as folhas metálicas usados como padrões. Para estes ajustes foram usados os valores de $\mathrm{N}=12$ para os padrões de $\mathrm{Pd}$ e Pt (característicos das estruturas cfc de Pd e Pt metálicos), sendo $\mathrm{R}=2,74 \AA$ e $\mathrm{R}=2,76 \AA$, respectivamente [84]. A Tabela 2 mostra esses resultados:

TABELA 2 - Parâmetros obtidos através da geração do sinal EXAFS. $\Delta r=1,40-3,20 \AA$ e 1,85-3,10 A para Pd e Pt, respectivamente.

\begin{tabular}{|c|c|c|c|c|}
\hline & $\mathrm{P}(\mathrm{V})$ & $\mathrm{N}$ & $\Delta \sigma()$ & $\mathrm{R}(\mathrm{)}$ \\
\hline \multirow{3}{*}{$\mathrm{Pd}$} & 0,05 & 12,2 & $8,6 \times 10^{-3}$ & 2,82 \\
\hline & 0,5 & 11,5 & $6,1 \times 10^{-3}$ & 2,74 \\
\hline & 0,84 & 10,8 & $5,9 \times 10^{-3}$ & 2,74 \\
\hline \multirow{4}{*}{$\mathrm{Pt}$} & 0,05 & 10,6 & $5,4 \times 10^{-3}$ & 2,75 \\
\hline & 0,2 & 9,5 & $5,8 \times 10^{-3}$ & 2,76 \\
\hline & 0,5 & 9,0 & $5,9 \times 10^{-3}$ & 2,75 \\
\hline & 0,84 & 9,7 & $5,4 \times 10^{-3}$ & 2,75 \\
\hline
\end{tabular}

Tanto no caso do $\mathrm{Pd}$ como da $\mathrm{Pt}$ os valores de $\Delta \mathrm{E}_{0}$ resultaram bastante pequenos, o que indica que as energias da borda de absorção dos átomos são 
próximas para as amostras dispersas e os padrões metálicos, fato que está em concordância com os resultados XANES.

Os números de coordenação encontrados para os átomos de Pd nas partículas dispersas resultaram em valores de aproximadamente 12,$2 ; 11,5$ e 10,8 para os potenciais de 0,$05 ; 0,5$ e $0,84 \mathrm{~V}$, respectivamente. O termo de Debye-Waller apresenta aumento de valor em potencial de $0,05 \mathrm{~V}\left(8,6 \times 10^{-3} \AA^{2}\right)$ em relação aos demais resultados (aproximadamente $5 \times 10^{-3} \AA^{2}$ ). Este termo, que representa o fator de desordem do arranjo atômico, indica que pode estar havendo uma desordem estrutural das celas cristalinas do Pd decorrente da presença de hidrogênio absorvido.

As distâncias interatômicas mostraram que há um aumento bastante pronunciado nas mesmas em potencial de $0,05 \mathrm{~V}(2,74 \AA$ na folha de Pd e $2,82 \AA$ para Pd disperso). Esta diferença diminui com ao aumento do potencial e, em 0,84 V, os valores são os mesmos que os encontrados para a folha de Pd. Esta diferença nas distâncias interatômicas indica que a mesma é também decorrente da presença de hidrogênio no metal (Pd-H), em cujo caso a expansão do volume da célula unitária é confirmada através de medidas de difração de raios X $[82,85]$.

Os números de coordenação obtidos para a Pt dispersa nos vários potenciais estudados $\sim 10,63 ; 9,53 ; 9,04$ e 9,67 para os potenciais 0,$05 ; 0,2 ; 0,5$ e $0,84 \mathrm{~V}$, respectivamente. Por causa da grande fração de átomos localizados na superfície das partículas nanométricas, o número de coordenação Pt-Pt é menor que o valor normal de 12 para a estrutura cfc em uma folha metálica. Benfield [86] desenvolveu algorítmos para calcular os números médios de coordenação como uma função do tamanho das partículas para as estruturas cubo-octahédrica e icosahédrica. O gráfico da Figura 45 mostra esses cálculos. Com os números de coordenação obtidos, verifica-se que o tamanho das partículas de Pt depositadas foi de 30-40 A para o 
potencial de $0,05 \mathrm{~V}$ e $18-22 \AA$ para os demais potenciais. A explicação para esta surpreendente observação é de uma possível mudança de morfologia das partículas na região de oxidação/redução de hidrogênio onde as mesmas podem estar mais esféricas, enquanto que nos outros potenciais, podem se encontrar em configuração mais "achatada" e, por isso, com tamanhos aparentemente menores.

As análises de MEV mostraram que a Pt é depositada na forma de aglomerados com diâmetro da ordem de 0,2 $\mu \mathrm{m}$. A análise dos resultados de EXAFS indicou que estes aglomerados consistem de pequenas partículas, com tamanho médio similar ao encontrado para partículas dispersas em carbono, para o qual o diâmetro médio é de cerca de 3-4 nm [32]. Estas observações são consistentes com trabalhos anteriores em eletrodos poliméricos modificados [86]. Portanto, a nãovariação dos espectros de XANES da Pt com o potencial não podem ser atribuída ao fato de que as partículas são grandes, o que indica que a matriz polimérica pode estar afetando as propriedades eletrônicas da $\mathrm{Pt}$, dificultando a formação de óxidos superficiais.

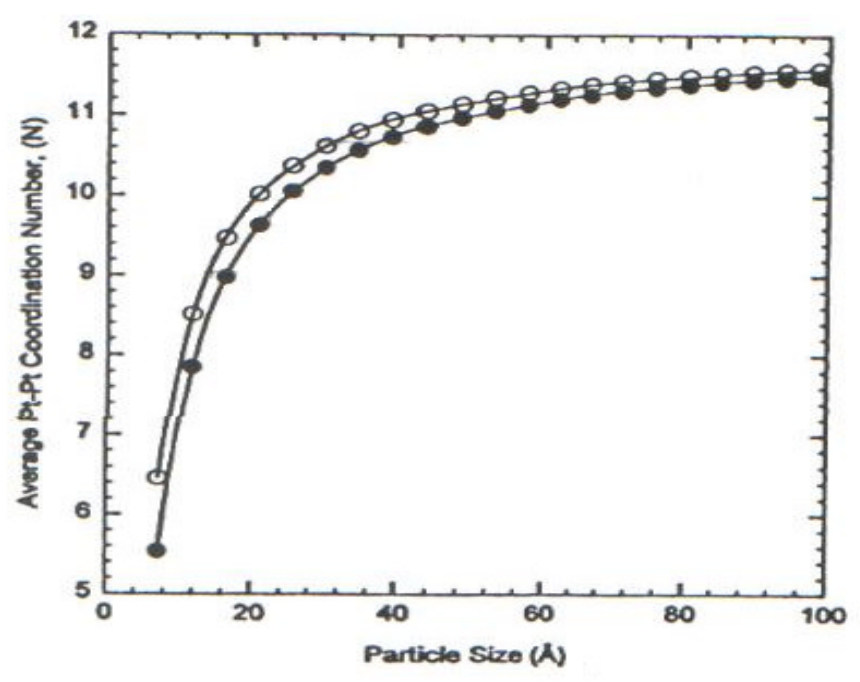

FIGURA 45 - Números de coordenação Pt-Pt médios como um função do tamanho das partículas para estruturas icosahédricas $(\bullet)$ e cubo-octahédricas $(O)$. 


\section{3. 2. Reação de Oxidação de Hidrogênio}

Foram realizados estudos da Reação de Oxidação de Hidrogênio (ROH) nos polímeros contendo partículas dispersas de platina e paládio sintetizados em meio aquoso. Para a prata não foi possível a realização destes experimentos pelas razões apresentadas anteriormente, ou seja, em meio ácido as partículas de prata não resultaram estáveis. O substrato utilizado para estes experimentos foi o de carbono vítreo e o número de ciclos de crescimento do polímero, o número de ciclos de incorporação de platina e o tempo de polarização do eletrodo para incorporação de paládio foram variados para que se encontrassem melhores condições para promover a reação.

A reação de oxidação de hidrogênio foi estudada em 900, 1600, 2500 e 3600 rpm para todos os sistemas estudados, sendo o intervalo de potenciais utilizado de $0,0 \mathrm{~V}$ até $0,5 \mathrm{~V}$ (vs. ERH). A velocidade de varredura foi de $5 \mathrm{mV} \mathrm{s}^{-1}$ e antes de ser iniciada a reação, borbulhava-se hidrogênio por aproximadamente 40 minutos na solução para que esta estivesse saturada de hidrogênio.

A Figura 46 apresenta as curvas de polarização frente à ROH para o eletrodo de politiofeno na ausência de partículas catalisadoras e contendo platina. Observa-se que o filme polimérico não apresenta atividade para a oxidação de hidrogênio e a pequena corrente anódica observada deve-se ao processo de oxidação da própria cadeia polimérica. O filme contendo partículas de Pt apresentou alguma atividade, porém nota-se que com o aumento da velocidade de rotação, há diminuição dessa atividade, o que pode ser observado pela diminuição progressiva de corrente no início das curvas de polarização e pela diminuição do valor da corrente. Na Figura 47 são apresentadas curvas de polarização frente à $\mathrm{ROH}$ para o eletrodo de politiofeno 
contendo partículas de paládio. Neste caso, o filme também apresentou pequena atividade para a reação e nota-se que com o aumento da velocidade de rotação, assim como para o filme contendo platina, há diminuição dessa atividade.

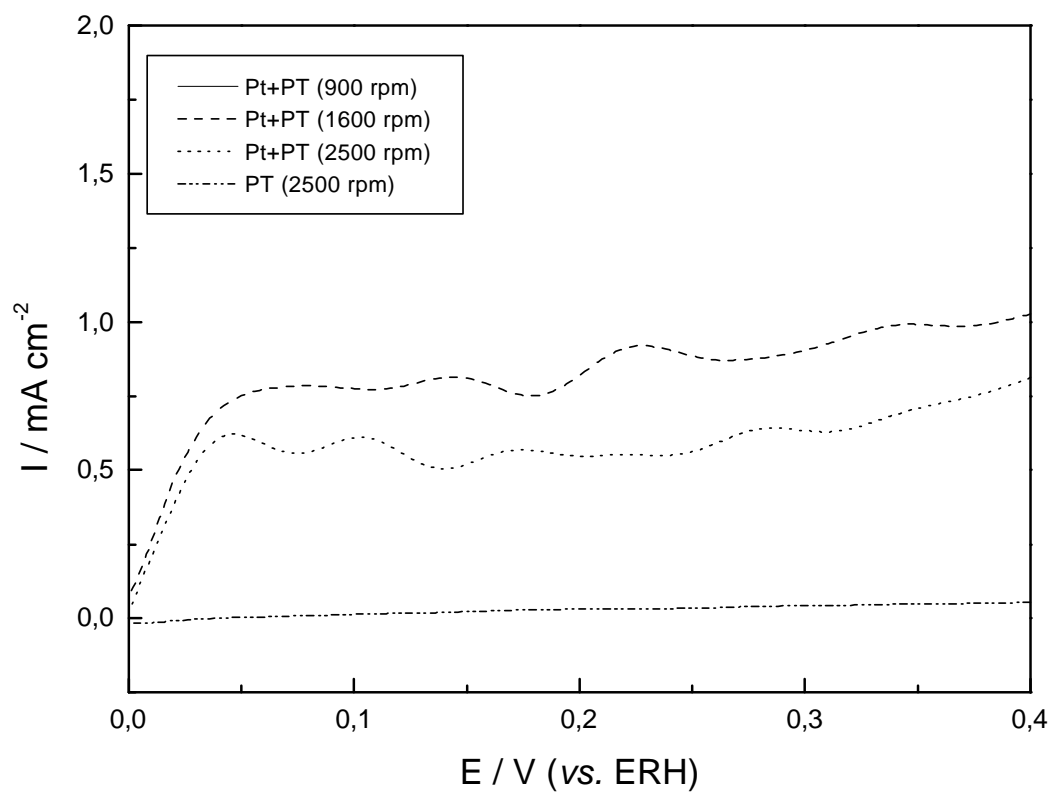

FIGURA 46 - Curvas potenciodinâmicas da ROH em politiofeno crescido por 35 ciclos, sem presença de catalisadores e com 80 ciclos de incorporação de $\mathrm{Pt}$, em solução de $\mathrm{H}_{2} \mathrm{SO}_{4} 2,0 \mathrm{M}$ e velocidade de varredura de $5 \mathrm{mV} \mathrm{s}^{-1}$.

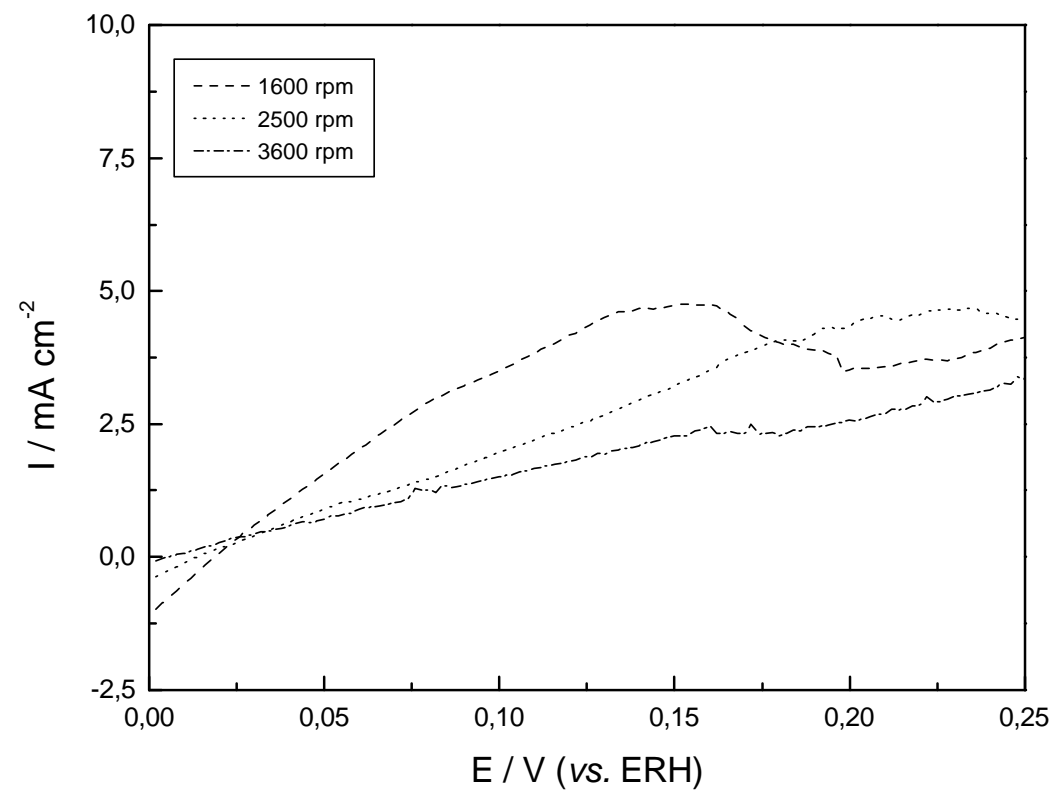

FIGURA 47 - Curvas potenciodinâmicas da ROH em PT crescido por 35 ciclos, com $60 \mathrm{~s}$ de incorporação de $\mathrm{Pd}$, em solução de $\mathrm{H}_{2} \mathrm{SO}_{4} 2,0 \mathrm{M}$ e velocidade de varredura de $5 \mathrm{mV} \mathrm{s}^{-1}$. 
A diminuição da atividade frente a $\mathrm{ROH}$ nos dois casos pode ser explicada por uma diminuição da atividade eletroquímica do polímero. Tomando o caso da platina, é sabido que a oxidação do hidrogênio em meio ácido ocorre através do mecanismo Tafel/Volmer [44,45]:

$$
\begin{gathered}
\mathrm{H}_{2}+2 \mathrm{Pt} \rightleftharpoons 2 \mathrm{Pt}-\mathrm{H} \quad(\text { Tafel }) \\
\mathrm{Pt}-\mathrm{H} \rightarrow \mathrm{Pt}+\mathrm{H}^{+}+\mathrm{e} \quad \text { (Volmer) }
\end{gathered}
$$

Sendo estes processos bastante rápidos no domínio de potenciais abrangidos nos experimentos aqui realizados. Conforme mencionado na Seção 3.1.7, neste domínio, o polímero sofre um processo de oxidação, primeiramente formando polarons:

$$
\mathrm{PTH}^{+}\left(\mathrm{HSO}_{4}^{-}\right)_{\mathrm{n}} \rightleftharpoons\left(\mathrm{PT}^{\bullet+} \mathrm{HSO}_{4}^{-}\right)_{\mathrm{n}}+\mathrm{nH}^{+}+\mathrm{ne}
$$

que, com o aumento do potencial aplicado são levados à forma bipolarônica:

$$
\left(\mathrm{PT}^{\bullet+}\left(\mathrm{HSO}_{4}^{-}\right)\right)_{\mathrm{n}}+\mathrm{nHSO}_{4}^{-} \rightleftharpoons\left(\mathrm{PT}^{+2}\left(\mathrm{HSO}_{4}{ }^{-}\right)_{2}\right)_{\mathrm{n}}+\mathrm{ne}
$$

$\mathrm{ou}$

$$
\left(\mathrm{PT}^{\bullet+}\left(\mathrm{HSO}_{4}^{-}\right)\right)_{\mathrm{n}} \rightleftharpoons\left(\mathrm{PT}^{+2}\left(\mathrm{SO}_{4}^{-2}\right)\right)_{\mathrm{n}}+\mathrm{nH}^{+}+\mathrm{ne}
$$

Com base nestes processos, verifica-se que à medida em que se aplica potencial ao eletrodo, três processos podem ocorrer concomitantemente. Um deles é a adsorção das moléculas de hidrogênio sobre Pt que leva à formação de átomos adsorvidos; o outro é a oxidação do polímero que leva à formação de polarons; e o terceiro é a ionização dos átomos de hidrogênio adsorvido (Volmer). Os resultados do presente trabalho parecem indicar que um quarto processo ocorre em paralelo 
com os demais: trata-se da reação química de acoplamento do hidrogênio atômico adsorvido sobre Pt com o carbono radicalar das espécies polarônicas:

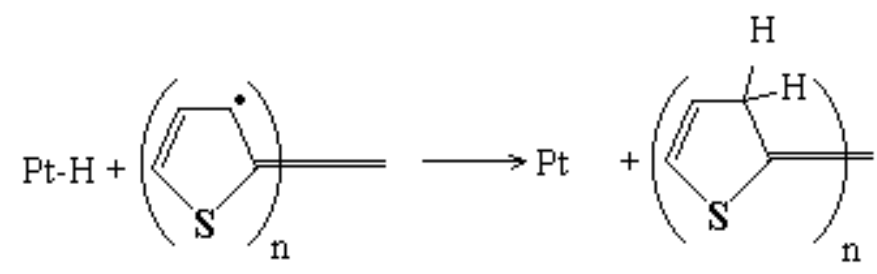

Este processo leva à interrupção da ressonância eletrônica e, portanto, à degradação das propriedades elétricas do polímero. No caso do $\mathrm{Pd}$, o mecanismo deve ser inteiramente similar, exceto pelo fato de que o fenômeno deve ser ainda mais acentuado devido à quantidade extra de hidrogênio atômico acumulado na forma de hidreto metálico. Esta conclusão se deve também ao fato de que foi observado experimentalmente que o filme de PT, quando ciclado em potenciais pouco menores que $0,0 \mathrm{~V}$ gerava uma alta densidade de carga negativa e se degradava quebrando-se e desprendendo-se do material eletródico.

\section{3. 3. Reação de Redução de Oxigênio}

Em todas as condições, a reação de redução de oxigênio (RRO) foi estudada em 900, 1600, 2500 e $3600 \mathrm{rpm}$, sendo o intervalo de potenciais utilizado de $0,9 \mathrm{~V}$ até $0,0 \mathrm{~V}(v s . \mathrm{ERH})$. A velocidade de varredura foi de $5 \mathrm{mV} \mathrm{s}^{-1}$ e antes de ser iniciada a reação, borbulhava-se oxigênio por aproximadamente 40 minutos na solução para que esta estivesse saturada com o gás.

Os resultados obtidos neste trabalho foram analisados através dos conceitos e equações clássicas desenvolvidas para o eletrodo de disco rotatório [87], assim como 
em outros trabalhos encontrados na literatura sobre RRO em eletrodos poliméricos modificados [35,37]. A partir dessas análises, é possível estabelecer o mecanismo da reação, e assim o número de elétrons (n) envolvidos na mesma.

A Figura 48 apresenta as curvas potenciodinâmicas da RRO em politiofeno sintetizado com 35 ciclos de crescimento, na ausência de platina e paládio e em solução de $\mathrm{H}_{2} \mathrm{SO}_{4}$ 2,0 M saturada por $\mathrm{O}_{2}$. Observa-se que praticamente nenhuma atividade é observada na ausência do catalisador pois as correntes catódicas para este material referem-se exclusivamente a oxidação do polímero, já que a resposta é a mesma na presença ou ausência de $\mathrm{O}_{2}$. Pode-se então dizer que politiofeno não é um polímero cataliticamente ativo para a reação de redução de oxigênio. Portanto, qualquer efeito diferenciado observado na presença do catalisador se deve à ação do mesmo frente à reação de interesse.

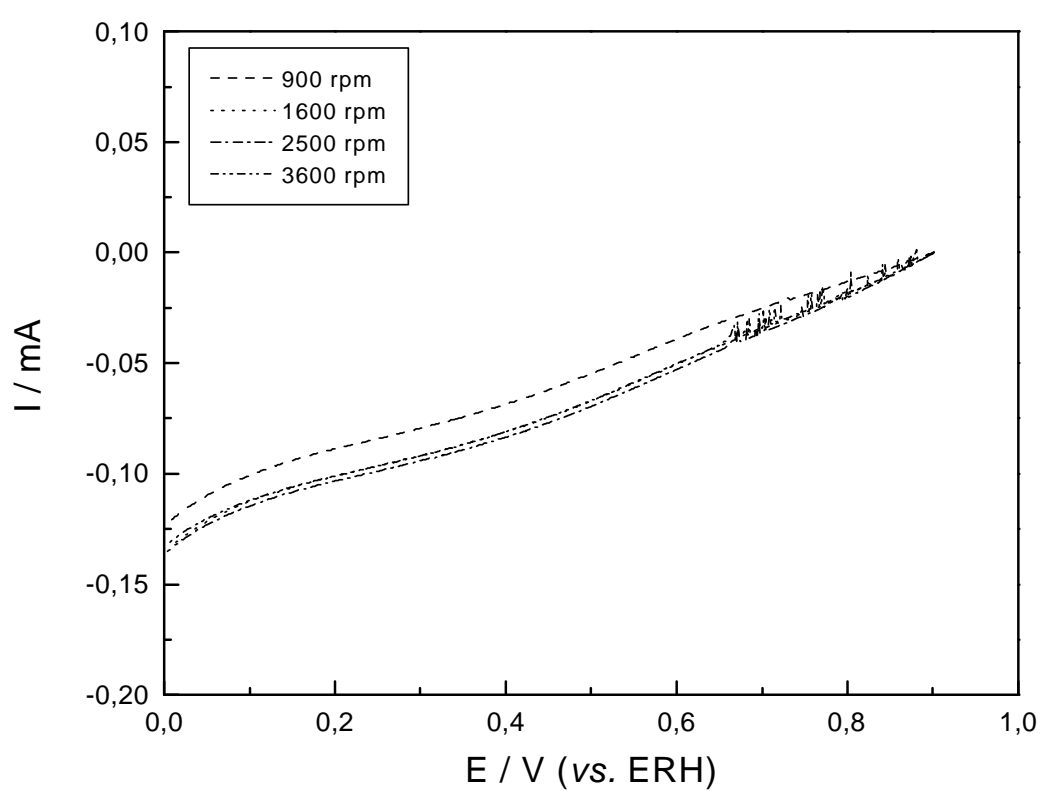

FIGURA 48 - Curvas potenciodinâmicas da RRO em politiofeno crescido por 35 ciclos em $\mathrm{H}_{2} \mathrm{SO}_{4} 12,5 \mathrm{M}$ em eletrodo de $\mathrm{C}$ vítreo, sem a presença de catalisador em solução de $\mathrm{H}_{2} \mathrm{SO}_{4}$ 2,0 M e velocidade de varredura de $5 \mathrm{mV} \mathrm{s}^{-1}$. 
A Figura 49 apresenta as curvas potenciodinâmicas da $\mathrm{RRO}$ em $\mathrm{H}_{2} \mathrm{SO}_{4} 2,0 \mathrm{M}$ em politiofeno crescido por 35 ciclos e contendo Pd eletrodepositado através de polarização por $60 \mathrm{~s}$ em potencial de $0,43 \mathrm{~V}$ em várias velocidades de rotação. $\mathrm{Na}$ Figura 50 são apresentadas as correspondentes curvas potenciodinâmicas da RRO para o eletrodo com 80 ciclos de incorporação de platina. Observa-se claramente a atividade desses materiais frente a RRO e que a corrente de limite difusional aumenta como função da rotação do eletrodo, embora isto seja menos evidente para o paládio.

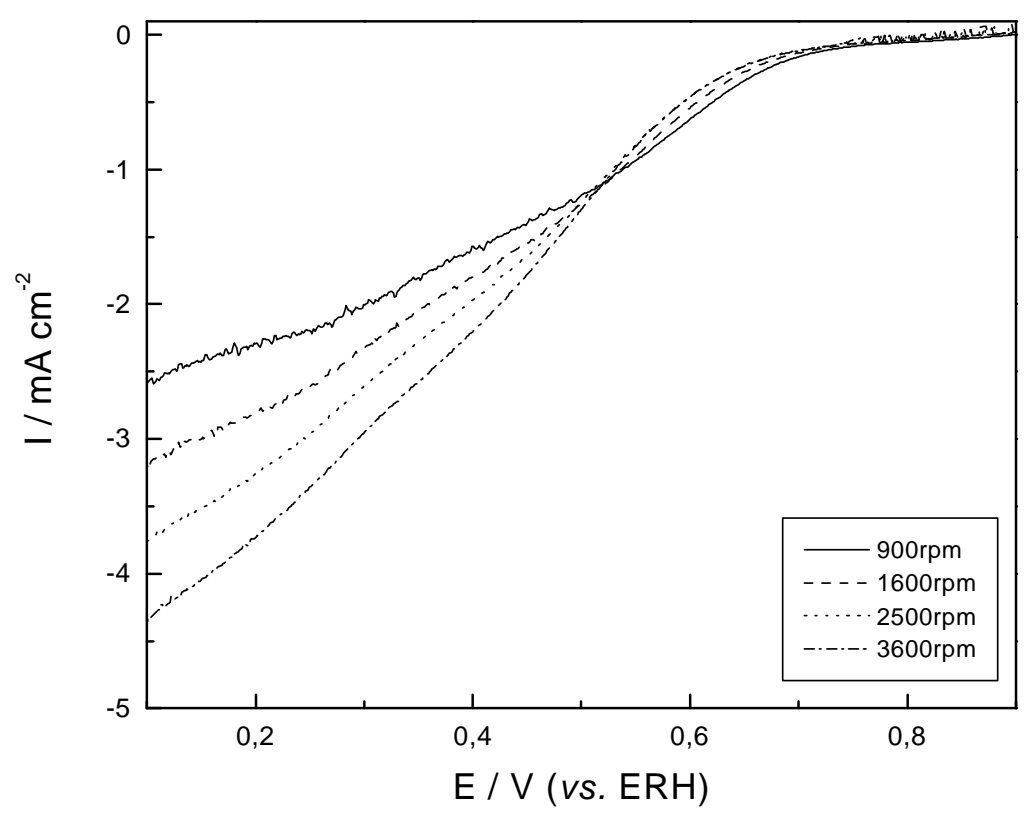

FIGURA 49 - Curvas potenciodinâmicas da RRO em PT crescido por 35 ciclos em $\mathrm{H}_{2} \mathrm{SO}_{4}$ 12,5 M em eletrodo de $\mathrm{C}$ vítreo, com $60 \mathrm{~s}$ de incorporação de $\mathrm{Pd}$, em solução de $\mathrm{H}_{2} \mathrm{SO}_{4}$ 2,0 $\mathrm{M}$ e velocidade de varredura de $5 \mathrm{mV} \mathrm{s}^{-1}$. 


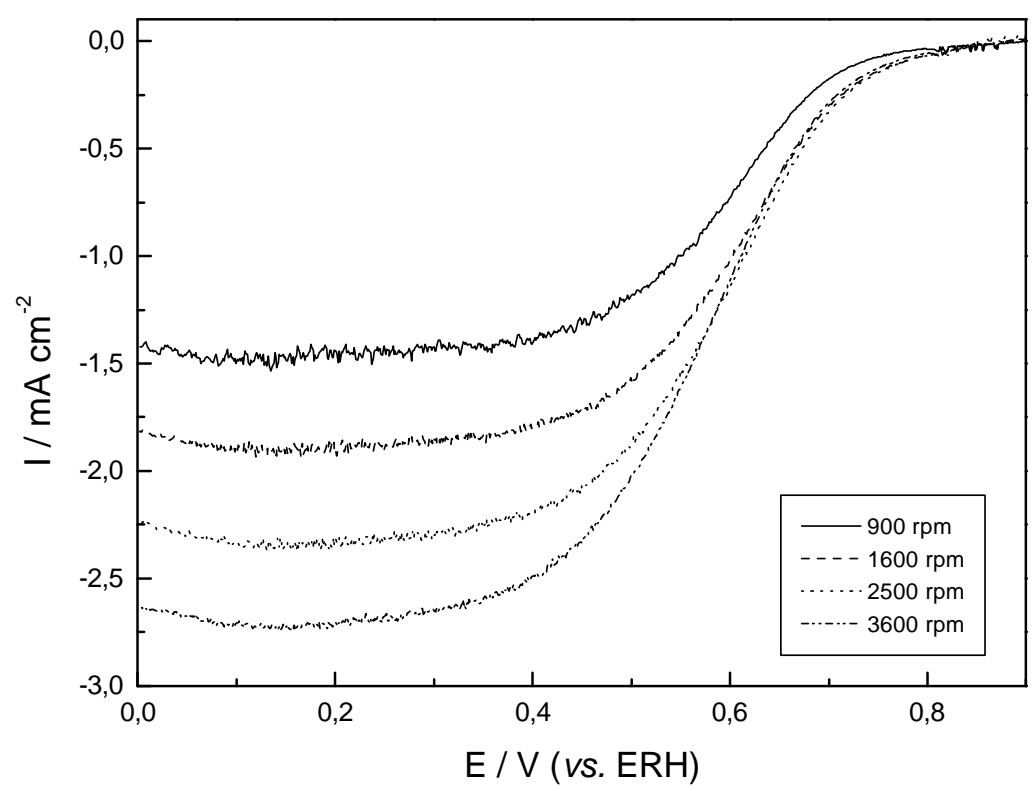

FIGURA 50 - Curvas potenciodinâmicas da RRO em PT crescido por 35 ciclos em $\mathrm{H}_{2} \mathrm{SO}_{4}$ 12,5 M em eletrodo de $\mathrm{C}$ vítreo, com 80 ciclos de incorporação de $\mathrm{Pt}$, em solução de $\mathrm{H}_{2} \mathrm{SO}_{4}$

$$
2,0 \mathrm{Me} \mathrm{v}=5 \mathrm{mV} \mathrm{s}^{-1} \text {. }
$$

Comparando-se os dois conjuntos de resultados, observa-se que no do eletrodo de Pt, há somente um patamar de corrente limite, enquanto no caso da Pd, existem dois pequenos patamares, um em aproximadamente $0,4 \mathrm{~V}$ e o outro em aproximadamente $0,2 \mathrm{~V}$. Também observa-se que as densidades de corrente finais envolvidas são maiores para os catalisadores de $\mathrm{Pd}$, porém as correntes de redução num mesmo intervalo de potenciais é menor que para a Pt.

A Figura 51 apresenta as curvas potenciodinâmicas da $\mathrm{RRO}$ em $\mathrm{H}_{2} \mathrm{SO}_{4} 2,0 \mathrm{M}$ em politiofeno crescido por 35 ciclos e contendo Pd eletrodepositado através de polarização por 60, 120 e $180 \mathrm{~s}$ em potencial de 0,43 V. Observa-se que, com o aumento da quantidade de partículas de Pd na matriz polimérica, a RRO inicia-se em potenciais cada vez menores. Isto indicaria uma surpreendente inibição do processo com o aumento do teor de Pd. No entanto, foi observado que com o aumento do tempo de deposição das partículas de Pd no filme, formavam-se pequenos acúmulos 


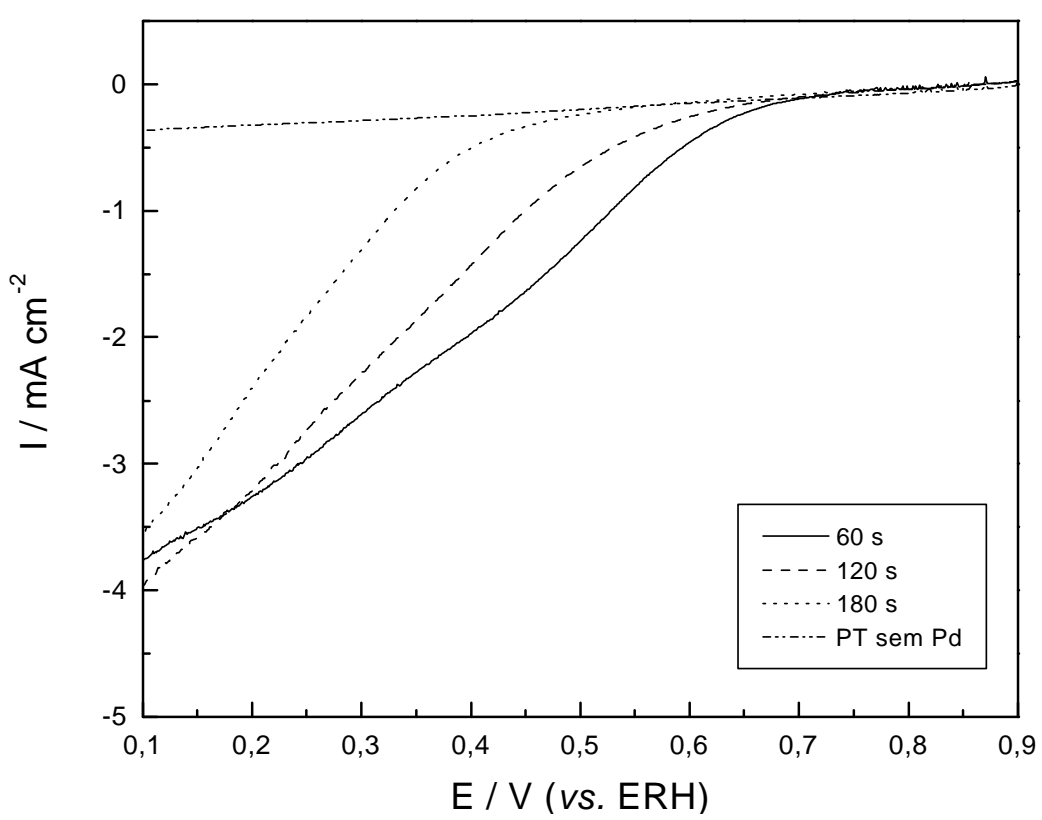

FIGURA 51 - Curvas potenciodinâmicas da RRO em PT crescido por 35 ciclos em $\mathrm{H}_{2} \mathrm{SO}_{4}$

12,5 M em eletrodo de C vítreo, com 60, 120 e 180 s de incorporação de Pd e de PT na ausência do catalisador, em $\mathrm{H}_{2} \mathrm{SO}_{4} 2,0 \mathrm{M} \mathrm{e} \mathrm{v}=5 \mathrm{mV} \mathrm{s}^{-1}$. $\mathrm{w}=2500 \mathrm{rpm}$.

do material que facilmente se desprendiam do eletrodo durante a lavagem com água. Isto indica que com o aumento de tempo de polarização, há na realidade uma diminuição da quantidade de partículas de Pd no eletrodo, o que explicaria a menor atividade catalítica do filme para maiores tempos de eletrodeposição.

As curvas potenciodinâmicas de redução de oxigênio em $\mathrm{H}_{2} \mathrm{SO}_{4}$ 2,0 $\mathrm{M}$ em politiofeno com diferentes números de ciclos de crescimento (15, 35 e 95, respectivamente) e com o mesmo número de ciclos de incorporação de platina, são apresentadas na Figura 52. Comparando-se as correntes limite, têm-se que as mesmas são similares nos filmes mais finos (15 e 35 ciclos), porém são menores para o filme mais espesso. Isto pode estar relacionado a uma diminuição do número de elétrons envolvidos na reação conforme será discutido mais adiante. 


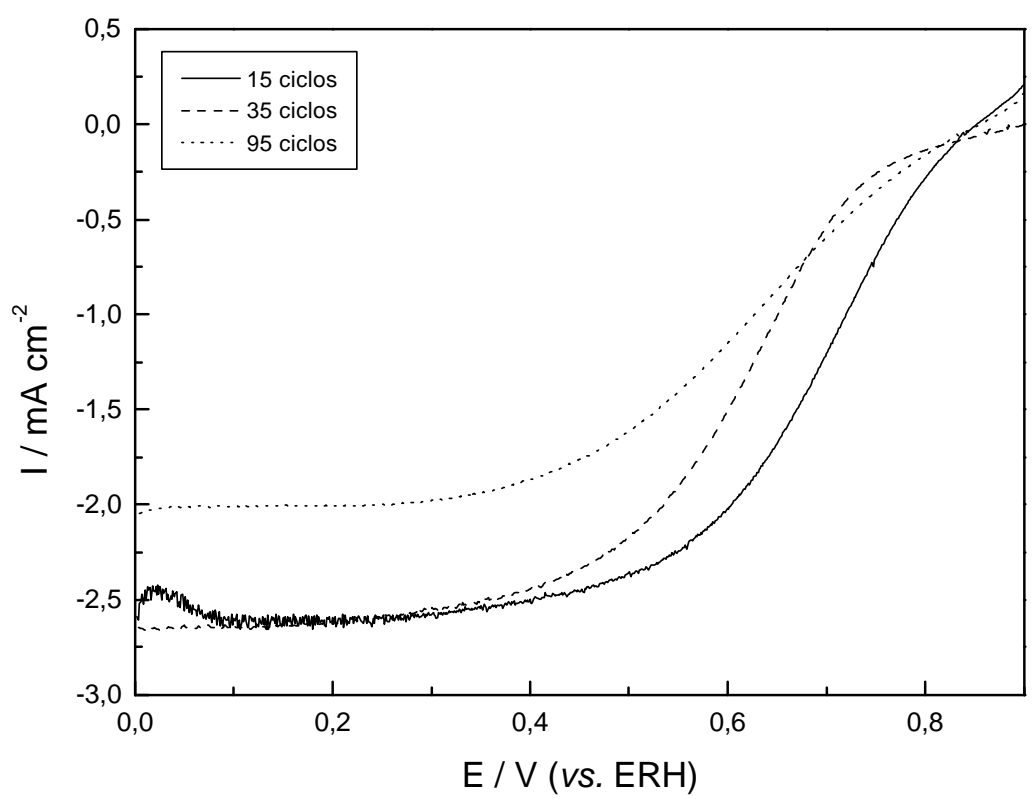

FIGURA 52 - Curvas potenciodinâmicas da RRO em politiofeno crescido por 15, 35 e 95 ciclos em $\mathrm{H}_{2} \mathrm{SO}_{4}$ 12,5 $\mathrm{M}$ em eletrodo de $\mathrm{C}$ vítreo, com 40 ciclos de incorporação de $\mathrm{Pt}$, em solução de $\mathrm{H}_{2} \mathrm{SO}_{4} 2,0 \mathrm{M} \mathrm{e} \mathrm{v}=5 \mathrm{mV} \mathrm{s}^{-1}$.

Na Figura 53 estão apresentadas as curvas de polarização para a RRO em politiofeno crescido por 35 ciclos na ausência de catalisador, politiofeno contendo diferentes quantidades de partículas de Pt, politiofeno contendo Pt e recoberto por outra camada do filme polimérico (15 ciclos) e platina metálica. Para os casos dos eletrodos de Pt dispersa sem o filme superficial de polímero, nota-se que as correntes limite são praticamente independentes do número de ciclos de incorporação de partículas de platina. Este comportamento é esperado já que a corrente limite difusional é dependente apenas da área geométrica do eletrodo, que nestes experimentos foi mantida constante. Observa-se também que, na região de ativação, as correntes são mais altas para o politiofeno contendo Pt do que para Pt metálica, o que tem sido observado em outros trabalhos na literatura $[86,88,89]$ e pode ser devido ao aumento da área superficial. O politiofeno contendo Pt e o filme 
superficial apresentou característica um pouco diferente dos outros materiais, fato que será discutido mais adiante.

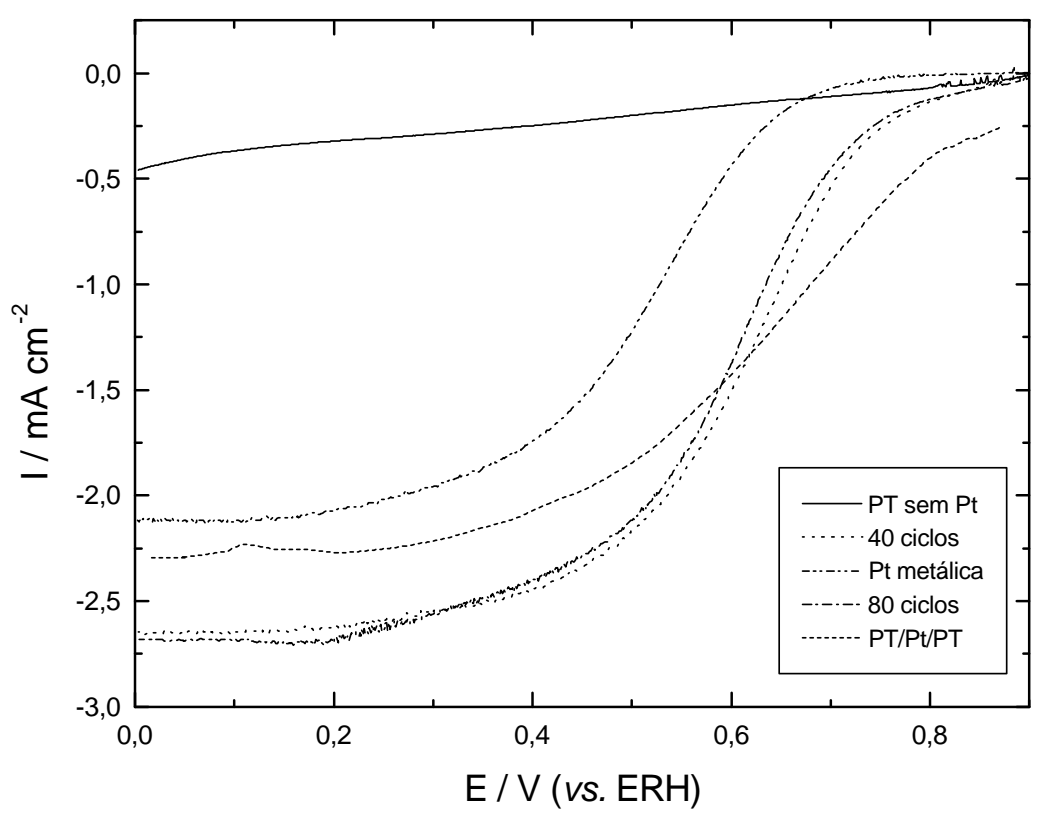

FIGURA 53 - Curvas potenciodinâmicas da RRO de vários materiais em solução de $\mathrm{H}_{2} \mathrm{SO}_{4}$ 2,0 M e velocidade de varredura de $5 \mathrm{mV} \mathrm{s}^{-1}$. $\mathrm{w}=2500 \mathrm{rpm}$.

Os resultados obtidos foram analisados utilizando as equações de Eletrodo de Disco Rotatório desenvolvidas para eletrodos lisos [87]. Alguns trabalhos mostram ser possível a aplicação destas equações para o caso de eletrodos poliméricos [26], como é o caso do presente trabalho. Gráficos de Levich $\left(i_{d} v s . w^{1 / 2}\right.$, onde $i_{d}$ é a densidade de corrente limite) e gráficos de Tafel corrigidos por transporte de massa (E vs. $\left.\log \left[\left(i_{d} x i\right) /\left(i_{d}-i\right)\right]\right)$ foram construídos e alguns exemplos estão ilustrados nas Figuras 54 a 57 para ambos os catalisadores. Para a construção dos gráficos de Levich e Tafel correspondentes a estas Figuras, a contribuição do processo de redução do polímero foi descontada das densidades de corrente obtidas nas medidas de polarização frente a RRO. 
$\mathrm{Na}$ Figura 54 são apresentados os gráficos de Levich para o eletrodo contendo partículas de Pd. Foram construídas duas curvas de Levich relativas, respectivamente, aos potenciais de 0,2 e 0,4 V. Os gráficos resultaram em retas que cortam aproximadamente a origem, porém apresentam diferentes coeficientes angulares. Isto indica que o número de elétrons envolvido nas reações que ocorrem nestes potenciais são diferentes. No caso dos eletrodos de Pt, observa-se que as retas (Figura 55) são essencialmente coincidentes, exceto para os filmes de politiofeno com partículas de Pt e recoberto por filme de PT. Este comportamento indica que a reação de redução de oxigênio é de primeira ordem com relação à concentração da espécie reagente e que o número de elétrons (n) envolvido na mesma é praticamente o mesmo. Os valores de $\mathrm{n}$ encontrados para a RRO nos eletrodos poliméricos modificados, calculados a partir dos coeficientes angulares dos gráficos de Levich nas Figuras 54 e 55 e assumindo-se que $n=4$ para o eletrodo de platina lisa, são apresentados na Tabela 3 .

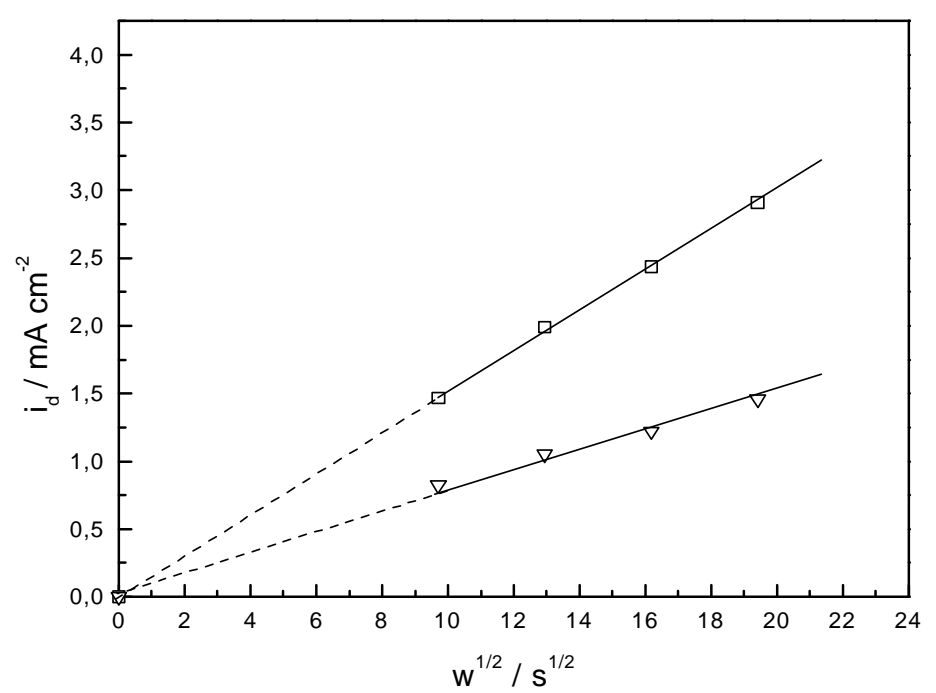

FIGURA 54 - Gráficos de Levich correspondendo ao PT sintetizado por 35 ciclos em eletrodo de $\mathrm{C}$ vítreo, com $60 \mathrm{~s}$ de incorporação de $\mathrm{Pd}$, em solução de $\mathrm{H}_{2} \mathrm{SO}_{4} 2,0 \mathrm{M} \mathrm{e} \mathrm{v} \mathrm{=} 5$ $\mathrm{mV} \mathrm{s}^{-1} .(\square) \mathrm{E}=0,2 \mathrm{~V} \mathrm{e}(\nabla) \mathrm{E}=0,4 \mathrm{~V}(v s . \mathrm{ERH}) . \mathrm{w}=2500 \mathrm{rpm}$. 


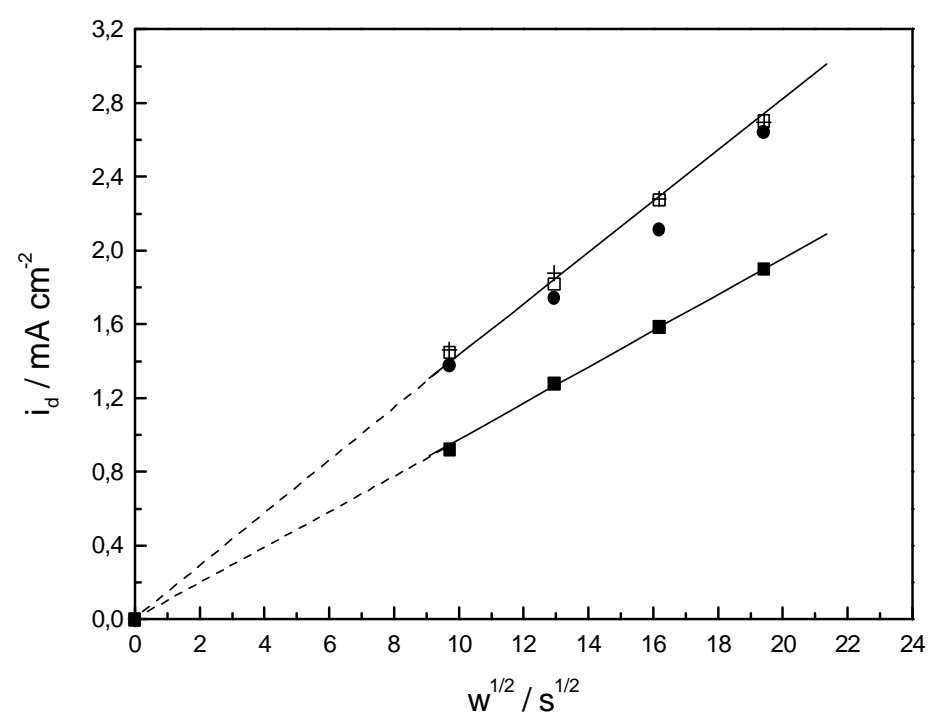

FIGURA 55 - Gráficos de Levich correspondendo ao politiofeno sintetizado por 35 ciclos em eletrodo de carbono vítreo correspondendo aos resultados da Figura 53: ( $\square$ ) 40 ciclos; (+) 80 ciclos de eletrorredução de Pt; (ם) 80 ciclos de eletrorredução de Pt recoberto por PT e (@) Pt pura. Solução utilizada: $\mathrm{H}_{2} \mathrm{SO}_{4} 2,0 \mathrm{M}$ e velocidade de varredura de $5 \mathrm{mV} \mathrm{s}^{-1}$.

A Figura 56 apresenta as curvas de Tafel corrigidas por transporte de massa para a RRO no filme de politiofeno contendo partículas de Pd. Os valores de $\mathrm{i}_{\mathrm{d}}$ usados para o cálculo das densidades de corrente corrigidos por transporte de massa foi aquele obtido no potencial de $0,2 \mathrm{~V}$. Esta curva mostra comportamento linear somente em altas densidades de corrente ou em potenciais menores que aproximadamente $0,8 \mathrm{~V}$. Acima deste potencial, há uma considerável incerteza nos dados experimentais o que resulta dos valores de corrente muito pequenos medidos nesta faixa de potenciais. Os valores dos coeficientes de Tafel em ambas as regiões são estimados como aproximadamente 70 e $150 \mathrm{mV} \mathrm{dec}^{-1}$. Em vários trabalhos na literatura $[90,91]$ foi encontrada a presença de dois coeficientes de Tafel distintos (60 $\mathrm{mV} \operatorname{dec}^{-1}$ para potenciais acima de $0,8 \mathrm{~V}$ e $120 \mathrm{mV} \mathrm{dec}^{-1}$ para potenciais abaixo deste valor). Foi demonstrado que os dois coeficientes diferentes são produzidos pelo grau de recobrimento da superfície do catalisador por espécies oxigenadas quimissorvidas. 
Assim, os resultados obtidos no presente trabalho são consistentes com os valores encontrados na literatura.

Vracar e cols. [92] afirmaram que na região de potencial onde a RRO é caracterizada pelo coeficiente de Tafel de aproximadamente $60 \mathrm{mV} \mathrm{dec}{ }^{-1}$, o eletrodo de Pd é parcialmente coberto por espécies contendo oxigênio, por exemplo, monohidróxido de paládio $\left(\mathrm{Pd}(\mathrm{OH})_{\mathrm{ads}}\right)$, o qual seria reduzido continuamente com o aumento do sobrepotencial, de acordo com:

$$
\mathrm{Pd}(\mathrm{OH})_{\mathrm{ads}}+\mathrm{e} \rightleftharpoons \mathrm{Pd}+\mathrm{OH}^{-}
$$

Considerando que $\mathrm{Pd}(\mathrm{OH})_{\text {ads }}$ retarda a RRO pelo mecanismo direto que leva à formação de água [93] envolvendo 4 elétrons, é razoável supor que nos potenciais acima de $0,8 \mathrm{~V}$ ocorre uma formação considerável do intermediário peróxido de hidrogênio (ver página 13), resultando em um processo envolvendo apenas 2 elétrons. Com o decréscimo do potencial eletródico ocorre a redução dos óxidos superficiais, o que facilita a redução posterior do $\mathrm{H}_{2} \mathrm{O}_{2}$ resultando em um processo global envolvendo 4 elétrons. Os valores dos números de elétrons obtidos através do diagrama de Levich (Tabela 3) são inteiramente consistentes com esta proposição mecanística. 


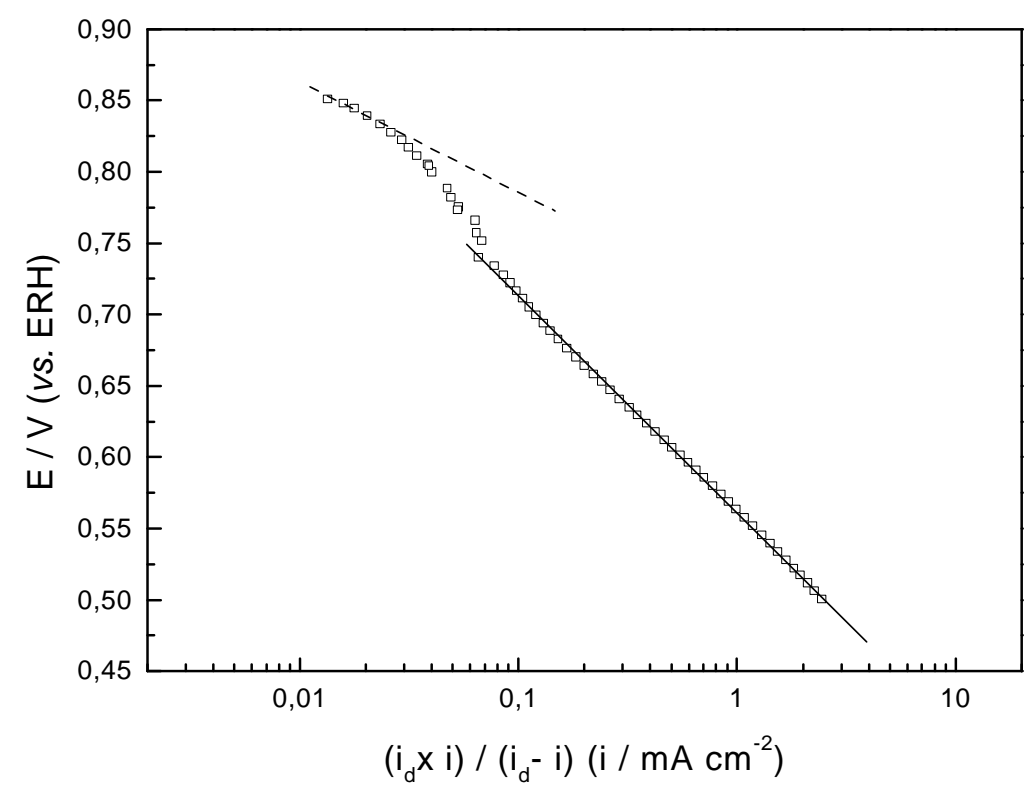

FIGURA 56 - Curvas de Tafel para politiofeno crescido por 35 ciclos em $\mathrm{H}_{2} \mathrm{SO}_{4} 12,5 \mathrm{M}$ em eletrodo de $\mathrm{C}$ vítreo, com $60 \mathrm{~s}$ de incorporação de $\mathrm{Pd}$, em solução de $\mathrm{H}_{2} \mathrm{SO}_{4} 2,0 \mathrm{M} \mathrm{e}$ velocidade de varredura de $5 \mathrm{mV} \mathrm{s}^{-1}$.

Os gráficos de Tafel apresentados na Figura 57 para os filmes contendo partículas de Pt mostram um comportamento bastante similar ao das partículas de Pd. Neste caso, para se obter valores exatos dos coeficientes de Tafel, os dados na região linear dos diagramas de Tafel corrigidos por transporte de massa foram ajustados à fórmula [26,94-98],

$$
E=E^{b}-b \log \left[\frac{\left(i_{d} \times i\right)}{\left(i_{d}-i\right)}\right]-R i
$$

onde,

$\mathrm{E}^{\mathrm{b}}=\mathrm{E}^{\mathrm{r}}+\mathrm{b} \log \mathrm{i}_{0}$

$E^{r}$ é o potencial reversível do eletrodo $\left(E^{r}=1,23 V\right)$;

b: coeficiente de Tafel;

$\mathrm{i}_{0}$ : densidade de corrente de troca para a reação de redução de oxigênio (RRO) na platina; 
R: resistência elétrica proveniente do filme polimérico que é assumida como constante no intervalo de potenciais dos diagramas de Tafel.

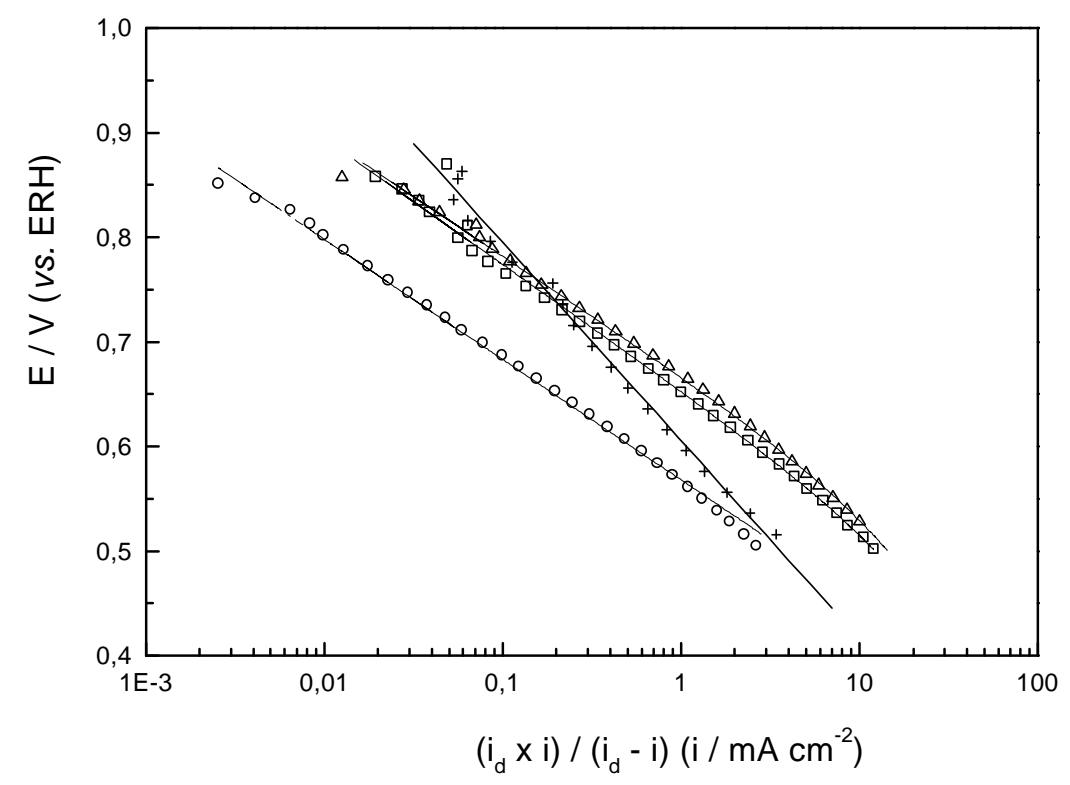

FIGURA 57 - Gráficos de Tafel para RRO em eletrodo de politiofeno contendo partículas de $\mathrm{Pt}$ (35 ciclos de crescimento a $75 \mathrm{mV} \mathrm{s}^{-1}$ ) em eletrodo de carbono vítreo e $\mathrm{H}_{2} \mathrm{SO}_{4} 2,0 \mathrm{M}$ para o polímero contendo diferentes quantidades de partículas de Pt: $(\square) 80$ ciclos; $(\triangle) 40$ ciclos de eletrorredução de Pt; (O) Pt pura e (+) PT/Pt80/PT. w = 2500 rpm.

Os resultados encontrados para os parâmetros $i_{o}$, b e R estão sumarizados na Tabela 3. Os valores da resistência elétrica mostrados na Tabela 3 podem ser convertidos em resistividade dos materiais dividindo pelo valor da espessura do filme polimérico. Usando os valores de espessura estimados por MEV, os cálculos resultam em valores da ordem de $10^{4} \mathrm{Ohm}^{-1}$, que pode ser considerado alto para polímeros condutores. Uma explicação para isto pode ser dada em termos da concentração de ácido sulfúrico (2,0 M) empregado como eletrólito para a RRO, pois o polímero apresenta baixas correntes de oxidação/redução nestas condições (Figura 32b), indicando baixa condutividade para o mesmo. Entretanto, isto não é uma 
limitação severa para a interpretação mecanística, já que, através da equação (3.3.1), o efeito de resistência pode ser separado dos dados de polarização.

Na Tabela 3, observa-se que os valores de $\mathrm{n}$ resultaram aproximadamente iguais a 4 para os polímeros modificados contendo partículas de Pt na ausência de recobrimento por camada de filme polimérico. Os valores dos coeficientes de Tafel

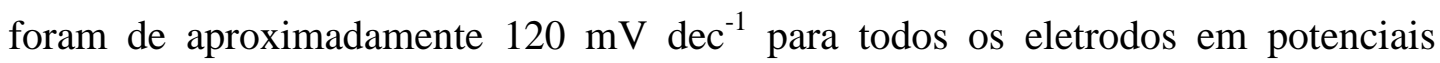
abaixo de aproximadamente $0,8 \mathrm{~V}$. As diferenças nos valores de densidade de corrente de troca observados na Tabela 3 são conseqüência das diferenças nas áreas ativas de Pt devido aos diferentes números de ciclos utilizados para incorporação da mesma. Isto é responsável por obter-se retas de Tafel paralelas, conforme encontradas na Figura 57.

TABELA 3 - Parâmetros cinéticos obtidos dos ajustes das equações (3.3.1 e 3.3.4) para a polarização dos dados experimentais em altas correntes de densidade.

\begin{tabular}{ccccc}
\hline $\begin{array}{c}\text { Eletrodo } \\
\text { Ciclos de crescimento do polímero / Pt } \\
\text { Ciclos de deposição de Pt }\end{array}$ & $\begin{array}{c}\mathrm{i}_{\mathrm{o}} / \\
10^{-9} \mathrm{~A} \mathrm{~cm}^{-2}\end{array}$ & $\begin{array}{c}\mathrm{b} / \\
\mathrm{V} \mathrm{dec}\end{array}$ & $\begin{array}{c}\mathrm{R} / \\
\Omega \mathrm{cm}^{2}\end{array}$ & $\begin{array}{c}\text { Número de } \\
\text { Elétrons }\end{array}$ \\
\hline $35 / 40$ & & & & \\
$35 / 80$ & 18 & 0,114 & 2,5 & 4,0 \\
PT/Pt80/PT & 16 & 0,120 & 1,9 & 4,0 \\
Pd (baixos sobrepotenciais) & - & 0,200 & - & 2,8 \\
Pd (altos sobrepotenciais) & - & 0,08 & - & 2,2 \\
Pt lisa & - & 0,150 & - & 4,3 \\
\hline
\end{tabular}


É bastante conhecido o fato de que a RRO pode ocorrer através de processo envolvendo transferência de 4 elétrons gerando água como produto final ou via 2 elétrons para formar peróxido de hidrogênio, dependendo do material eletródico (ver página 13). Eletrodos lisos formados por ouro policristalino, grafite e carbono catalisam a reação através do mecanismo de 2 elétrons [95], enquanto que prata, platina e outros metais do grupo da platina promovem a reação via 4 elétrons [9498]. Duas regiões lineares de Tafel, com coeficientes de 60 e $120 \mathrm{mV}$ para baixos e altos sobrepotenciais, respectivamente, têm sido observadas para RRO sobre Pt em soluções ácidas. Como no caso do Pd, a existência de dois coeficientes é explicada em termos do recobrimento do eletrodo por oxigênio adsorvido, que segue a isoterma de Tempkin (alto recobrimento) em baixos sobrepotenciais e a isoterma de Langmuir (baixo recobrimento) em altos sobrepotenciais [26,94-98].

No caso dos eletrodos poliméricos modificados com Pt foi possível observar apenas a região linear com inclinação de $120 \mathrm{mV}$, indicando que o polímero inibe a formação de óxidos superficiais que, como conseqüência, resultam em baixos recobrimentos. Por outro lado, o número de elétrons igual a 4 mostra a pouca influência do polímero sobre o mecanismo reacional, que é o mesmo que em Pt pura ou Pt dispersa em carbono $[94,96]$.

Os valores da densidade de corrente de troca apresentados na Tabela 2 são similares para os eletrodos modificados, porém são mais altos comparados com platina pura. O valor de $\mathrm{i}_{\mathrm{o}}$ mais alto para a RRO nos polímeros modificados é consequência da maior área ativa de $\mathrm{Pt}$, como indicado pelo pequeno tamanho das partículas de Pt que formam estes eletrodos.

Sabe-se que o tamanho das partículas do catalisador pode afetar a cinética da reação de redução de oxigênio. Alguns trabalhos na literatura [34,36] afirmam que 
pequenas partículas de $\mathrm{Pt}$ apresentam menor atividade catalítica e isto estaria relacionado à forte adsorção de oxigênio. A pequena diferença encontrada para o comportamento da platina nos resultados de absorção de raios $\mathrm{X}$ em função do potencial indica pouca formação de óxidos superficiais, ao contrário do que se observa para o mesmo catalisador disperso em carbono [60]. Alguns autores atribuem este fato aos efeitos eletrônicos da matriz polimérica como é o caso da polianilina contendo partículas dispersas de $\mathrm{Pt}, \mathrm{Pt} / \mathrm{Ru}$ e $\mathrm{Pt} / \mathrm{Sn}$. Este comportamento explica o fato de se obter gráficos de Tafel para a RRO congruentes com um mecanismo envolvendo baixos recobrimentos por óxidos superficiais e também o elevado efeito catalítico da platina incorporada na matriz polimérica.

Para analisar o caso do PT contendo partículas de Pt e cobertas por filme polimérico (PT/Pt80/PT), utilizou-se a teoria de Gough e Leypoldt [99] para um eletrodo de disco rotatório recoberto por uma membrana semi-permeável (filme polimérico) inerte, conforme mostra a Figura 58.

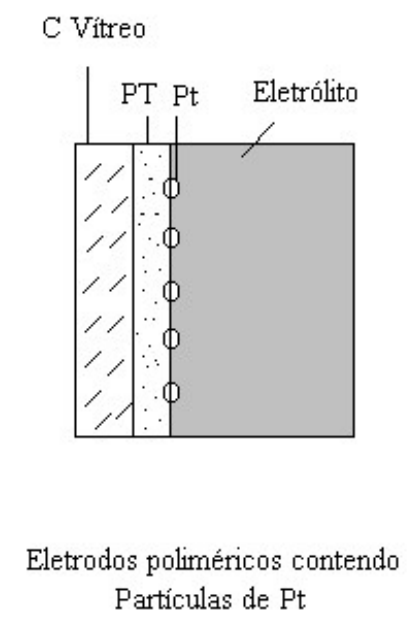

Partículas de Pt

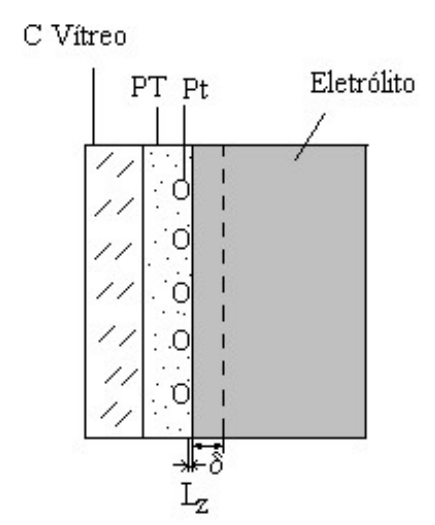

Eletrodos poliméricos contendo Partículas de Pt recobertas por filme de

FIGURA 58 - Esquema mostrando eletrodos poliméricos contendo partículas de Pt recobertas ou não por camada adicional de polímero. 
Neste caso, a corrente limite difusional é dada por:

$$
I_{d}=I_{L}\left[\frac{1}{1+\left(P_{f} / P_{z}\right)}\right]
$$

onde,

$\mathrm{I}_{\mathrm{L}}$ : corrente de limite difusional na ausência do filme polimérico;

$\mathrm{P}_{\mathrm{f}}$ : permeabilidade do $\mathrm{O}_{2}$ no eletrólito líquido;

$\mathrm{P}_{\mathrm{z}}$ : permeabilidade do $\mathrm{O}_{2}$ no filme polimérico superficial.

Neste casos [97],

$$
P_{f}=\frac{D_{f}}{\delta} \text { e } P_{z}=\frac{C_{z} \times D_{z}}{C_{O_{2}} \times L_{z}}
$$

onde,

$\mathrm{D}_{\mathrm{f}}$ : coeficiente de difusão do $\mathrm{O}_{2}$ no eletrólito líquido;

$\delta$ : espessura da camada de Nerst (Fig. 58);

$\mathrm{D}_{\mathrm{z}}$ : coeficiente de difusão do $\mathrm{O}_{2}$ no filme superficial;

$\mathrm{C}_{\mathrm{z}}$ : solubilidade do $\mathrm{O}_{2}$ no filme superficial;

$\mathrm{C}_{\mathrm{O} 2}$ : concentração de $\mathrm{O}_{2}$ na interface eletrólito/filme superficial;

$\mathrm{L}_{\mathrm{z}}$ : espessura do filme superficial (Fig. 58).

Considerando que o filme com 15 ciclos de crescimento possui espessura aproximada menor que $1 \mu \mathrm{m}$, como calculado pelos resultados de microscopia apresentados anteriormente, e considerando $\delta>10 \mu \mathrm{m}$ [96], tem-se que:

$$
P_{f} \ll P_{z}
$$

e, portanto, 


$$
\frac{P_{f}}{P_{z}}<<1
$$

Assim, levando-se em conta a equação 3. 3. 2, conclui-se que

$$
I_{d} \cong I_{L}
$$

que implica que a equação de Levich é também aplicável para esta situação experimental. Assim, a reta correspondente a este sistema na Figura 55 apresenta-se similar aos outros casos, porém, por apresentar coeficiente angular diferente, indica que o número de elétrons envolvidos na reação é diferente. Calculando este valor, considerando que $n=4$ para a platina lisa, obtém-se que $n=2,8$. Pode-se dizer então, que a reação deve ocorrer levando primeiramente à formação de $\mathrm{H}_{2} \mathrm{O}_{2}$, sendo que somente parte deste produto participa do passo eletroquímico que leva à formação de água, como mostram as etapas $\mathrm{k}_{5}$ e $\mathrm{k}_{3}$, respectivamente, apresentadas no diagrama mostrado na pág. 13.

O gráfico de Tafel correspondente a este eletrodo está mostrado na Figura 57. Observa-se que a inclinação de Tafel (b) para este caso apresenta valor de aproximadamente $200 \mathrm{mV} \mathrm{dec}{ }^{-1}$ (Tabela 3). Isto pode ser explicado levando-se em conta que este sistema sofre influência de fatores estruturais, fato que não se verifica nos demais eletrodos. Para o eletrodo polimérico recoberto por filme, deve-se utilizar a seguinte equação para descrever a polarização estacionária [100] (em lugar da equação 3. 3. 1):

$$
E=E+b \log \left(\frac{n F C_{O_{2}}{ }^{*} D_{a}}{L_{z}}\right)-2 b \log \left(\frac{i_{d} \times i}{i_{d}-i}\right)-R i \quad(\text { para } \eta>0,3 \mathrm{~V})
$$

onde; 
n: número de elétrons envolvidos na reação;

F: constante de Faraday;

$\mathrm{C}_{\mathrm{O} 2}{ }^{*}$ : solubilidade do $\mathrm{O}_{2}$ no eletrólito;

$D_{\mathrm{a}}$ : coeficiente de difusão do $\mathrm{O}_{2}$ no filme;

$\mathrm{L}_{\mathrm{z}}$ : espessura do filme.

Uma comparação entre os termos das equações 3. 3. 1 e 3. 3. 4 mostra que a presença do filme leva a mudanças no coeficiente linear do diagrama de Tafel. Além disto observa-se que a inclinação da reta obtida para este eletrodo representa na realidade o dobro do valor do coeficiente de Tafel, explicitado pela equação 3. 3. 1.

Por esta análise conclui-se que o valor obtido experimentalmente para o coeficiente angular $\left(\sim 200 \mathrm{mV} \mathrm{dec}^{-1}\right)$ no caso do eletrodo com filme superficial refere-se a um valor verdadeiro de $\mathrm{b} \sim 100 \mathrm{mV} \operatorname{dec}^{-1}$. Desta forma conclui-se que também neste caso o valor situa-se próximo ao valor esperado, correspondente a $\mathrm{b}=$ $120 \mathrm{mV} \mathrm{dec}^{-1}$. O número de elétrons igual a 2,8 obtido neste caso pode ser explicado pelo fato de que a reação ocorre na interface Pt/PT (ao invés da interface $\mathrm{Pt} / \mathrm{H}_{2} \mathrm{SO}_{4}$, como nos outros casos), onde o $\mathrm{pH}$ certamente difere daquele do eletrólito líquido.

\section{3. 4. Sumário dos Resultados}

Analisando-se os resultados para os filmes de politiofeno contendo partículas dispersas de Pd e os resultados apresentados na Tabela 2, observa-se que neste catalisador a RRO ocorre em duas etapas, como mostram os dois valores distintos de n. 
1) $\mathrm{O}_{2} \rightarrow \mathrm{O}_{2(\text { ads })}$

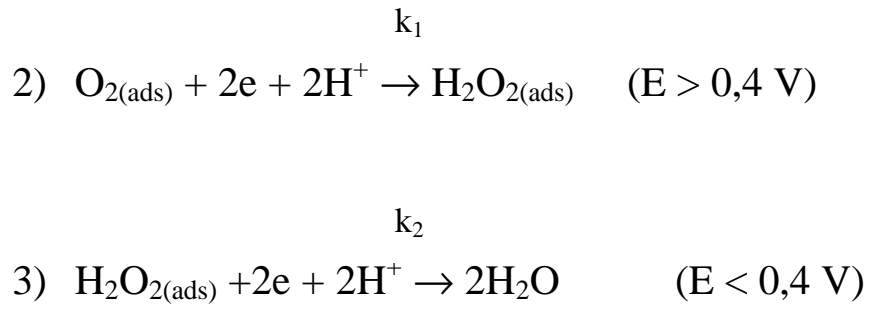

No caso da platina o esquema reacional é essencialmente o mesmo que sobre paládio. A diferença de comportamento entre os catalisadores está na velocidade do passo correspondente à decomposição do peróxido de hidrogênio. Enquanto que no paládio, esta etapa ocorre mais lentamente, na platina, a decomposição ocorre instantaneamente e não se observa a presença do mesmo em solução, a não ser para o caso em que o eletrodo apresenta-se recoberto por camada de PT. Neste caso, deve haver uma mudança no $\mathrm{pH}$ da solução nas proximidades das partículas e assim o peróxido formado se decompõe mais lentamente, o que leva a um número de elétrons correspondente $\mathrm{a} \sim 3$. 


\section{CAPÍTULO IV:}

\section{CONCLUSÕES}

Os resultados experimentais obtidos neste trabalho permitiram que fossem estudadas algumas características da síntese eletroquímica e das propriedades redox do politiofeno em meio fortemente ácido. Foram preparados eletrocatalisadores dispersos de $\mathrm{Pt}$ e $\mathrm{Pd}$ ancorados sobre filmes deste polímero, os quais foram caracterizados e investigados quanto à ação catalítica frente a ROH e RRO. As principais conclusões dos estudos realizados são descritas a seguir.

Observou-se que o polímero apresenta-se mais estável em meio aquoso. A polimerização em meio aquoso ácido ocorre a partir de um complexo $\pi$ cuja concentração é maior em meio ácido concentrado, mas que no geral não é muito elevada. Verificou-se que a solução deve ser agitada continuamente para que este precursor esteja presente em quantidades suficientes nas proximidades do eletrodo e assim favorecer a polimerização.

Os filmes produzidos nestas condições apresentam-se bastante homogêneos e com forte aderência à superfície dos substratos empregados, ou seja, platina, ouro ou 
carbono vítreo. Medidas realizadas com a técnica de UV-Visível, in situ com medidas eletroquímicas, sugerem que o mecanismo de oxidação/redução do polímero segue o modelo de formação/destruição de polarons e bipolarons.

Através de experimentos XANES e EXAFS foi possível calcular o diâmetro médio das partículas de Pt incorporadas nos filmes de politiofeno, que resultaram da ordem de 20-40 ̊. Também foi possível concluir que as partículas incorporadas, tanto de Pt como de Pd, não se apresentam oxidadas, mas sim na forma metálica, independentemente do potencial eletródico. Para as partículas de Pd, os valores dos parâmetros de Debye-Waller e das distâncias atômicas indicaram que em potenciais baixos a presença de hidrogênio absorvido leva a uma maior desordem do arranjo atômico e a um estiramento do comprimento da ligação Pd-Pd.

Verificou-se que na ausência de catalisador, o filme polimérico não apresenta atividade catalítica frente à ROH. Por outro lado, os filmes contendo qualquer um dos metais mostraram atividades pouco estáveis frente à mesma reação. Os estudos indicaram que em presença de $\mathrm{H}_{2}$ e sob a ação do potencial eletródico, ocorrem processos de degradação da cadeia polimérica ao mesmo tempo em que o hidrogênio é oxidado. Isto leva a uma perda progressiva de atividade eletroquímica do polímero e, conseqüentemente, a uma perda da eficiência catalítica das partículas incorporadas frente à $\mathrm{ROH}$.

Da mesma forma que para a $\mathrm{ROH}$, filmes de PT sem a presença de catalisador disperso são inativos frente a reação de redução de oxigênio. Observou-se que na presença de Pt há uma acentuada eletrocatálise da reação, particularmente quando se emprega filmes finos. A análise dos dados mostrou que a reação é de primeira ordem com relação à concentração de oxigênio no meio eletrolítico e que o número de elétrons depende da natureza da interface que forma a zona reacional. 
Para o caso da interface $\mathrm{Pt} / \mathrm{H}_{2} \mathrm{SO}_{4}$ observou-se que o número de elétrons é igual a 4 , indicando que a reação leva à formação de água como produto final e ocorre através de um mecanismo envolvendo baixas concentrações do intermediário peróxido de hidrogênio. No caso do eletrodo formado por partículas de Pt recorbertas com politiofeno, a reação ocorre com formação do peróxido de hidrogênio que somente reduz-se parcialmente para produzir água. Um fato importante também observado é que a presença do filme do polímero inibe a formação de óxidos superficiais de Pt, fazendo com que a reação se verifique em condições de baixos recobrimentos por espécies oxigenadas.

Verificou-se que o catalisador de $\mathrm{Pd}$ é menos efetivo que a $\mathrm{Pt}$ na eletrocatálise da RRO. Os resultados indicam que o mecanismo reacional é formado por duas etapas, sugerindo que o processo primeiramente leva à formação de peróxido de hidrogênio em baixos sobrepotenciais, para posterior formação de água nos sobrepotenciais mais elevados. 


\section{REFERÊNCIAS BIBLIOGRÁFICAS}

1) DE PAOLI, M A; MENESCAL, R K. Polímeros orgânicos condutores de corrente elétrica: uma revisão. Química Nova, v.9, n.2, p.133-140, 1986.

2) DE PAOLI, M A; ZOPPI, R A. Aplicações tecnilógicas de polímeros intrinsecamente condutores: perspectivas atuais. Química Nova, v.16, n.6, p.560-569, 1993.

3) ITO, T; SHIRAKAWA, H; IKEDA, S. Simultaneous polymerization of polyacetylene film on surface of concentrated soluble Zigler-type catalyst solution. J. Polym. Sci. Part A - Polym. Chem., v.12, p.11-20, 1974.

4) CHIANG, $\mathrm{C} \mathrm{K}$; FINCHER, $\mathrm{C} \mathrm{R}$; PARK, $\mathrm{Y} \mathrm{W}$; HEEGER, A J; SHIRAKAWA, H; LUIS, E J; LUIS, S C; GAU, S C; MACDIARMID, A J. Electrical - conductivity in doped polyacetylene. Phys. Rev. Lett., v.39, p.1098-1101, 1977.

5) BAZZAOUI, EL A; AEIYACH, S; LACAZE, P C. Low potential electropolymerization of thiophene in aqueous perchloric acid. J. Electroanal. Chem., v.364, p.63-69, 1994.

6) HEINZE, J. Topics in Current Chemistry. New York/Berlin, Springer Verlag, 1990. v.152, 151p.

7) TOURILLON, G. Polythiophene and its derivatives, In: SKOTHEIM, T A. Handbook of Conducting Polymers. New York, M. Dekker, 1986. v.1, p.293-350.

8) CZERWINSKI, A; ZIMMER, H; PHAM, C V; MARK JR, H B. The electrochemical deposition of conducting poly(3-methyl-2,5-thienylene) films from aqueous media. J. Electrochem. Soc., v.132, n.11, p.26692672, Nov. 1985.

9) DONG, S; ZHANG, W. Study on conducting polythiophene electrochemically polymerized in phosphoric-acid aqueous-solution. Synthetic Metals, v.30, n.3, p.359-369, Jun.1989. 
10) DIAZ, A F; CROWLEY, J; BARGON, J; GARDINI, G P; TORRANCE, J B. Electrooxidation of aromatic oligomers and conducting polymers. J. Electroanal. Chem., v.121, p.355-361, 1981.

11) MU, S; PARK, S-M. Electrochemistry of conductive polymers XVII. Preparation and characterization of polythiophene in aqueous solutions. Synthetic Metals, v.69, p.311-312, 1995.

12) DEMANZE, F; YASSAR, A; GARNIER, F. Push-Pull substituted polythiophene. Synthetic Metals, v.76, p.269-272, 1996.

13) COWAN, D O; WIYGUL, F M. The organic solid state. Chem. Eng. News, v.64, n.29, p.28, 1986.

14) LAPKOWSKI, M; GÈNIES, E M. Evidence of two kinds of spin in polyaniline from in situ EPR and electrochemistry. Influence of the electrolyte composition. J. Electroanal. Chem., v.279, p.157-168, 1990.

15) BUTTRY, D A; WARD, M D. Measurement of Interfacial Process at Electrode Surfaces with the Electrochemical Quartz Crystal Microbalance. Chem. Rev., v.92, n.6, p.1355-1379, 1992.

16) SABATINI, E; TICIANELLI, E A; REDONDO, A; RUBINSTEIN, I; RISHPON, J; GOTTESFELD, S. Morphologycal effects in conducting polymer films studied by combined OCM and spectroscopic ellipsometry. Synthetic Metals, v.55-57, p.1293-1298, 1993.

17) INZELT, G. In: Bard, A J. Electroanalytical Chemistry: a series of advances. New York, Marcel Dekker, 1994. v.18.

18) MATENCIO, T; DE PAOLI, M A; PEREZ, R C D; TORRESI, R M; CORDOBA DE TORRESI, $S$ I. Ionic exchanges in dodecylbenzenesulfonate doped polypyrrole. Part 1. Optical beam deflection studies. Synthetic Metals, v.72, p.59-64, 1995.

19) ARCA, M; MIRKIN, M V; BARD. A J. Polymer-films on electrodes. 26. Study of ion transport and electron transfer at polypyrrole films by scanning electrochemical microscopy. J. Phys. Chem., v.99, n.14, p.5040-5050, 1995.

20) WAINRIGHT, J S; ZORMAN, C A. Rutherford backscattering studies of polypyrrole films. J. Electrochem. Soc., v.142, n.2, p.379-383, Feb. 1995.

21) WAINRIGHT, J S; ZORMAN, C A. Rutherford backscattering studies of polypyrrole films. II. Effect of ionic size on mobility. J. Electrochem. Soc., v.142, n.2, p.384-388, Feb. 1995. 
22) HARIMA, Y; KUNUGI, Y; YAMASHITA, K; SHIOTANI, M. Determination of mobilities of charge carriers in electrochemistry aniondoped polythiophene film. Chem. Phys. Letters, v.317,p.310-314, Feb. 2000.

23) REYNOLDS, J R. Electrically conductive polymers. Chemtech, p.440447, July 1988.

24) LAMY, C; LÉGER, J-M; GARNIER, F. Electrocatalytic properties of conductive polymers. In: NALWA, H S, ed. Handbook of Organic Conductive Molecules and Polymers. New York, 1997. v.3, p.471-496.

25) NOUFI, R. The incorporation of ruthenium oxide in polypyrrole films and the subsequent photooxidation of water at n-Gap photoelectrode. $\mathbf{J}$. Electrochem. Soc., v.130, n.10, p.2126-2128, Oct. 1983.

26) FlORIANO, J B. Preparação, caracterização e propriedades catalíticas de eletrodos poliméricos modificados. São Carlos, 1997. Tese (Doutorado) - Instituto de Química de São Carlos, Universidade de São Paulo.

27) DAMJANOV, A; GENSHAW, M A; BOCKRIS, J O' M. Mechanism of oxygen reduction at platinum in alkaline solutions with special reference to $\mathrm{H}_{2} \mathrm{O}_{2}$. J. Electrochem. Soc., v.114, n. 11, p.1107, 1967.

28) SCHREBLER, R; DEL VALLE, M A; GÓMEZ, H; VEAS, C; CÓRDOVA, R. reparation of polythiophene-modified electrodes by electrodeposition of $\mathrm{Pt}$ and $\mathrm{Pt}+\mathrm{Pb}$. Application to formic acid electronoxidation. . Electroanal. Chem., v.380, p.219-227, 1995.

29) TOURILLON, G; GARNIER, F. Inclusion of Metallic Aggregates in Organic Conducting Polymers. A New Catalytic System, [Poly93methylthiophene)-Ag-Pt], for proton electrochemical reduction. J. Phys. Chem., v.88, n.22, p.5281-5285, 1984.

30) YASSAR, A; RONCALI, J; GARNIER, F. Preparation and electroactivity of poly(thiophene) electrodes modified by electrodeposition of palladium particles. J. Electroanal. Chem., v.255, p.53-69, 1988.

31) MUKERJEE, S; SRINIVASAN, S; SORIAGA, M P. Role of structural and electronic properties of Pt and Pt alloys on electrocatalysis of oxygen reduction. An in situ XANES and EXAFS investigation. J. Electrochem. Soc., v.142, n.5, p.1409-1422, May 1995.

32) MUKERJEE, S; SRINIVASAN, S; SORIAGA, M P; MCBREEN, J. Effect of preparation conditions of Pt alloys on their electronic, structural, and electrocatalytic activities for oxygen reduction - XRD, XAS, and Electrochemical studies. J. Phys. Chem., v.99, n.13, p.4577-4589, 1995. 
33) MCBREEN, J; MUKERJEE, S. In situ x-ray absorption studies of a Pt-Ru electrocatalyst. J. Electrochem. Soc., v.142, n.10, p.3399-3404, Oct. 1995.

34) TAKASU, Y; OHASHI, N; ZHANG, X-G; MARAKAMI, Y; MINAGAWA, H; SATO, S; YAHIKOZAWA, K. Size effects of platinum particles on the electroreduction of oxygen. Electrochim. Acta, v.41, n.16, p.2595-2600, 1996.

35) LAI, E K W; BEATTIE, P D; ORFINO, F P; SIMON, E; HOLDCROFT, S. Electrochemical oxygen reduction at composite films of Nafion ${ }^{\circledR}$, polyaniline and Pt. Electrochim. Acta, v.44, p.2559-2569, 1999.

36) GAMEZ, A; RICHARD, D; GALLEZOT, P; GLOAGUEN, F; FAURE, $\mathrm{R}$; DURAND, R. Oxygen reduction on well-defined platinum nanoparticles inside recast ionomer. Electrochim. Acta, v.41, n.2, p.307314, 1996.

37) LAI, E K W; BEATTIE; P D; HOLDCROFT, S. Electrocatalytic reduction of oxygen by platinum microparticles deposited on polyaniline films. Synthetic Metals, v.84, p.87-88, 1997.

38) YANG, Y; ZHOU, Y. Particle size effects for oxygen reduction on dispersed silver + carbon electrodes in alkaline solution. J. Electroanal. Chem., v.397, p.271-278, 1995.

39) GASTEIGER, H A; MARKOVIC, N M; ROSS JR, P N. $\mathrm{H}_{2}$ and CO electrooxidation on well-characterized $\mathrm{Pt}, \mathrm{Ru}$ and $\mathrm{Pt}-\mathrm{Ru}$. 1. Rotating-Disk electrode studies of the pure gases including temperature effects. J. Phys. Chem, v.99, n.20, p.8290-8301, 1995.

40) LEY, K L; LIU, R; PU, C; FAN, Q; LEYAROVSKA, N; SEGRE, C; SMOTKIN, E S. Methanol oxidation on single-phase Pt-Ru-Os ternary alloys. J. Electrochem. Soc., v.144, n.5, p.1543-1548, 1997.

41) SWATHIRAJAN, S; MIKHAIL, Y M. Methanol oxidation on platinumtin catalysts dispersed on poly(3-methyl)thiophene conducting polymer. J. Electrochem. Soc., v.139, n.8, p.2105-2110, Aug. 1992.

42) MOUTET, J C; QUENNOUGHI, Y; OURARI, A; HAMAR-THIBAULT, S. Electrocatalytic hydrogenation on noble metal particles dispersed in polymer films. Enhanced catalytic activity induced by the incorporation of bimetallic catalysts. Electrochim. Acta, v.40, n.12, p.1827-1833, 1995.

43) CALEGARO, M L. Estudo da Reação de Oxigênio em meio alcalino sobre diversos substratos, na presença e na ausência de zincato. São Carlos, 2000. 110p. Tese (Doutorado) - Instituto de Química de São Carlos, Universidade de São Paulo. 
44) DE MELlO, R M Q. Estudo da Reação de Oxidação de Hidrogênio sobre Pt e Pt-EPS em vários meios. São Carlos, 1995. 85p. Dissertação (Mestrado) - Instituto de Química de São Carlos, Universidade de São Paulo.

45) VAlbuena, W H L. Estudo da Reação de Oxidação de Hidrogênio em Eletrodos de Camada Fina Porosa. São Carlos, 1998. 101p. Dissertação (Mestrado) - Instituto de Química de São Carlos, Universidade de São Paulo.

46) MALINAUSKAS, A. Electrocatalysis of conducting polymers. Synthetic Metals, v.107, p.75-83, 1999.

47) GILMAN, S. The anodic film on platinum electrodes. In: BARD, A J. Electroanalytical Chemistry. New York, Marcel Dekker, 1982. v.2, p.119-132.

48) WHIFFEN, D H. Espectroscopy, 2.ed. New York/London, Logman, 1971. p.92.

49) SILVERSTEIN, R M; BASSLER, G C; MORRIL, T C. Identificação Espectrométrica de Compostos Orgânicos. Trad. de R. B. ALENCASTRO. 5.ed. Rio de Janeiro, Guanabara Koogan, 1994. p. 263.

50) THOMAS, M J K. Ultraviolet and Visible Spectroscopy. ANDO, D J, ed. 2.ed. New York, J. Willey, 1996. p.1.

51) FESSER, K; BISHOP, A R; CAMPBELL, D K. Optical-absorption from polarons in a model of polyacetylene. Phys. Rev. B, v.27, n. 8, p.4804$4825,1983$.

52) ELLIS, A B; GESELBRACHT, M J; JOHNSON, B J; LISENSKY, G C; ROBINSON, W R. Teaching General Chemistry - A Materials Science Companion, Washington, DC, American Chemical Society, 1993. p.216221.

53) GOLDENSTEIN, J I; NEWBURY, D E; ECHLIN, P; JOY, D C; ROMIG JR, A D; LYMAN, C E; FIORI, C; LIFSHIN, E. Scanning Electron Microscopy and X-Ray Microanalysis, 2.ed, New York, 1981. p.22.

54) CHINAGLIA, C R; BOLFARINI, C. Apostila Básica para o credenciamento de operadores do Microscopio Eletrônico de Varredura LEICA/CAMBRIDGE Modelo Stereoscan 440 do CCDM, p.2.

55) WINICK, H; DONIACH, S, eds. Synchrotron Radiation Research. New York, Plenum Press, 1982. p.1.

56) Home Page: www.nsls.bnl.gov 
57) KURZ, C, ed. Topics in Current Physics - Synchrotron Radiation Techniques and Applications, 1979. p.1.

58) CULLITY, B D, ed. Elements of X-ray diffraction. Addison-Wesley, 1978. p.13.

59) FLORES, W H. Estudo da Evolução Estrutural, Magnética e Magnetoresistiva em Filmes Finos de $\mathrm{Co}_{\mathbf{x}} \mathrm{Fe}_{1-\mathrm{x}} / \mathrm{Ag}$. Porto Alegre, 2000. 85p. Tese (Doutorado) - Instituto de Física, Universidade Federal do Rio Grande do Sul.

60) MCBREEN, J; MUKERJEE, S. In situ X-ray absorption studies of carbonsupported $\mathrm{Pt}$ and $\mathrm{Pt}$ alloy nanoparticles. In: Wieckowski, A, ed. Interfacial Chemistry - Theory, Experiment and Applications, New York, Marcel Dekker Inc., 1999. p.895-913.

61) DOWNARD, A J; PLETCHER, D. A study of the conditions for the electrodeposition of polythiophene in acetonitrile. J. Electroanal. Chem., v.206, p.147-152, 1986.

62) GÈNIES, E M; BIDAN, G; DIAZ, A F. Spectroelectrochemical study of polypyrrole films. J. Electroanal. Chem., v.149, p.101-113, 1983.

63) FICHOU, D; HOROWITZ, G; XU, B; GARNIER, F. Low temperature optical absorption of polycristalline thin films of $\alpha$-quaterthiophene, $\alpha$ sexithiophene and $\alpha$-octithiophene, three model oligomers of polythiophene. Synthetic Metals, v.48, p.167-179, 1992.

64) LEE, J Y; CUI, C Q. Electrochemical copolymerization of aniline and metanilic acid. J. Electroanal. Chem., v.403, p.109-116, 1996.

65) OUYANG, M; CHAN, C M. Conductive polymer composites prepared by polypyrrole-coated poly(vinyl chloride) powder: relationship between conductivity and surface morphology. Polymer, v.39, n.10, p.1857-1862, 1998.

66) ANDRADE, G D; AGUIRRE, M J; BIAGGIO, S R. Influence of the first potential scan on the morphology and electrical properties of potentiodynamically grown polyaniline films. Electrochem. Acta, v.44, n.10, p.633-642, 1998.

67) JIN, S; XUE, G. Interaction between thiophene and solvated Lewis Acids and the Low-Potential electrochemical deposition of a highly anisotropic conducting Polythiophene film. Macromolecules, v.30, n.19, p.57535757, 1997.

68) PAVIA, D; LAMPMAN, G; KRIZ, G. Infrared Spectroscopy. In: Introduction to Spectroscopy - a guide for students of Organic Chemistry, 2.ed., Saunders Golden Sunburst Series, 1996. p.14-95. 
69) RONCALI, J. Conjugated poly(thiophenes): synthesis, functionalization, and applications. Chem. Rev., v.92, n.4, p.711-738, 1992.

70) GOLDENBERG, L M; AEIYACH, S; LACAZE, P C. Low potential anodic polymerization of benzene in strong acid and superacid solutions. J. Electroanal. Chem., v.335, p.151-161, 1992.

71) PUD, A A. Stability and degradation of conducting polymers in electrochemical systems. Synthetic Metals, v.66, p.1-18, 1994.

72) WANG, S; TANAKA, K; YAMABE, T. A study of the electroactivity decay of polythiophene film electrodes. Synthetic Metals, v.32, p.141$150,1989$.

73) LI, Y; QIAN, R. Effect of anion and solution $\mathrm{pH}$ on the electrochemical behavior of polypyrrole in aqueous solution. Synthetic Metals, v.28, p.C127-C132, 1989.

74) LIM, J Y; PAIK, W-K; YEO, I-H. A study on ion transports and growth of conducting polypyrrole with electrochemical quartz crystal microbalance. Synthetic Metals, v.69, p.451-454, 1995.

75) ASAVAPIRIYANONT, S; CHANDLER, G K; GUNAWARDENA, G A; PLETCHER, D. The electrodeposition of polypyrrole films from aqueous solutions. J. Electroanal. Chem., v.177, p.229-244, 1984.

76) GIACOMINI, M T; TICIANELLI, E A. Influência da acidez do meio sobre a síntese e o comportamento redox do polipirrol. Química Nova, v.22, n.5, p.639-644, 1999.

77) OLBRICH-STOCK, M; POSDORFER, J; SCHINDLER, R N. UV-visible spectroscopy studies in the diffusion layer during electropolymerization of thiophene. J. Electroanal. Chem., v.368, p.173-181, 1994.

78) GIACOMINI, M T; DE SOUZA, L M M; TICIANELLI, E A. Spectroscopic ellipsometry investigation of the redox process of polypyrrole in several aqueous solutions. Surface Science, v.409, p.465473, 1998.

79) GROZDIC, T D; STOJIC, D LJ. Electrochemical characteristics of binary silver alloys in alkaline solution. J. Power Sources, v.79, p.1-8, 1999.

80) CZERWINSKI, A; KIERSZTYN, I; GRDEN, M; CZAPLA, J. The study of hydrogen sorption in palladium limited volume electrodes (Pd-LVE) I. Acidic solutions. J. Electroanal. Chem., v.471, p.190-195, 1999.

81) DALL'ANTONIA, L H. Eletroformação de óxidos sobre metais nobres. São Carlos, 1999. 177p. Tese (Doutorado) - Instituto de Química de São Carlos, Universidade de São Paulo. 
82) MCCAULlEY, J A. Temperature dependence of the Pd K-edge extended X-ray absorption fine structure of $\operatorname{PdC}_{\mathrm{x}}(\mathrm{x} \sim 0,13)$. Phys. Rev. B, v. 47, n.9, p.4873-4879, Mar. 1993.

83) MCCAULLEY, J A. In-situ X-ray absorption spectroscopy studies of hydride and carbide formation in supported palladium catalysts. J. Phys. Chem., v.97, n.40, p.10372-10379, 1993.

84) DE CRESCENZI, M; DIOCIAIUTI, M; PICOZZI, P; SANTUCCI, S. Electronic and structural investigations of palladium clusters by $\mathrm{x}$-ray absorption near-edge structure and extended x-ray absorption fine structure spectroscopies. Phys. Rev. B, v.34, n.6, p.4334-4337, 1986.

85) BIANCONI, A; SOLDATOV, A V; IVANCHENKO, T I. Confirmation of hydrogen-induced unoccupied states in $\mathrm{PdH}$ : multiple-scattering analysis of palladium $\mathrm{L}_{1}$ and $\mathrm{L}_{3}$ XANES. Nuclear Instruments and Methods in Physics Research, v.A308, p.248-250, 1991.

86) HEPEL, M. The electrocatalytic oxidation of methanol at finely dispersed platinum nanoparticles in polypyrrole films. J. Electrochem. Soc., v.145, n.1, p.124-134, Jan. 1998.

87) BARD, A J; FAULKNER, L R. Electrochemical Methods Fundamentals and Applications. New York, John Wiley \& Sons, 1980. p.291.

88) STRIKE, D J; DE ROOIJ, N F; KOUDELKA-HEP, M; ULMANN, M; AUGUSTYNSKI, J. Electrocatalytic oxidation of methanol on platinum microparticles in polypyrrole. J. Appl. Electrochem., v.22, p.922-926, 1992.

89) LABORDE, H; LEGER, J M; LAMY, C. Electrocatalytic oxidation of methanol and $\mathrm{Cl}$ molecules on highly dispersed electrodes. Part 1: Platinum in polyaniline. J. Appl. Electrochem., v.24, p.219-226, 1994.

90) VRACAR, LJ M; SEPA, D B; DAMJANOVIC, A. Palladium electrode in oxygen saturated solutions. J. Electrochem. Soc., v.134, n.7 p.1695-1697, 1987.

91) KIM, J-D; PYUN, S-I; YANG, T-H; JU, J B. A study of the mechanism of oxygen reduction on bare palladium in $0.1 \mathrm{M}$ LiOD solution using Ptring-Pd-disk electrode. J. Electroanal. Chem., v.383, p.161-166, 1995.

92) VRACAR, LJ M; SEPA, D B; DAMJANOVIC, A. Palladium electrode in oxygen-saturated aqueous solutions. J. Electrochem. Soc., v.133, p.18351839, 1986.

93) TARASEVICH, M R; SADKOWSKI, A; YEAGER, E. In: CONWAY, B E; BOCKRIS, J O’M; YEAGER, E; KHAN, S U M; WHITE, R E, (eds). 
Comprehensive Treatise of Electrochemistry. New York, Plenum, 1983. v.7, p.301.

94) PEREZ, J; TANAKA, A A; GONZALEZ, E R; TICIANELli, E A. Application of the flooded-agglomerated model to study oxygen reduction on thin porous coating rotating disk electrode. J. Electrochem. Soc., v.141, n.2, p.431-436, Feb. 1994.

95) SENA, D R; TICIANELLI, E A; GONZALEZ, E R. Characterization of the limiting strutural effects on the electrochemical behavior of porous gas diffusion electrodes. J. Electroanal. Chem., v.357, p.225-236, 1993.

96) CALEGARO, M L; PEREZ, J; TANAKA, A A; TICIANELli, E A; GONZALEZ, E R. Study of oxygen reduction reaction in sulfuric acid on thin porous electrodes composed of carbon and platinum. Denki Kagaku (J. Electrochem. Soc. Of Japan), v.64, p.436-442, 1996.

97) PEREZ, J; GONZALEZ, E R; TICIANELli, E A. Oxygen electrocatalysis on thin porous coating rotating platinum electrodes. Electrochim. Acta, v.44, p.1329-1339, 1998.

98) PEREZ, J; GONZALEZ, E R; TICIANELLI, E A. Impedance studies of the oxygen reduction on thin porous coating rotating platinum electrodes. J. Electrochem. Soc., v.145, n.7, p.2307-2313, July 1998.

99) GOUGH, D A; LEYPOLDT, J K. Membrane-covered, rotated disc electrode. Anal. Chem., v.51, n.3, p.439-444, Mar.1979.

100) E SILVA, S A M. Caracterização Físico-Química de pó de carbono de alta área superficial. São Carlos, 1997. 74p. Dissertação (Mestrado) Instituto de Química de São Carlos, Universidade de São Paulo. 